\title{
Atomic Layer Deposition of Vanadium Oxides: process and application review
}

\author{
Vasu Prasad Prasadam ${ }^{\mathrm{a}}$, Naoufal Bahlawane ${ }^{\mathrm{a}}$, Felix Mattelaer ${ }^{\mathrm{b}}$, Geert Rampelberg ${ }^{\mathrm{b}}$, \\ Christophe Detavernier ${ }^{\mathrm{b}}$, Libin Fang ${ }^{\mathrm{c}}$, Yinzhu Jiang ${ }^{\mathrm{c}}$, Koen Martens ${ }^{\mathrm{d}}$, Ivan P. Parkin ${ }^{\mathrm{e}}$, \\ Ioannis Papakonstantinou ${ }^{\mathrm{f}, *}$ \\ ${ }^{a}$ Material Research and technology department, Luxembourg Institute of Science and Technology, 41, rue \\ du Brill, Belvaux, L-4422, Luxembourg \\ ${ }^{b}$ Department of Solid State Sciences, Ghent University, Krijgslaan 281, Ghent, S1, 9000 Gent, Belgium \\ ${ }^{c}$ Key Laboratory of Novel Materials for Information Technology of Zhejiang Province and School of \\ Materials Science and Engineering, Zhejiang University, State Key Laboratory of Silicon Materials, \\ Hangzhou, 310027, China \\ ${ }^{d}$ IMEC, Kapeldreef 75, 3001 Leuven, Belgium \\ ${ }^{e}$ Faculty of Mathematical and Physical Sciences, University College London, Gower Street, London, WC1E \\ $6 B T, U K$ \\ ${ }^{f}$ Department of Electronic and Electrical Engineering, University College London, Torrington Place, \\ London, WC1E 7JE, UK
}

\section{Abstract}

Atomic Layer Deposition (ALD) is a method of choice for the growth of highly conformal thin films with accurately controlled thickness on planar and nanostructured surfaces. These advantages make it pivotal for emerging nanotechnology applications. This review sheds light on the current developments on the ALD of vanadium oxide, which, with proper postdeposition treatment yields a variety of functional and smart oxide phases. The application of vanadium oxide coatings in electrochemical energy storage, microelectronics and smart windows are emphasized.

\section{Introduction}

With $0.019 \%$ in the earth crust, vanadium can be considered a highly abundant element, [1]. The strong electron-electron interactions in several vanadium oxide phases resulting from the localized character of partially occupied " $\mathrm{d}$ " orbitals provide these materials with remarkable properties for numerous technological applications, [2]. Vanadium shows

\footnotetext{
*Corresponding author.

Email addresses: naoufal.bahlawane@list.lu (Naoufal Bahlawane), christophe.detavernier@ugent.be (Christophe Detavernier), yzjiang@zju.edu.cn (Yinzhu Jiang), Koen.Martens@imec.be (Koen Martens), i.p.parkin@ucl.ac.uk (Ivan P. Parkin), i.papakonstantinou@ucl.ac.uk (Ioannis Papakonstantinou)
} 
multiple oxidation states ranging from -3 to +5 and exhibits crystalline structures with different oxygen coordinations like for example octahedra, pentagonal bipyramids, square pyramids and tetrahedra sharing corners, edges or faces, [3]. In these compounds, vanadium features either single or mixed oxidation states. The Magneli $\mathrm{V}_{n} \mathrm{O}_{2 n-1}$ and Wadsley series $\mathrm{V}_{n} \mathrm{O}_{2 n+1}$ are examples of compounds with mixed oxidation states. The physicochemical properties of the different phases vary substantially with the oxidation state of vanadium cations, [4].

The strongly correlated and the layered vanadium oxide phases feature interesting chemical and physical properties making them valuable building blocks for the design of functional and smart devices. Vanadium oxides find applications in microelectronics, [5, 6], energy storage devices, $[1,7]$, smart windows, [8-10], and catalysis, [11]. Ternary vanadium oxides with $\mathrm{AVO}_{3}$ perovskite, e.g. $\mathrm{SrVO}_{3}$ and $\mathrm{CaVO}_{3}$, do not feature strong Metal-Insulator (MIT) behaviour, [6, 11], nevertheless they exhibit interestingly high transparency and electrical conductivity with a plasmon energy superior to $1.33 \mathrm{eV}$. These properties make them promising transparent conducting oxides, [12]. Rare-earth vanadate like $\mathrm{LaVO}_{3}$, however, feature a Mott-insulator gap of $1.1 \mathrm{eV}$, which makes them appealing as solar absorbers, [13].

Several review articles on the state of the art regarding the synthesis of vanadium oxides address the physical vapour deposition, chemical vapour deposition and liquid-phase synthesis, [14-16]; in this review we focus, instead, on Atomic Layer Deposition, a process which has not been reviewed so far. Firstly introduced in 1960's, this technique is currently receiving an ever-growing attention as a method of choice for the growth of conformal coatings on nanostructures with high aspect ratios. The sequential and self-terminating character of the ALD enables an exclusive surface reaction between the precursor and the reactant, while excluding the precursor thermolysis. A detailed history of the ALD technique was recently reported, $[17,18]$. The self-termination of the sequential reactions is particularly appealing for the deposition on nano-powder and nanostructured surfaces. This paper is organised as following; Section 3 reviews the available precursors and developed ALD chemistries for the growth of amorphous $\mathrm{VO}_{x}$ while, section 4 discusses the (non-trivial) annealing conditions required to convert $\mathrm{VO}_{x}$ into crystalline phases. The last three sections focus on applications where ALD has already found or we believe will find wide usage in the near term. In particular, section 5 focuses on energy storage applications, section 6 focuses on electronic devices, particularly ones utilising electronic means to control the metal to insulator transition in $\mathrm{VO}_{2}$ and finally, section 7 reviews the application of ALD grown $\mathrm{VO}_{2}$ in smart windows.

\section{Atomic Layer Deposition of $\mathrm{VO}_{x}$}

Controlling the ALD process of vanadium oxide is an efficient mean to secure conformal coatings and achieve high control over the thickness on the nanometer scale. The ALD process is cyclic, involving the chemisorption of the precursor until surface saturation, and then its reaction with the reactants $\left(\mathrm{H}_{2} \mathrm{O}, \mathrm{NH}_{3}, \mathrm{O}_{3} \ldots\right)$ to form the desired coating. Efficient purging between the sequential exposures is mandatory to confine the chemical reactions during the growth sequences. The self-limitation of the sequential ALD surface reactions is therefore a pre-requisite. Extending the subsequent surface exposure to the reactants should 
not influence the growth rate per cycle when this condition is satisfied, and an increase of the growth rate per cycle when extending the surface exposure to the precursor is an evidence of its thermolysis reaction, which is considered as a parasitic side-reaction in the ALD process. A second characteristic of a controlled ALD process is the presence of a temperature window, within which saturation occurs. This temperature window is often limited by the volatility of the precursor on one side and its thermolysis on the other, [19-21]. Thirdly, the self-limiting nature of the ALD half-cycles implies that coatings can be conformal on high-aspect ratio structures. Indeed, ALD is nearly unmatched in high aspect-ratio coverage, which has been essential for the development of microelectronics over the last decade, [22]. In the following sections, we report on ALD chemistries of vanadium oxides.

\section{1. $\beta$-diketonate compounds}

\subsubsection{Vanadyl Acetylacetonate (IV)}

Vanadyl acetylacetonate, $\left[\mathrm{VO}\left(\mathrm{C}_{5} \mathrm{H}_{7} \mathrm{O}_{2}\right)_{2}\right]$, is a blue-green solid compound in which the vanadium cation is in the +4 oxidation state. The four oxygen atoms of the "acetylacetonate" ligands (acac) form a square pyramid, while the vanadyl oxygen occupies the apex position. The two acac skeletons of the same molecule are not coplanar and form an angle of $15.7^{\circ}$ with each other. The overall coordination geometry is displayed in the inset of Figure 1, [23]. $\mathrm{VO}(\mathrm{acac})_{2}$ features a molecular-type structure with temperature-sensitive intermolecular Van der Waals interaction, [24]. The thermogravimetric analysis (TGA), Figure 1, reveals a weight loss above $150^{\circ} \mathrm{C}$ with no residue under vacuum $(0.7$ mbar) indicating its complete sublimation, [25]. At atmospheric pressure, the TGA exhibits a weight loss above $250^{\circ} \mathrm{C}$ resulting in partial decomposition with a residue of $20 \mathrm{w} \%$, [24]. A vapour pressure of 0.21 $\mathrm{Pa}$ was reported at $96^{\circ} \mathrm{C}$ for this compound, which sublimes as a monomer [25].

While the $\mathrm{VO}(\mathrm{acac})_{2}$ synthesis was reported in 1957, [26], the first ALD results using this precursor were reported by J. Keranen et al, [27]. In this study, the precursor was maintained at $170^{\circ} \mathrm{C}$ to generate sufficient vapour pressure, and the implementation of a carrier gas was necessary. While, the thermolysis threshold was demonstrated at $180^{\circ} \mathrm{C}$, no systematic study confirming the self-limited ALD half-cycles was reported. Upon interaction with the deposition surface the vanadium content reached nearly the theoretical monolayer of vanadate with $2.3 \mathrm{VO}_{x} / \mathrm{nm}^{2}$.

The deposition of $\mathrm{VO}_{x}$ starting from $\left[\mathrm{VO}(\text { acac })_{2}\right]$ and molecular oxygen was reported by Dagur et al, [28], at a substrate temperature of $400-475^{\circ} \mathrm{C}$, resulting in crystalline $\mathrm{VO}_{2}$. Although the ALD cycles were optimised at 4s and 1s of exposure to $\mathrm{VO}(\mathrm{acac})_{2}$ and oxygen respectively, no evidence of self-saturating ALD half-cycles was provided. The growth rate was nevertheless measured at $0.24 \mathrm{~nm} /$ cycle, which is nearly equal to one monolayer of $\mathrm{VO}_{2}$ structure. As the reported TGA analyses show, Figure 1, [24, 25, 29], significant thermolysis of the precursor occurs above $180^{\circ} \mathrm{C}$. Therefore, chemical vapour deposition (CVD) is certainly dominating the growth at $400-475^{\circ} \mathrm{C}$.

The available literature with the commercially available $\left[\mathrm{VO}(\mathrm{acac})_{2}\right]$ shows its limited pertinence as an ALD precursor. While high temperatures are needed for the evaporation $\left(170^{\circ} \mathrm{C}\right)$ its thermolysis occurs already at $180^{\circ} \mathrm{C}$, which leaves a very narrow processing window for ALD growth. The only reported systematic study with this precursor was 

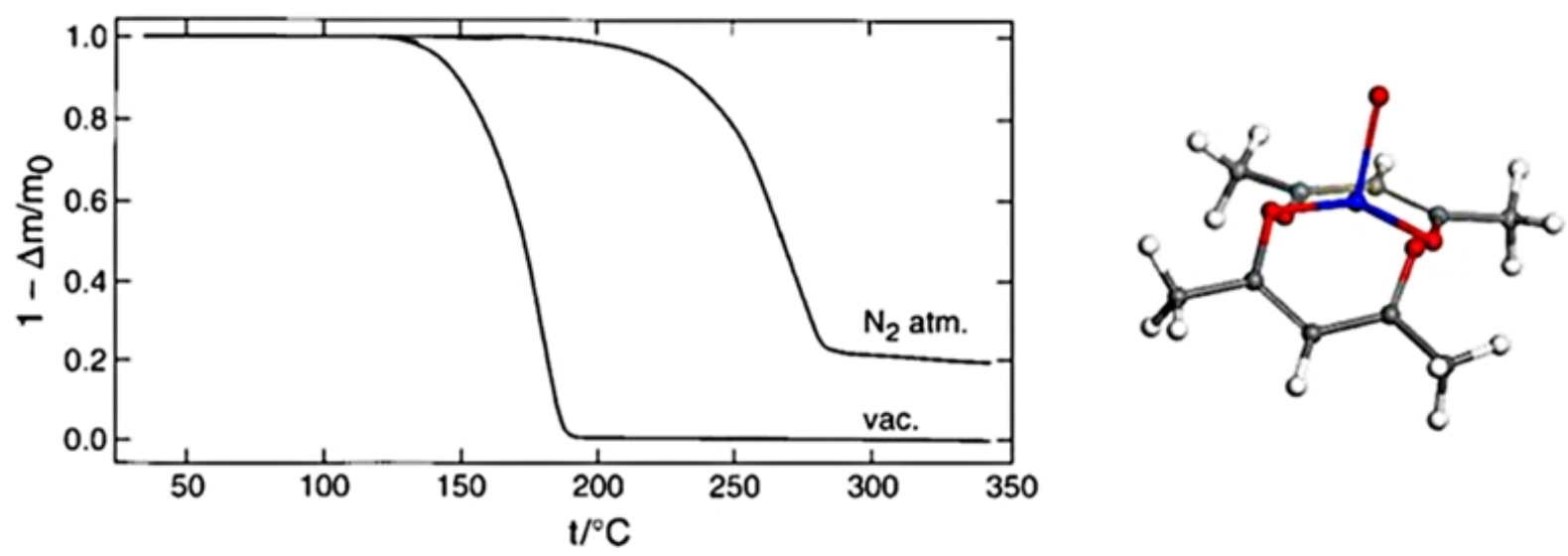

Figure 1: Thermogravimetric analysis of $\mathrm{VO}(\text { acac })_{2}$ performed at $2{ }^{\circ} \mathrm{C} / \mathrm{min},[24]$. Reproduced with permission from John Wiley and Sons. The inset corresponds to the molecular structure: V: blue; O: Red; C: Grey, H: white.

performed at temperature far exceeding the thermal decomposition, where the CVD process dominates the growth.

\subsubsection{Vanadyl Tetramethyl Heptadionate}

Vanadyl bis $\left.(2,2,6,6 \text {-tetramethyl-3,5,- heptadionate [VO(tmhd })_{2}\right] /\left[\mathrm{VO}\left(\mathrm{C}_{11} \mathrm{H}_{19} \mathrm{O}_{2}\right)_{2}\right]$, is a solid compound in which the vanadium cation is in the +4 oxidation state. The skeleton structure is similar to that of vanadyl acetylacetonate except that the change from methyl to tert-butyl group on the ketonate ring. The overall coordination geometry is displayed in the inset of Figure 2, [23]. [VO(tmhd $\left.)_{2}\right]$ features a molecular-type structure with temperature-sensitive Van der Waals intermolecular interaction from 105 to 295K [24]. The thermogravimetric analysis (TGA), Figure 2, reveals a weight loss starting at $110^{\circ} \mathrm{C}$ with no residue under vacuum (0.7 mbar), [24]. At atmospheric pressure, the TGA exhibits a weight loss starting at $160^{\circ} \mathrm{C}$ and results in a $5 \mathrm{w} \%$ residue, indicating the occurrence of a partial decomposition [24]. Relative to $\left[\mathrm{VO}(\mathrm{acac})_{2}\right]$, $\left[\mathrm{VO}(\mathrm{tmhd})_{2}\right]$ features a significantly lower fraction of decomposition, which is in line with a higher thermal stability. A vapour pressure of $0.27 \mathrm{~Pa}$ was measured for this compound at $96^{\circ} \mathrm{C}$, which vaporises as a monomer [25].

Erik Ostreng et al, [30, 31], have implemented the reaction of $\left[\mathrm{VO}(\mathrm{tmhd})_{2}\right]$ with ozone $\left(\mathrm{O}_{3}\right)$ for the ALD of $\mathrm{VO}_{x}$. The precursor was sublimed at $125^{\circ} \mathrm{C}$ under a flow of inert carrier gas. Self-limited reactions were reported at $186^{\circ} \mathrm{C}$, using exposure times above 2 and $3 \mathrm{~s}$ for $[\mathrm{VO} \text { (tmhd })_{2}$ ] and $\mathrm{O}_{3}$ respectively. The growth rate per cycle was far below a monolayer and is temperature-dependent within the $162-235^{\circ} \mathrm{C}$ window. Furthermore, evidence of parasitic CVD contribution were observed above $200^{\circ} \mathrm{C}$, [30, 31].

As the ALD growth requires on one side an efficient vaporization of the precursor and on the other side its self-limited reaction on the surface, an operating ALD window within the $125-160^{\circ} \mathrm{C}$ range might be expected based on the reported TGA results. The excessively low deposition rate per cycle below $160^{\circ} \mathrm{C}$ is probably the reason why the $125-160^{\circ} \mathrm{C}$ temperature 
window was not given attention.
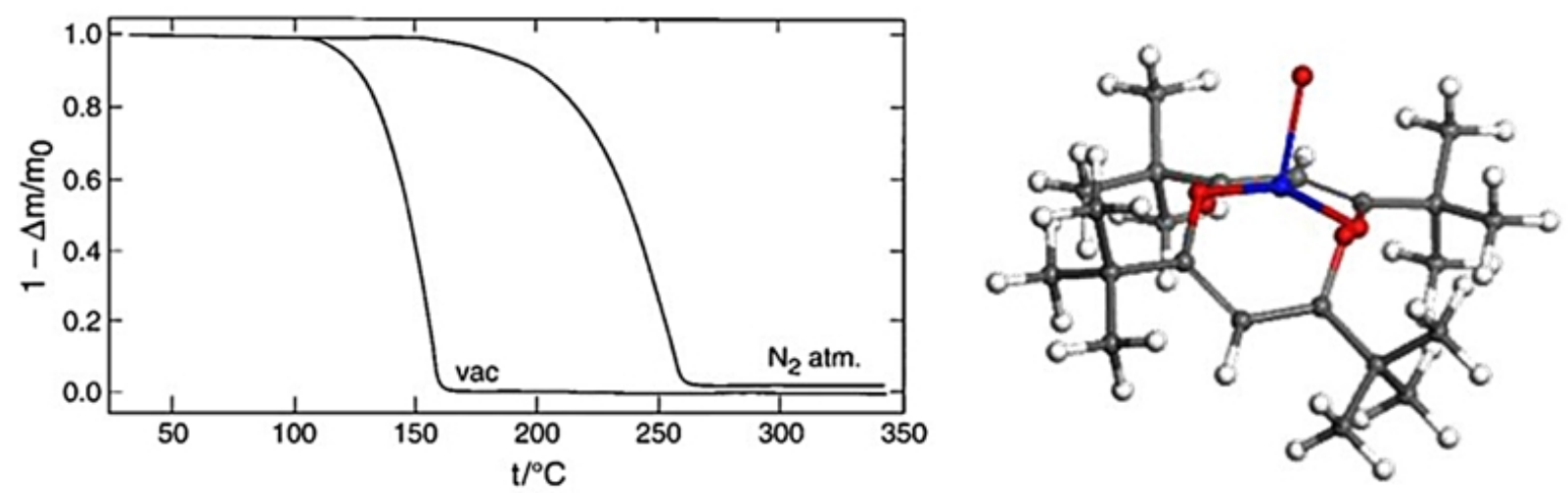

Figure 2: Thermogravimetric analysis of $\mathrm{VO}(\mathrm{tmhd})_{2}$ at $2^{\circ} \mathrm{C} / \mathrm{min},[24]$. Reproduced with permission from John Wiley and Sons.. The inset represents the molecular structure: V: blue; O: Red; C: Grey, H: white.

Although the precursor contains a $\mathrm{V}^{4+}$ cation, the reported ALD processes implement ozone, which results in its further oxidation to form amorphous or crystalline $\mathrm{V}_{2} \mathrm{O}_{5}$ films depending on the temperature. The low reactivity of $\left[\mathrm{VO}(\mathrm{tmhd})_{2}\right]$ has probably hindered the investigation of its hydrolysis reaction in the ALD process. Beyond its low vapour pressure and low reactivity, $\left[\mathrm{VO}(\mathrm{tmhd})_{2}\right]$ is not commercially available, which considerably limits its suitability for the ALD of vanadium oxide thin films.

\subsubsection{Statement regarding $\beta$-diketonate compounds}

The available literature on the ALD of vanadium oxide starting from $\beta$-diketonate compounds is very limited, and the reported growth processes are systematically performed at temperatures exceeding the thermolysis threshold of the vanadium precursor, which is certainly related to their low reactivity.

The volatility and thermal stability of vanadyl $\beta$-deketonate compounds have been compared, see Figure 3, [25]. Based on the weight-loss threshold temperature, the performed TGA in argon ambient reveals a volatility that evolves in the order: $\left[\mathrm{VO}(\mathrm{hfa})_{2}\right]>>$ $\left[\mathrm{VO}(\mathrm{tmhd})_{2}\right]>\left[\mathrm{VO}(\mathrm{acac})_{2}\right]$. Furthermore, the thermal stability, assessed by the residual mass, shows an equivalent performance for $\left[\mathrm{VO}(\mathrm{hfa})_{2}\right]$ and $\left[\mathrm{VO}(\mathrm{tmhd})_{2}\right]$, both are more stable than $\left[\mathrm{VO}(\mathrm{acac})_{2}\right]$. Among the discussed compounds, $\mathrm{VO}(\mathrm{hfa})_{2}$ appears as the most promising beta-diketonate for the ALD of $\mathrm{VO}_{x}$, however no study was reported so far with this compound. The low reactivity of $\beta$-diketonates in general would be a significant drawback with this family of precursors.

\subsection{Alkoxide compounds}

Vanadium oxy-tri-isopropoxide (VTOP) $\left[\mathrm{VO}\left(\mathrm{OC}_{3} \mathrm{H}_{7}\right)_{3}\right]$, is a liquid compound at room temperature with vanadium in the +5 oxidation state. The molecule features a trigonal pyramidal structure with vanadyl oxygen at the apex and alkoxide groups at the edges (Figure 4). The precursor possesses a vapour pressure of $6 \mathrm{~Pa}$ at room temperature, [32], 


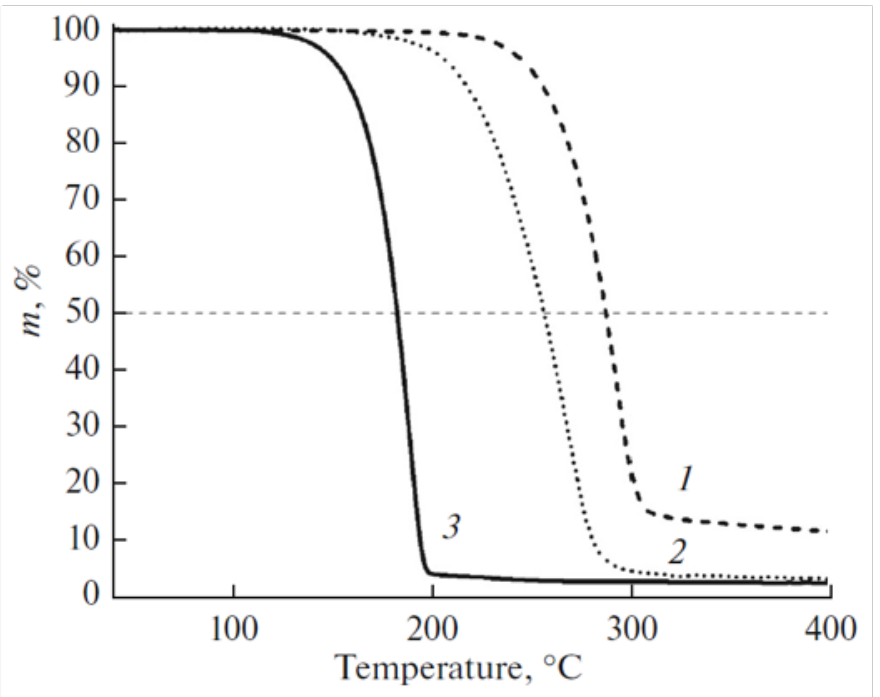

\begin{tabular}{|l|l|l|l|}
\hline Compounds & $\mathrm{T}\left({ }^{\circ} \mathrm{C}\right)$ & Vapour pressure $/ \mathrm{Pa}$ & $\Delta_{\mathrm{s}} \mathrm{H}^{\circ}(298 \mathrm{~K}) \mathrm{kJ} / \mathrm{mol}$ \\
\hline VO(acac) $)_{2}$ & 96 & 0.21 & $132 \pm 4$ \\
\hline \multirow{2}{*}{$\mathrm{VO}(\mathrm{tmhd})_{2}$} & 96 & 0.27 & \multirow{2}{*}{$126 \pm 11$} \\
\cline { 2 - 4 } & 57 & 0.0047 & $119 \pm 10$ \\
\hline $\mathrm{VO}(\mathrm{hfa})_{2}$ & 57 & 0.18 & 1 \\
\hline
\end{tabular}

Figure 3: Thermogravimetric analysis of (1) $\left[\mathrm{VO}(\mathrm{acac})_{2}\right]$, (2) $\left[\mathrm{VO}(\mathrm{tmhd})_{2}\right]$ and (3) $\left[\mathrm{VO}(\mathrm{hfac})_{2}\right]$ at $10^{\circ} \mathrm{C} / \mathrm{min}$. hfac: hexafuoro acetylacetonate, [25]. Reproduced with permission from Springer Nature. The table summarizes the vapour pressures and evaporation enthalpies of these compounds.

$39 \mathrm{~Pa}$ at $45^{\circ} \mathrm{C}$, [33], and $268 \mathrm{~Pa}$ at $82^{\circ} \mathrm{C}$, [34]. According to the previous work, [35, 36], the vanadium oxy-tri-alkoxide is reported to be monomeric in pentane solution. The formation of oligomers in vanadium oxy-tri-alkoxide compounds depends on the temperature, solvent, concentration and size of the alkyl groups. Compounds with smaller alkyl groups, e.g. vanadium oxy tri methoxide, dimerize, whereas the compound with iso-butoxide groups remains as a monomer. As the tri-iso-propoxide compound is bulky, the stabilization of the monomer form is most likely. This precursor was widely used for the synthesis of vanadium pentoxide but no TGA investigation has been reported so far.

Vanadium pentoxide films were grown by ALD from the reaction of VTOP precursor with $\mathrm{H}_{2} \mathrm{O}$, [33], $\mathrm{O}_{2}$ plasma, [37], or $\mathrm{O}_{3}$, [38].

D. Lincot et al have reported on the hydrolysis reaction of VTOP, [33], and the obtained films were extensively investigated for electrochemical energy storage, [39-44]. The evaporation of VTOP was performed either at room temperature, [33], or at $40-45^{\circ} \mathrm{C}$ using an inert carrier gas, [37, 38]. A temperature-independent growth rate was observed in the $50-100^{\circ} \mathrm{C}$ window with a rate of $0.017-0.02 \mathrm{~nm} /$ cycle, [33]. Significantly higher growth per 


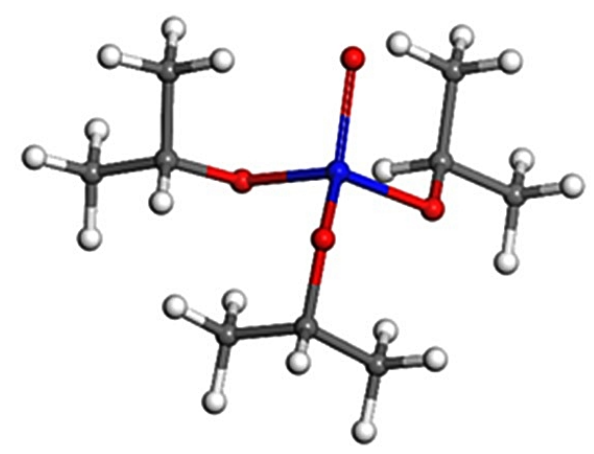

Figure 4: Molecular structure of VTOP. (V: blue; O: Red; C: Grey, H: white)

cycle was noticed above this temperature range, [33, 37, 45]. The observed slow reaction of water with the adsorbed VTOP was attributed to the bulky iso-propoxide ligands that hinder access to the vanadium-oxygen bond, [37]. The observed precursor thermolysis at $150-190^{\circ} \mathrm{C}$ is kinetically limited and enables still a high conformality of the coating, [33]. It is worth mentioning that even at $190^{\circ} \mathrm{C}$, the growth rate was still below one monolayer of vanadium oxide per cycle. As-deposited films were amorphous with vanadium in the +5 oxidation state, [33].

J. Musschoot et al have reported on the plasma-enhanced (PE-ALD) and thermal ALD for the growth of vanadium pentoxide with VTOP precursor using either $\mathrm{H}_{2} \mathrm{O}$ or $\mathrm{O}_{2}$, [37]. Constant growth rate was observed between $50-100^{\circ} \mathrm{C}$ with the typical self-saturating half cycle reactions. PE-ALD with either water or oxygen has given a constant growth rate of $0.07 \mathrm{~nm} /$ cycle, which is significantly high relative to the thermal ALD with water, [37]. Films obtained with PE-ALD exhibited however a higher carbon contamination using water plasma, $22 \%$ versus $6.5 \%$ with the thermal ALD using water. However, when an oxygen plasma is used, no carbon was reported in the as-deposited films, [37]. This indicates that the oxygen plasma burns carbon species generating volatile products, resulting in pure films.

Chen et al have implemented the reaction of $\mathrm{O}_{3}$ with VTOP, [38], and reported an ALD window with a constant rate of $0.027 \mathrm{~nm} /$ cycle at $170-185^{\circ} \mathrm{C}$. Nevertheless, the investigated very short exposure times marginalize the CVD contribution. The as-deposited films under these conditions were pure-phase, crystalline $\mathrm{V}_{2} \mathrm{O}_{5}$ with an enhanced (001) orientation. The growth kinetics was noticed to be slow below $170^{\circ} \mathrm{C}$, which was attributed to the insufficient energy to activate the reaction of $\mathrm{O}_{3}$ with surface ligands. Higher deposition rates, were attributed to the precursor thermolysis, [38].

Other studies, Table 1, were devoted to the ALD of vanadium oxide starting from VTOP, but no systematic demonstrations of the self-limitation of the sequential ALD reactions were reported. A clear disagreement regarding the thermolysis temperature threshold of VTOP is worth mentioning. Extending the exposure time of the surface to VTOP was observed to yield an increasing growth rate even at $100^{\circ} \mathrm{C}$, [46], due to its thermal decomposition. Consequently, the VTOP thermolysis is very likely affecting all experiments performed above $100^{\circ} \mathrm{C}$ in Table 1 . Therefore, only few studies were performed under thermolysis-free ALD 
process. In general, VTOP has been evaporated at $\mathrm{RT}-45^{\circ} \mathrm{C}$, which defines an appealing ALD processing window at $45-100^{\circ} \mathrm{C}$. It is worth noting that other equivalent alkoxide compounds are commercially available such as: vanadium(V) oxytrietoxide and vanadium(V) oxytripropoxide. Although, these compounds feature comparable physicochemical properties, their thermolysis behaviour and reactivity with water vapour might exhibit significant contrast. Unfortunately, these compounds were not investigated as ALD precursors so far. [46-57]

Table 1: Summary of the ALD parameters used for the growth of $\mathrm{VO}_{x}$ starting from VTOP precursor.

\begin{tabular}{|c|c|c|c|c|c|c|c|}
\hline $\begin{array}{l}\text { Ox- } \\
\text { i- } \\
\text { dant }\end{array}$ & $\begin{array}{l}\text { Pro- } \\
\text { cess }\end{array}$ & $\begin{array}{l}\text { Car- } \\
\text { rier } \\
\text { gas }\end{array}$ & $\begin{array}{l}\text { Evaporation } \\
\text { Temp. }\left({ }^{\circ} \mathrm{C}\right)\end{array}$ & $\begin{array}{l}\text { Deposition } \\
\text { Temp. }\left({ }^{\circ} \mathrm{C}\right)\end{array}$ & $\begin{array}{l}\text { Exposure time (s) } \\
\text { VTOP/Oxidant }\end{array}$ & $\begin{array}{l}\text { Rate } \\
(\AA / \text { cycle })\end{array}$ & Ref \\
\hline \multirow[t]{3}{*}{$\mathrm{O}_{3}$} & $\begin{array}{l}\text { Ther- } \\
\text { mal }\end{array}$ & $\mathrm{N}_{2}$ & 45 & $170-195$ & $0.5 / 2$ & $\begin{array}{l}0.27- \\
0.81\end{array}$ & $\begin{array}{c}{[38} \\
47,48]\end{array}$ \\
\hline & & & 45 & $50-140$ & $0.1 / 1.2$ & 0.17 & $\begin{array}{l}{[33,39,} \\
41-44]\end{array}$ \\
\hline & Thormol & $\mathrm{N}_{2}$ & & $70-130$ & $0.5 / 2$ & 0.3 & {$[49,50]$} \\
\hline \multirow{6}{*}{$\mathrm{H}_{2} \mathrm{O}$} & & & & $125-175$ & $2.6 / 0.2$ & $0.2-0.3$ & {$[51,52]$} \\
\hline & & & & 180 & $20 / 20$ & - & [53] \\
\hline & & & & 135 & $2 / 5$ & 0.3 & [45] \\
\hline & & Ar & 40 & $50-200$ & $2 / 5$ & 0.2 & [37] \\
\hline & & & & $110-150$ & $0.5 / 2$ & 0.37 & [54] \\
\hline & & & - & 150 & $120 / 120$ & $0.8-1$ & {$[55,56]$} \\
\hline & Plasma & Ar & 40 & - & $2 / 5$ & 0.7 & [37] \\
\hline \multicolumn{8}{|l|}{$\mathrm{O}_{2}$} \\
\hline & & $\mathrm{N}_{2}$ & 45 & 180 & $20 / 60$ & - & {$[57]$} \\
\hline
\end{tabular}

\subsection{Alkylamide compounds}

Vanadium (IV) amide complexes are volatile, reactive, produce noncorrosive by-products, and leave marginal impurities in the films, [58]. Alkylamide compounds with higher molec- 
ular weight decompose at higher temperatures due to the steric hindrance, [59, 60]. Ethylamide compound have e.g. higher thermal stability relative to methylamide counterpart but features a lower vapour pressure. Vanadium dialkyamides $\left[\mathrm{V}(\mathrm{NRR})_{4}\right],\left(\mathrm{R}, \mathrm{R}^{\prime}=\right.$ methyl or ethyl or both) are monomeric in nature [61, 62].

\subsubsection{Tetrakis ethylmethyl amino vanadium (TEMAV)}

TEMAV is a green liquid at room temperature and is commercially available. The reported TGA measurement of the precursor, Figure 5, shows a clear temperature window between evaporation and decomposition, where the ALD process can be optimized. The thermal decomposition of the precursor takes place above $175^{\circ} \mathrm{C}$, whereas it is significantly volatile under vacuum below $100^{\circ} \mathrm{C}$, [63]. The vapour pressure of this compound is reported as a function of temperature in the form of the Clausius-Clapeyron equation $\log (\mathrm{P} /$ torr $)=$ $6.59-2640 /(\mathrm{T} / \mathrm{K})$ in the range of $343-383 \mathrm{~K},[64]$. The implementation of TEMAV requires heating the precursor source at $65-70^{\circ} \mathrm{C}$ and the use of an inert carrier gas, [63, 65-67].
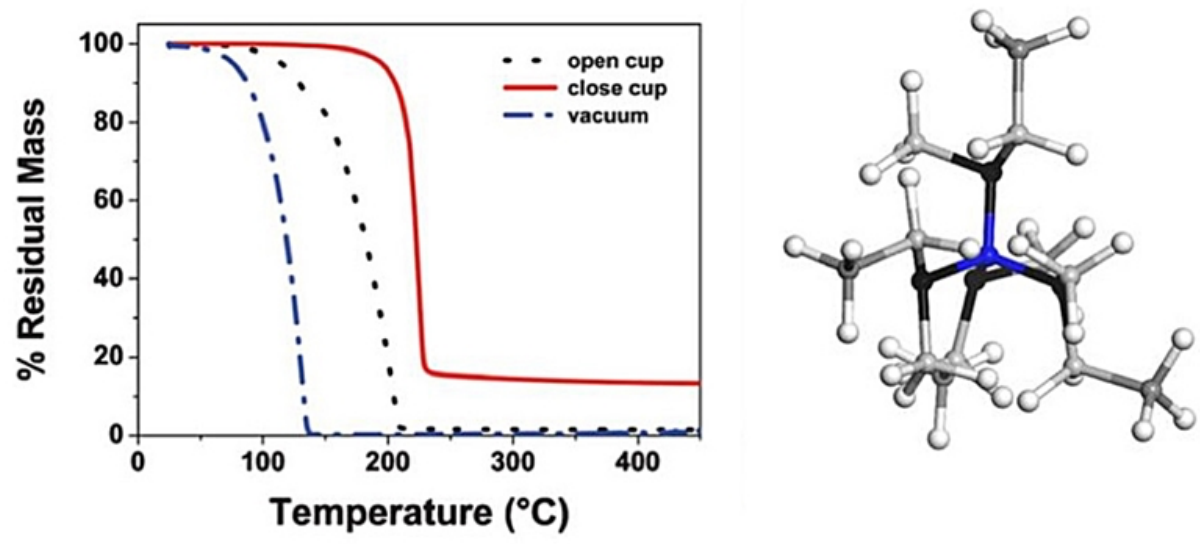

Figure 5: Thermogravimetric analysis of TEMAV, [63]. Reproduced with permission from the Royal Society of Chemistry. The inset corresponds to the structure of the compound: V: blue; N: Black; C: Grey, H: white.

The TEMAV precursor was implemented with $\mathrm{H}_{2} \mathrm{O}, \mathrm{O}_{3}$ and $\mathrm{O}_{2}$-plasma as reactants for the synthesis of vanadium oxide, [65-67]. Authors reported a thermal decomposition above $175^{\circ} \mathrm{C}$, while the self-limited ALD reactions were observed up to $150^{\circ} \mathrm{C}$. TEMAV quickly saturates the surface after $2 \mathrm{~s}$ of exposure while $5 \mathrm{~s}$ is required with ozone for the removal of the ligands at $150^{\circ} \mathrm{C}$ enabling a growth rate of $0.07 \mathrm{~nm} /$ cycle, [67]. The vanadium oxidation state $(+4)$ was retained in the as-deposited amorphous films $\mathrm{H}_{2} \mathrm{O}, \mathrm{O}_{3}$, [65]. In the case of plasma $\mathrm{O}_{2}$ as the oxidant, polycrystalline $\mathrm{V}_{2} \mathrm{O}_{5}$ was formed upon deposition, and vanadium has therefore $\mathrm{a}+5$ oxidation state.

T. Blanquart et al, [63], reported no temperature-dependence of the growth rate within the $100-175^{\circ} \mathrm{C}$ temperature range using the reaction of TEMAV with $\mathrm{O}_{3}$; nevertheless, the growth rate rose when extending the reactants' doses. This means that the half reactions in the process were not self-limited. Similar behaviour was observed using the reaction of TEMAV with $\mathrm{H}_{2} \mathrm{O}$ at $125-200^{\circ} \mathrm{C}$. The resulting films were amorphous and featured $\mathrm{a}+4,+5$ 
mixed oxidation states for vanadium. Despite the absence of self-limited reaction steps, the authors demonstrated a conformal coating on textured surfaces with a 60:1 aspect ratio, [63].

The supply of precursors in ALD can be performed using the direct liquid injection approach by diluting the precursor in an inert solvent. The precursor dose is then introduced into a flash vaporiser before reaching the growth chamber. Premkumar, P. A. et al have used this process for the ALD of vanadium oxide using the reaction of TEMAV with $\mathrm{H}_{2} \mathrm{O}$ and $\mathrm{O}_{3}$ as reactants, [68-70]. TEMAV in these reports was diluted to a concentration of $0.2 \mathrm{M}$ in octane. Authors noticed the thermal decomposition of the precursor already at $100^{\circ} \mathrm{C},[68]$, in the absence of any reactants. As a result, no self-limited reactions can take place at $\leq 100^{\circ} \mathrm{C}$, and the deposition rate per cycle increases with the extension of the exposure time to the precursor. The obtained films were amorphous, and vanadium features a mixed +4 and +5 oxidation state, [69].

A summary of the reported studies with TEMAV is displayed in Table 2. The highly dispersed growth rate, $0.45-1 \AA /$ cycle, is quite remarkable. It is also worth noting that $150^{\circ} \mathrm{C}$ is a common temperature for ALD in all reports regardless of the type of energy input and reactive gas.

Table 2: Summary of the ALD parameters used for the growth of $\mathrm{VO}_{x}$ starting from TEMAV precursor.

\begin{tabular}{|c|c|c|c|c|c|c|c|}
\hline $\begin{array}{l}\text { Oxi- } \\
\text { dant }\end{array}$ & $\begin{array}{l}\text { Pro- } \\
\text { cess }\end{array}$ & $\begin{array}{l}\text { Car- } \\
\text { rier } \\
\text { gas }\end{array}$ & $\begin{array}{l}\text { Evaporation } \\
\text { Temp. }\left({ }^{\circ} \mathrm{C}\right)\end{array}$ & $\begin{array}{l}\text { Deposition } \\
\text { Temp. }\left({ }^{\circ} \mathrm{C}\right)\end{array}$ & $\begin{array}{l}\text { Exposure time (s) } \\
\text { TEMAV/Oxidant }\end{array}$ & $\begin{array}{l}\text { Rate } \\
(\AA / \text { cycle })\end{array}$ & Ref \\
\hline \multirow{3}{*}{$\mathrm{O}_{3}$} & \multirow{3}{*}{ Thermal } & $\mathrm{N}_{2}$ & 70 & 150 & $5 / 5$ & $0.7-1$ & $\begin{array}{l}{[65-} \\
67]\end{array}$ \\
\hline & & & 65 & $100-175$ & $1.2 / 1$ & 0.45 & [63] \\
\hline & & $\mathrm{Ar}$ & - & $100-150$ & $5-10 / 10-5$ & $1-0.4$ & $\begin{array}{l}{[68,} \\
70]\end{array}$ \\
\hline \multirow{6}{*}{$\mathrm{H}_{2} \mathrm{O}$} & \multirow{5}{*}{ Thermal } & \multirow{4}{*}{$\mathrm{N}_{2}$} & $105-115$ & 150 & $\begin{array}{l}0.03-0.015 / \\
0.05-0.045\end{array}$ & $0.77-0.9$ & $\begin{array}{l}{[71-} \\
74]\end{array}$ \\
\hline & & & 70 & 150 & $5 / 5$ & 0.67 & $\begin{array}{l}{[65-} \\
67]\end{array}$ \\
\hline & & & 65 & $125-200$ & $1.2 / 1$ & 0.8 & [63] \\
\hline & & & - & $125-150$ & $0.05 / 0.015$ & - & $\begin{array}{c}{[75,} \\
76]\end{array}$ \\
\hline & & \multirow{2}{*}{$\mathrm{Ar}$} & - & 150 & $5 / 10$ & 0.5 & [69] \\
\hline & Plasma & & 60 & 150 & $12 / 0.2$ & 0.2 & {$[77]$} \\
\hline
\end{tabular}

\subsubsection{Tetrakis dimethylaminovanadium}

TDMAV is a solid compound at room temperature. The TGA analysis, Figure 6, shows a significantly low sublimation temperature, which confirms high volatility [78]. The TGA analysis features however, a residue with open and closed cups, which is a clear indication of the partial decomposition of the precursor in both cases. The vapour pressure of the 
compound was $133 \mathrm{~Pa}$ at $64^{\circ} \mathrm{C}$, which is significantly high relative to TEMAV that needs to be heated at $107^{\circ} \mathrm{C}$ to reaches this value. The compound exhibits a monomeric structure in the gas phase $[61,62]$.
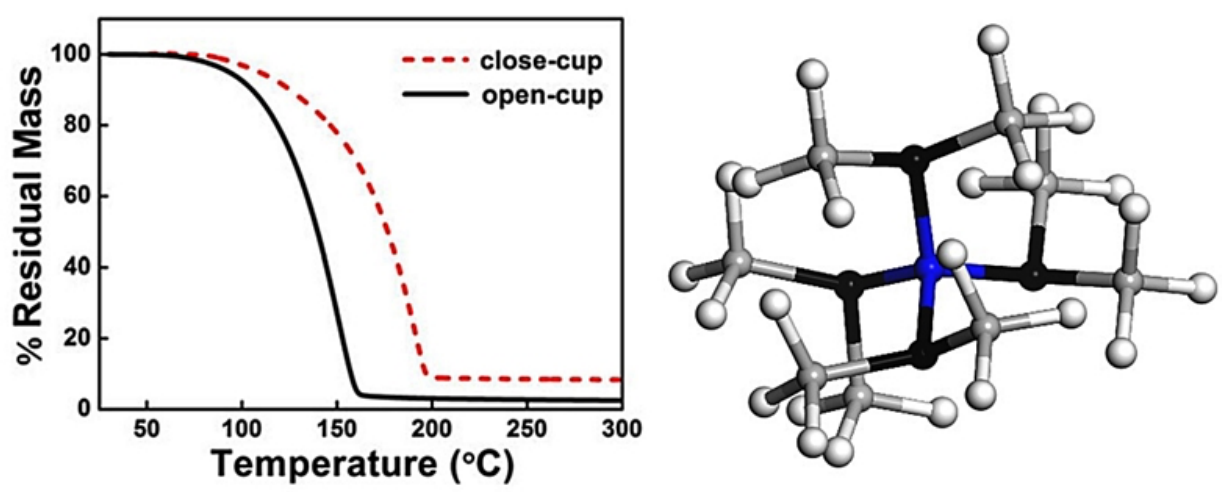

Figure 6: Thermogravimetric analysis of TDMAV, [78]. Reproduced with permission from Cambridge University Press. The inset corresponds to the molecule structure: V: blue; N: Black; C: Grey, H: white.

Wang et al, [78, 79], have reported the thermal ALD of vanadium oxide by implementing the reaction of TDMAV with $\mathrm{H}_{2} \mathrm{O}$ or $\mathrm{O}_{3}$. Authors reported that the volatility of the precursor is high enough to allow sublimation at room temperature. A temperature-independent growth rate was observed at temperatures between $50-120^{\circ} \mathrm{C}$. Below $120^{\circ} \mathrm{C}$, a growth rate of $0.045 \mathrm{~nm} /$ cycle was measured with $\mathrm{O}_{3}$, which is significantly high relative to $0.03 \mathrm{~nm} /$ cycle obtained with $\mathrm{H}_{2} \mathrm{O}$. A significant thermolysis of the precursor was noticed above $120^{\circ} \mathrm{C}$. Authors have demonstrated self-limited surface reactions with TDMAV and $\mathrm{H}_{2} \mathrm{O}$ at $50^{\circ} \mathrm{C}$. Increasing the temperature was however favourable for the attainment of pure films. Amorphous films with mixed +4 and +5 oxidation states of vanadium were obtained. Vanadium oxide films obtained with $\mathrm{H}_{2} \mathrm{O}$ as a reactant had less carbon and nitrogen contamination than films made using $\mathrm{O}_{3}$ oxidant, [78, 79].

$\mathrm{Lv}$ et al, [80], implemented the reaction of TDMAV with $\mathrm{H}_{2} \mathrm{O}$ in thermal ALD. The precursor was evaporated at $60^{\circ} \mathrm{C}$ and carried into the reactor using Ar flow. Temperatureindependent growth was reported at $150-200^{\circ} \mathrm{C}$, with a strong thermolysis contribution above $200^{\circ} \mathrm{C}$. Authors reported self-limed reactions at $150^{\circ} \mathrm{C}$. Amorphous films grew at the rate of $0.094 \mathrm{~nm} /$ cycle, and vanadium retained the oxidation state of the precursor $(+4)$.

Although the implementation of TDMAV for the ALD of $\mathrm{VO}_{x}$ was only addressed in a limited number of articles, a clear controversy can be highlighted as far as the thermolysis threshold, and temperature-independent growth rate region are concerned. The precursor features a sufficient volatility at room temperature and a high reactivity with water vapour as films could be grown at $50^{\circ} \mathrm{C}$.

\subsubsection{Vanadium amidinates}

Vanadium tris-diisopropylacetamidinate $\left[\left(\mathrm{V}(\mathrm{iPr}-\mathrm{MeAMD})_{3}\right)\right]$ is a red-brown solid compound with a vapour pressure of $6.6 \mathrm{~Pa}$ at $70^{\circ} \mathrm{C}$, [81]. Due to the chelating effect, the precursor is thermally stable relative to the other nitrogen coordinated alkylamide compounds. 
The molecule features a distorted geometry from octahedral toward trigonal prismatic. The precursor features a monomeric structure in the gas phase due to the bulky ligand and higher coordination to vanadium (III), which presents a distorted octahedral geometry, [82].

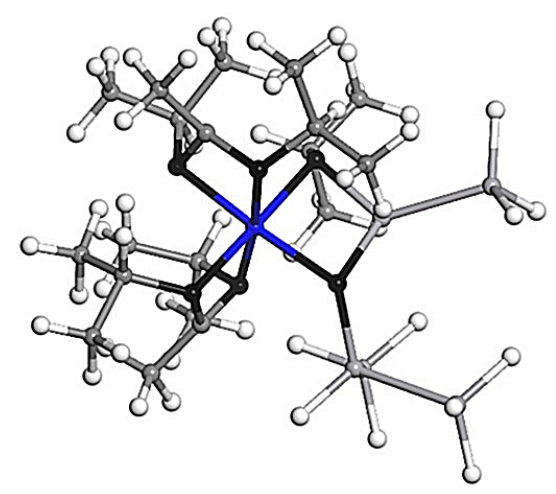

Figure 7: [V(iPr-MeAMD $\left.)_{3}\right]$ ) molecular structure: V: blue; N: Black; C: Grey, H: white.

M. Weimer et al., [83, 84], have implemented the [(V(iPr-MeAMD $\left.\left.)_{3}\right)\right]$ compound with different reactants for the growth of vanadium oxide thin films. The precursor was vaporized at $190^{\circ} \mathrm{C}$, and a temperature-independent growth was observed at $0.16 \mathrm{~nm} /$ cycle below $225^{\circ} \mathrm{C}$ with $\mathrm{O}_{3}$. Using $\mathrm{H}_{2} \mathrm{O}_{2}$ reactant, however, the temperature-independent growth was extended to $150-250^{\circ} \mathrm{C}$ with a significantly lower rate $0.04 \mathrm{~nm} /$ cycle. All reaction steps were confirmed to be self-limited at $200^{\circ} \mathrm{C}$. Amorphous $\mathrm{V}_{2} \mathrm{O}_{5}$ films were deposited with $\mathrm{O}_{3}$ and $\mathrm{H}_{2} \mathrm{O}, \mathrm{O}_{2}$ oxidants, whereas films grew neither with $\mathrm{H}_{2} \mathrm{O}, \mathrm{O}_{2}$ nor $\mathrm{H}_{2}$. Authors reported about the synergy effect between reactants and reported the growth of amorphous $\mathrm{VO}_{2}$ films with $\mathrm{H}_{2}$ dosing after the oxidation with $\mathrm{H}_{2} \mathrm{O}_{2}$. However, no self-limiting reactions were obtained.

\subsection{Statements regarding the $A L D$ of $V O_{x}$}

This section summarizes the reported studies on the ALD of vanadium oxide starting from various precursors. It is surprising to see the limited number of investigated precursors despite the immense interest towards vanadium materials and their growth by ALD. A considerable number of commercially available potential vanadium precursors remains unexplored. Surprisingly striking variations between different sources were observed regarding the thermolysis threshold and the ALD window. The values stated in Table 3 refer to the lowest reported thermolysis threshold. An increased growth per cycle when extending the exposure time to the vanadium precursor is considered as a signature of a parasitic thermolysis contribution. Among the investigated precursors, three featured a convenient reactivity with the conventionally used reactants for the growth of oxides by thermal ALD. These three precursors were also the ones exhibiting the highest vapour pressures: TDMAV; TEMAV and VTOP. If vaporized at room temperature, these precursors should enable a conveniently wide ALD processing window up to the thermolysis threshold. TDMAV can be distinguished among the three valuable precursors by its higher thermolysis temperature, which makes it particularly appealing for ALD processes with water vapour as reactant. In fact, using water as reactant at low temperatures implies the use of excessively long purge 
times, which makes the process slower. VTOP is the most investigated precursor so far, which is likely related to its convenient handling in air and the low toxicity of the reaction products.

Table 3: Summary of the main characteristics of the investigated precursors for the growth of vanadium oxide with ALD.

\begin{tabular}{|c|c|c|c|c|c|c|}
\hline \multirow{2}{*}{\multicolumn{2}{|c|}{ Precursor }} & \multirow{2}{*}{ Vapour pressure } & \multicolumn{3}{|c|}{ Reactivity } & \multirow{2}{*}{ Thermolysis threshold } \\
\hline & & & $\mathrm{H}_{2} \mathrm{O}$ & $\mathrm{O}_{3}$ & $\mathrm{O}_{2}$-Plasma & \\
\hline $\mathrm{V}^{3+}$ & $\mathrm{V}\left({ }^{i} \mathrm{Pr}-\mathrm{Me} \mathrm{AMD}\right)_{3}$ & $6.6 \mathrm{~Pa} @ 70^{\circ} \mathrm{C}$ & $\mathrm{X}$ & $\sqrt{ }$ & - & - \\
\hline \multirow[t]{4}{*}{$\mathrm{V}^{4+}$} & $\mathrm{V}\left(\mathrm{N} \mathrm{Me}_{2}\right)_{4}(\mathrm{TDMAV})$ & $\begin{array}{l}133 \mathrm{~Pa} @ 64^{\circ} \mathrm{C} \\
13 \mathrm{~Pa} @ 25^{\circ} \mathrm{C}\end{array}$ & $\sqrt{ }$ & $\sqrt{ }$ & $\sqrt{ }$ & $120^{\circ} \mathrm{C}$ \\
\hline & $\mathrm{V}(\mathrm{N} \text { Et } \mathrm{Me})_{4}(\mathrm{TEMAV})$ & $\begin{array}{l}24 \mathrm{~Pa} @ 45^{\circ} \mathrm{C} \\
57 \mathrm{~Pa} @ 82^{\circ} \mathrm{C}\end{array}$ & $\sqrt{ }$ & $\sqrt{ }$ & $\sqrt{ }$ & $>175^{\circ} \mathrm{C}$ \\
\hline & $\mathrm{VO}(\operatorname{acac})_{2}$ & $0.21 \mathrm{~Pa} @ 96^{\circ} \mathrm{C}$ & $\mathrm{X}$ & $\sqrt{ }$ & - & $180^{\circ} \mathrm{C}$ \\
\hline & $\mathrm{VO}(\mathrm{tmhd})_{2}$ & $0.24 \mathrm{~Pa} @ 96^{\circ} \mathrm{C}$ & $\mathrm{X}$ & $\mathrm{X}$ & $\sqrt{ }$ & $160^{\circ} \mathrm{C}$ \\
\hline $\mathrm{V}^{5+}$ & $\mathrm{VO}\left(\mathrm{O}^{i} \mathrm{Pr}\right)_{3}(\mathrm{VTOP})$ & $\begin{array}{l}6 \mathrm{~Pa} @ 25^{\circ} \mathrm{C} \\
39 \mathrm{~Pa} @ 45^{\circ} \mathrm{C} \\
268 \mathrm{~Pa} @ 82^{\circ} \mathrm{C}\end{array}$ & $\sqrt{ }$ & $\sqrt{ }$ & $\sqrt{ }$ & $100^{\circ} \mathrm{C}$ \\
\hline
\end{tabular}

\section{Post-treatment of ALD-grown vanadium oxides}

The as-deposited $\mathrm{VO}_{x}$ do not always feature the desired characteristics. The art of post-treatment in $\mathrm{VO}_{x}$ is far more challenging, as implied by the richness of the $\mathrm{V}$-O phase diagram. This section addresses the relevance between the oxidation state of vanadium in the as deposited film, and the post-treatment parameters; temperature, pressure and partial pressure of the oxidant, or reducer. We summarize the literature and highlight some new alternatives and un- or under-explored areas.

ALD-grown vanadium oxides already come in a wide range, i.e. from amorphous to crystalline and with vanadium in various oxidation states, as extensively discussed in section 3. However, the degree of crystallinity often plays a large role in the device characteristics. For example, amorphous $\mathrm{V}_{2} \mathrm{O}_{5}$ thin films, powders and aerogels have been reported to store lithium more efficiently and with higher capacities compared to their crystalline counterpart, [85-87]. As another example, the same vanadium IV oxidation state in a different crystal lattice form, i.e. $\mathrm{VO}_{2}(\mathrm{M} 1 / \mathrm{R})$ compared to $\mathrm{VO}_{2}(\mathrm{~A})$ or $\mathrm{VO}_{2}(\mathrm{~B})$, can either exhibit thermochromic properties in the former case while no thermochromic behaviour is observed in either of the latter lattices, [88]. Often, the degree of crystallinity can be controlled in-process, as described in section 3.1.2 for ALD using [VO(tmhd) $)_{2}$ and $\mathrm{O}_{2}$ (amorphous 162-196 ${ }^{\circ} \mathrm{C}$, crystalline $\mathrm{V}_{2} \mathrm{O}_{5} 196-235^{\circ} \mathrm{C}$ ) [31], or using TEMAV and $\mathrm{O}_{2}$ plasma as highlighted in section 3.3.1, which produces amorphous films below $100^{\circ} \mathrm{C}$, but crystalline $\mathrm{V}_{2} \mathrm{O}_{5}$ at higher temperatures, [37, 65, 67, 87, 89].

Besides the crystal structure, the vanadium oxidation state also plays a major role in device characteristics. The vanadium oxidation state can often be tuned in-process by 
choosing precursors with an appropriate vanadium oxidation state. As highlighted in section 3 , three oxidation states of vanadium are presently found in literature (table 3 ). If this is not sufficient, the oxidation state can be raised by utilizing an oxidizing ALD reactant such as oxygen plasma and ozone or lowered by utilizing a reducing ALD reactant such as hydrogen or ammonia plasma. Furthermore, deposition temperature also plays a role, as demonstrated by for example the TEMAV/ozone process, where the density of the grown films varied from $\sim 0.3 \mathrm{~mole} / \mathrm{cm}^{3}$ to more than 0.4 mole $/ \mathrm{cm}^{3}$ from 100 to $175^{\circ} \mathrm{C}$, respectively, [90].

Despite this large degree of in-process control already found in the ALD processes reported, there is a limitation in the films grown. In general, all reported films are either amorphous or crystalline $\mathrm{VO}_{2}$ or $\mathrm{V}_{2} \mathrm{O}_{5}$. When the phase diagram derived by Wriedt et al in figure 8 is observed, [91], five principal single-valent vanadium oxides exist $\mathrm{V}, \mathrm{VO}, \mathrm{V}_{2} \mathrm{O}_{3}$, $\mathrm{VO}_{2}$ and $\mathrm{V}_{2} \mathrm{O}_{5}$, with vanadium in the $0,+2,+3,+4$ and +5 oxidation state, respectively. Besides that, two families of mixed-valence vanadium oxides do exist: the Magnéli and Wadsley series, which can be written as $\mathrm{V}_{n} \mathrm{O}_{2 n-1}(\mathrm{n}=4-9)$ and $\mathrm{V}_{n} \mathrm{O}_{2 n+1}(\mathrm{n}=3,4,6)$, [14, 91, 92]. The wide range of stable oxidation states and polymorphic forms, each with their own physicochemical properties and application range, indicates that the crystallinity and phase control exhibited in-process during ALD is insufficient, and often a careful post-deposition treatment is necessary to obtain the required crystal phase. The complexity of the V-O phase diagram, ranging from the primary stable oxides as $\mathrm{VO}_{2}$ and $\mathrm{V}_{2} \mathrm{O}_{5}$ to metastable states such as $\mathrm{VO}_{2}(\mathrm{~B})$, makes the annealing very sensitive to all environmental parameters. Below, we will discuss the influence of ambient, temperature, substrate and deposited film

\subsection{Processing parameters}

\subsubsection{Influence of temperature and ambient}

Role of temperature. The influence of temperature on the crystallization of the ALD-made Vanadium oxide thin films cannot be understood only by simply reading the phase diagram in Figure 8. This would assume that the oxygen content in the film remains constant, which is not the case, as shown in many examples hereafter. Oxygen content in the film after the thermal treatment is largely influenced by the ambient, substrate, nature of the films as well as temperature. Furthermore, the annealing is not simply a function of temperature, but a function of the total thermal budget. A higher thermal budget is reached either by increasing the exposure temperature or the exposure time. This was for example demonstrated by Tangirala et al, which showed that the crystallization of a TEMAV $+\mathrm{H}_{2} \mathrm{O}$-grown film could be attained by a $30 \mathrm{~min}$ annealing at $450^{\circ} \mathrm{C}$ under a controlled $\mathrm{N}_{2} / \mathrm{O}_{2}$ atmosphere, while 5 min were not enough, [75]. Similarly, Lv et al found that annealing-induced crystallization of a TDMAV $+\mathrm{H}_{2} \mathrm{O}$-grown film features a long nucleation time at $450^{\circ} \mathrm{C}$ in $\mathrm{Ar}$ ambient, as shown in Figure 9 . Nanocrystalline films were formed after 30-min of annealing, whereas fully crystallised films are obtained after 100 minutes, [80]. In general, it can be stated that raising the temperature induces crystallisation and can raise the oxidation state, provided sufficient partial pressure of oxygen is available.

Oxidizing atmosphere. Mattelaer et al separated the concepts of thermodynamic phase formation and kinetic phase formation by applying in-situ XRD to observe the phase formation 


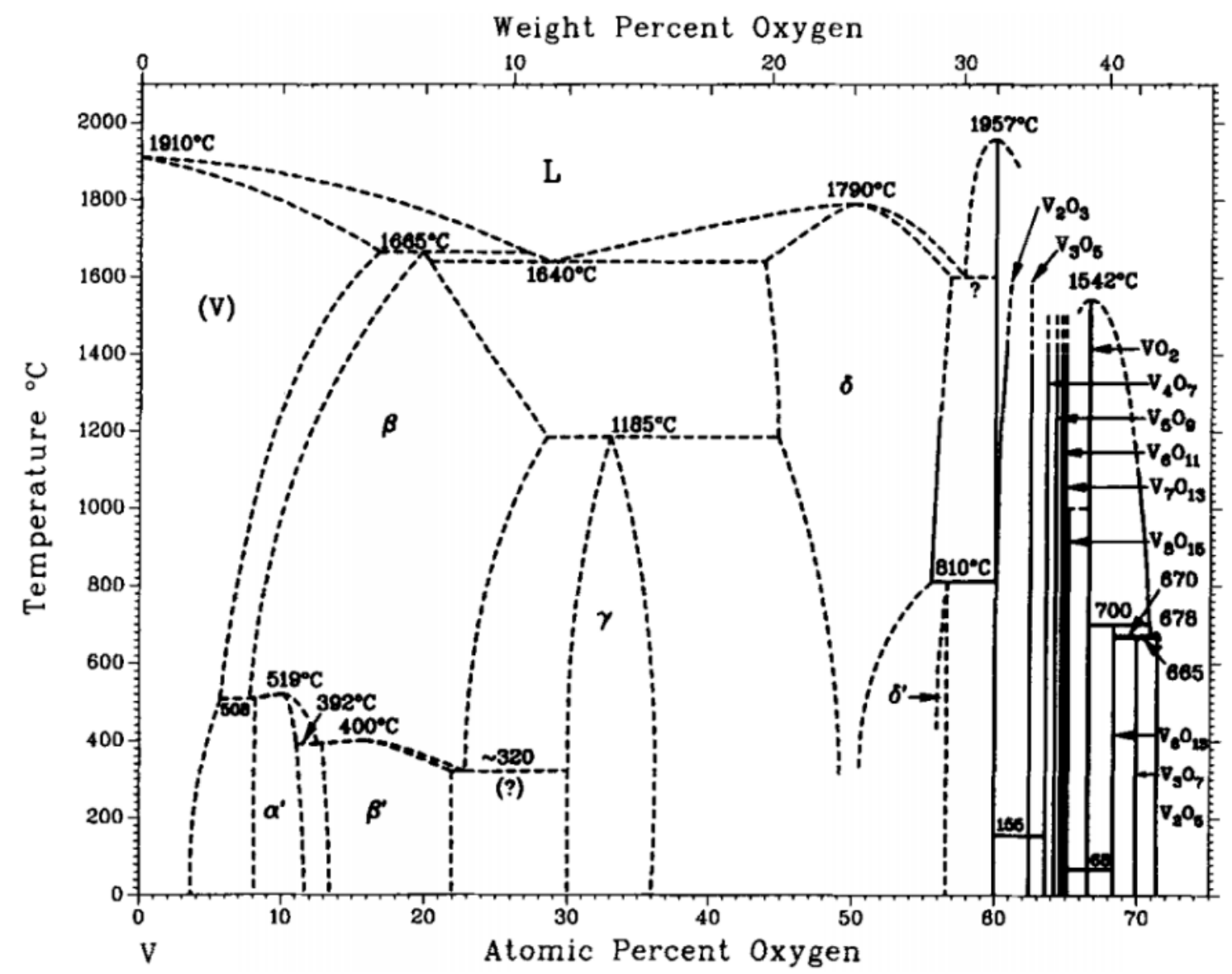

Figure 8: Assessed V-O phase diagram (Condensed System, 0.1 MPa). Reprinted by permission from Springer Nature: Springer, Bulletin of alloy phase diagrams [91], Copyright 1989.
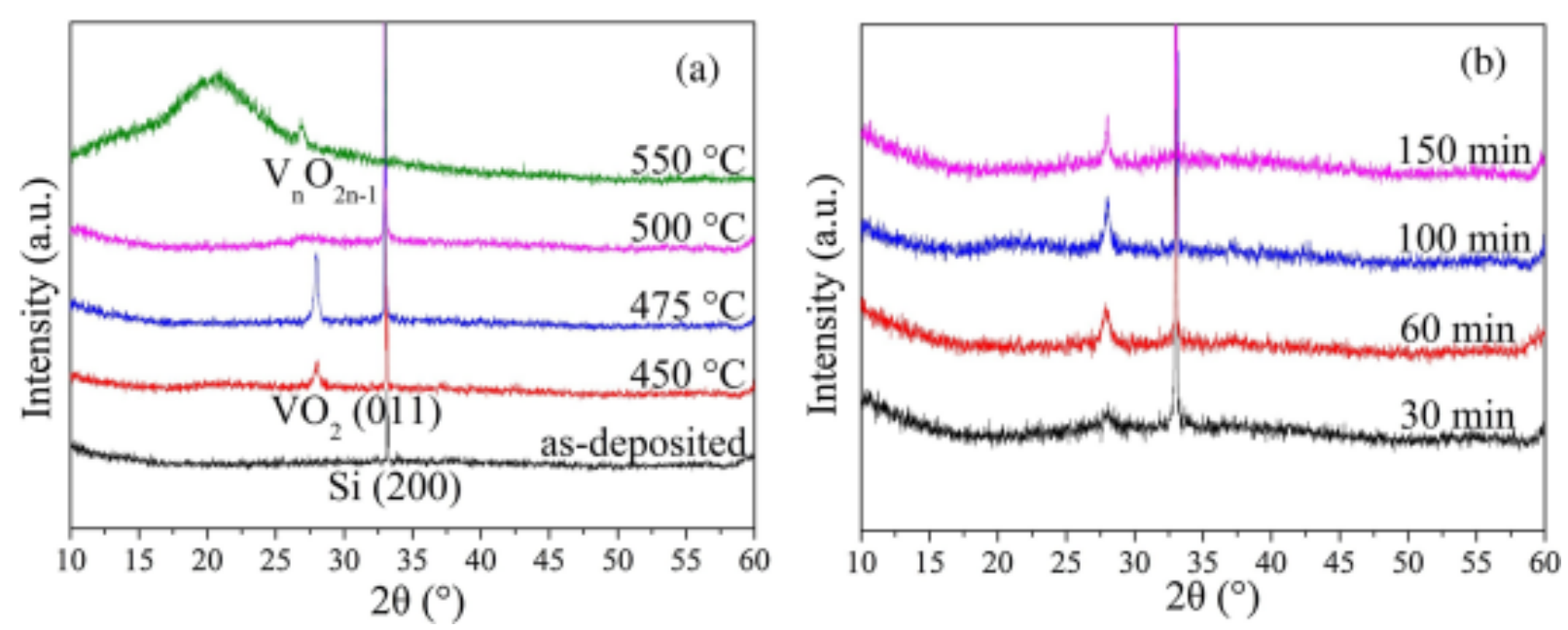

Figure 9: XRD patterns of (a) $\mathrm{VO}_{2} / \mathrm{Si}$ deposited using TDMAV and water at $200^{\circ} \mathrm{C}$ after 100 min annealing in $\mathrm{Ar}$ or (b) different duration at $450^{\circ} \mathrm{C}$, Reprinted from [80], Copyright 2017, with permission from Elsevier. 
of TEMAV-grown films dynamically in a range of oxygen partial pressures $(3.7,7.4,14.8$, 29.6 and $48.1 \mathrm{~Pa}$, and ambient air), as shown in Figure 10. The summary of this dataset, also shown in Figure 10, should not be interpreted as a thermodynamic phase diagram, since the process is not isothermal. The phase formation diagrams displays the kinetic path the films go through while being heated at $0.25^{\circ} / \mathrm{s}$ in the ambient under study. From these results, the trend in temperature confirms that higher temperatures favour crystallisation and eventually a change of oxidation state depending on the oxygen partial pressure. Phases emerge in oxidative ambient in order of increasing oxidation state: $\mathrm{VO}_{2}-\mathrm{V}_{6} \mathrm{O}_{13}-\mathrm{V}_{4} \mathrm{O}_{9}-\mathrm{V}_{3} \mathrm{O}_{7}-\mathrm{V}_{2} \mathrm{O}_{5}$ with respective to the average oxidation states for the $\mathrm{V}$ of $4-4.33-4.5-4.67-5,[65,87]$.

(a) $\mathrm{H}_{2} \mathrm{O}$ ALD

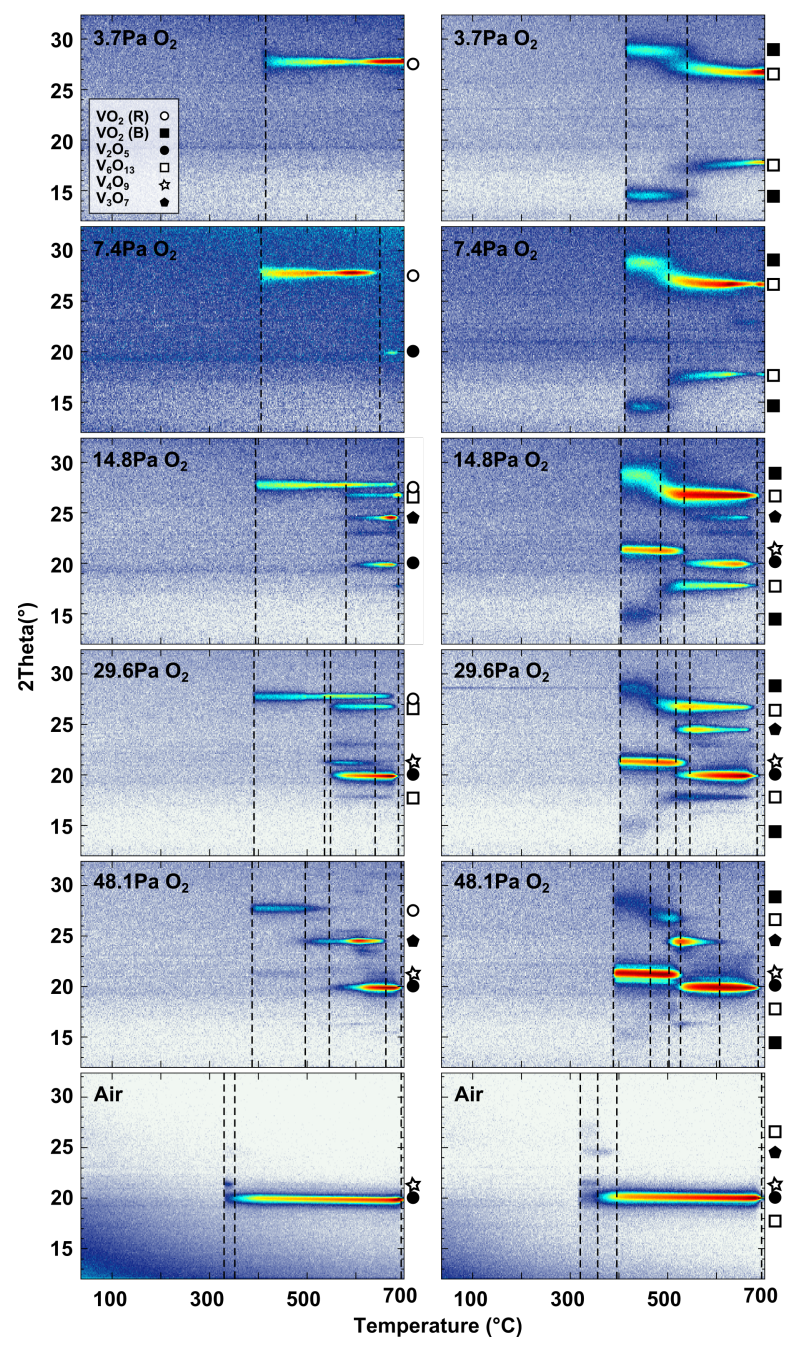

(b) $\mathrm{O}_{3}$ ALD

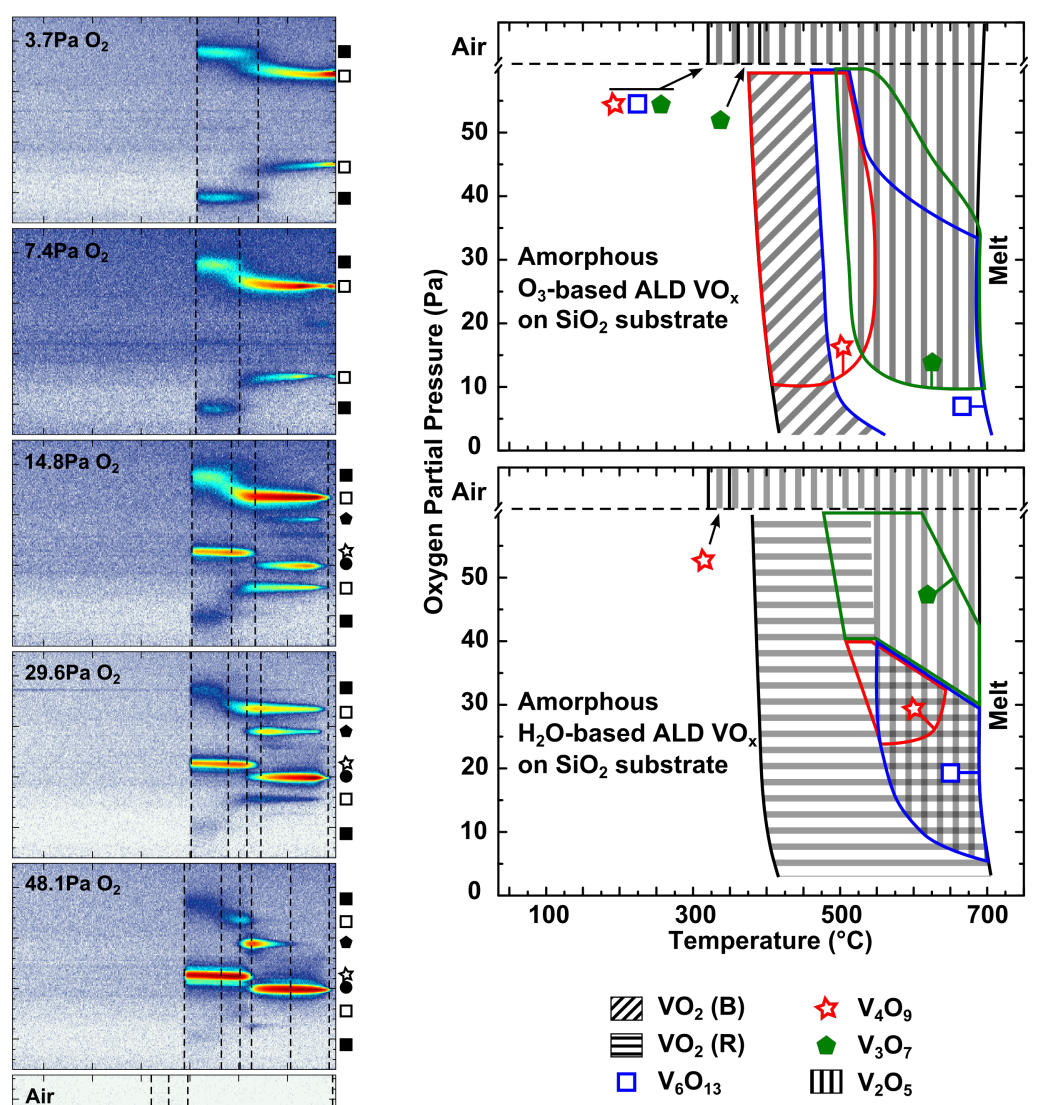

Figure 10: (left) in-situ XRD on TEMAV-grown ALD films with (a) $\mathrm{H}_{2} \mathrm{O}$ or (b) $\mathrm{O}_{3}$ as a reactant, at various oxygen partial pressures while annealing at $0.25^{\circ} /$ second. (right) Phase formation diagrams resulting from the in-situ XRD monitoring. Reproduced from , [65, 87] with permission from the Royal Society of Chemistry.

Besides varying oxygen partial pressure at atmospheric pressure, Tangirala et al also 
examined annealing at lower pressure. They found that TEMAV $+\mathrm{H}_{2} \mathrm{O}$-grown amorphous $\mathrm{VO}_{2}$ film crystallised only at well-defined conditions, i.e. $425^{\circ} \mathrm{C}$ or $450^{\circ} \mathrm{C}$ with a flow containing $1.22 \%$ or $1 \% \mathrm{O}_{2}$, respectively, under atmospheric pressure conditions. However, in mild vacuum conditions $\left(\sim 10^{-2}\right.$ Torr $)$, the oxygen component in the flow could be much higher, and crystallisation to $\mathrm{VO}_{2}$ was also achieved at $500^{\circ} \mathrm{C}$ in a $100 \% \mathrm{O}_{2}$ flow [75]. This opens up another parameter in phase-space, which is only marginally explored, the influence of the pressure on the oxidation/crystallisation.

Finally, Rambelberg et al showed that combining a well-defined partial pressure of an oxidizing gas (such as $\mathrm{O}_{2}$ ) to an otherwise reducing ambient (such as $\mathrm{H}_{2}$ ) resulted in a higher degree of control over the phase formation, [93]. This indicates that further research in the direction of bi-functional ambient could also be interesting.

Reducing atmosphere. Most art on post-deposition annealing of ALD vanadium oxide films deals with controlling the oxygen concentration between $0 \%$ (inert atmosphere such as He, $\mathrm{N}_{2}$ or $\mathrm{Ar}$ ) and $100 \%$ (pure $\mathrm{O}_{2}$ ), and investigates the effect of this ambient on the crystallisation and oxidation/reduction behaviour of the ALD-made $\mathrm{VO}_{x}$ films. In general, the crystallisation of films into a low oxidation-state oxide as $\mathrm{VO}_{2}(\mathrm{~B})$ or $\mathrm{VO}_{2}(\mathrm{M})$ is much more challenging than forming crystalline $\mathrm{V}_{2} \mathrm{O}_{5}$, as this is the high-temperature stable phase: traces of oxygen in the ambient will readily cause oxidation of crystalline $\mathrm{VO}_{2}$ to higher oxidation states, as shown in Figure 10 . However, besides controlling the oxygen concentration, the introduction of a reducing ambient can facilitate the formation of low-valence vanadium oxide films. Song et al investigated the crystallisation behaviour of $\mathrm{VTOP}+\mathrm{H}_{2} \mathrm{O}$-grown films in air and in forming gas ambient $\left(95 \% \mathrm{~N}_{2}+5 \% \mathrm{H}_{2}\right.$, FGA). Figure 11, shows the results of $1 \mathrm{~h}$ isothermal annealing at 300,400 or $500^{\circ} \mathrm{C}$. While $\mathrm{V}_{2} \mathrm{O}_{5}$ was readily formed already at $300^{\circ} \mathrm{C}$ in air, monoclinic $\mathrm{VO}_{2}$ was formed at $500{ }^{\circ} \mathrm{C}$ via monoclinic $\mathrm{V}_{3} \mathrm{O}_{7}$ at $400^{\circ} \mathrm{C}$, [45]. However, the obtained crystalline $\mathrm{VO}_{2}(\mathrm{M})$ features nanoparticles morphology rather than continuous films.
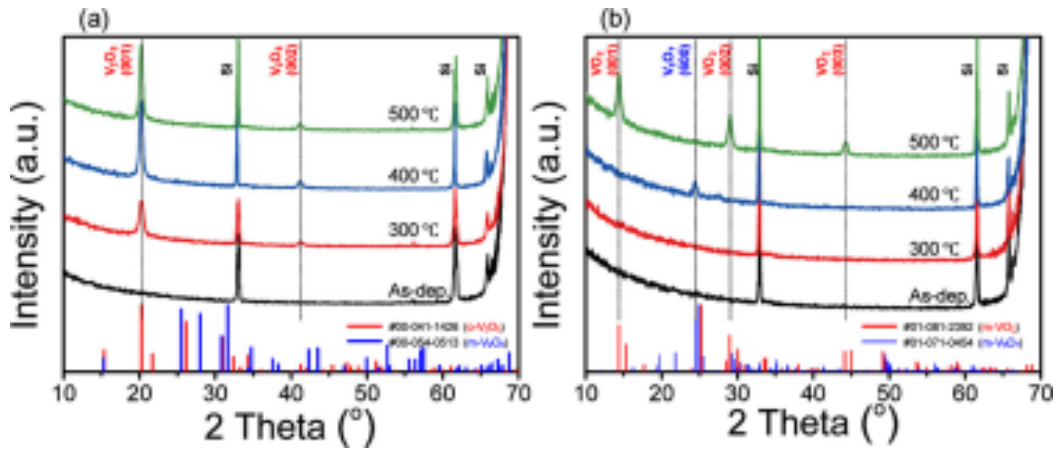

Figure 11: XRD patterns of the as-deposited and post-deposition annealed $\mathrm{VO}_{x}$ thin films at 300, 400, and $500{ }^{\circ} \mathrm{C}$ for $1 \mathrm{~h}$ in (a) air and (b) forming gas. Reprinted from , [45]. Copyright 2017 American Chemical Society.

The presence of oxygen during crystallization is a critical factor to maintain a continuous $\mathrm{VO}_{x}$ film, $[66,69,78]$. This implies that, if an enhanced surface area is required, as for catalysis or energy storage, annealing in oxygen-free ambient can be the optimal pathway. Very 
few researches have been performed using reducing ambient, which is potentially interesting to control the oxidation state further and form oxides below $\mathrm{VO}_{2}$ or metallic vanadium nanoparticles.

\subsubsection{Influence of deposited film}

Several precursors have been used for the deposition of vanadium oxides by atomic layer deposition, as extensively discussed in section 3. Generally, they can be divided into three classes according to their vanadium oxidation state as summarised in table 3: + III vanadium precursors such as $\mathrm{V}\left({ }^{i} \mathrm{Pr}-\mathrm{Me} \mathrm{AMD}\right)_{3},+\mathrm{IV}$ vanadium precursors such as $\left[\mathrm{VO}(\mathrm{tmhd})_{2}\right]$, $\left[\mathrm{VO}(\mathrm{acac})_{2}\right], \mathrm{V}\left(\mathrm{N} \mathrm{Me}_{2}\right)_{4}$ (TDMAV) and TEMAV, and $+\mathrm{V}$ vanadium precursors such as $\mathrm{VTOP}$ and $\mathrm{VOCl}_{3}$. According to pure ligand exchange reaction chemistry, this also determines the oxygen content into the deposited films, for example TEMAV $+\mathrm{H}_{2} \mathrm{O}$ ALD leads to $\mathrm{VO}_{2}$ films, [37, 89], and $\mathrm{VTOP}+\mathrm{H}_{2} \mathrm{O}$ leads to $\mathrm{V}_{2} \mathrm{O}_{5}$ films, [94]. However, the oxidative $\left(\mathrm{O}_{2}\right.$ plasma, $\mathrm{H}_{2} \mathrm{O}$ plasma, ozone) or reductive (acetic acid) ALD chemistry used alters the vanadium oxidation state in the films compared to that in the precursors, rendering different oxygen contents and often inducing crystallisation. The oxygen content (or vanadium oxidation state) in the deposited film will have a direct influence on the crystallisation and initial oxidation/reduction stages during post-deposition annealing of these films. Peter et al, and later Mattelaer et al, found that the deposition of films using TEMAV yielded almost identical amorphous $\mathrm{VO}_{2}$ films using either water or ozone as a reactant, except for the density, which was significantly higher for the water-grown films than for the ozonegrown films, [65], and strongly influenced by the deposition temperature and $\mathrm{O}_{3}$ exposure time, [69]. Rampelberg et al linked those density differences to the different crystalline states of $\mathrm{VO}_{2}$, i.e. higher-density $\mathrm{VO}_{2}(\mathrm{M} 1)$ or lower-density $\mathrm{VO}_{2}(\mathrm{~B})$, [90]. As shown in Figure 10 , at low oxygen partial pressure this indeed resulted in the crystallisation of $\mathrm{VO}_{2}(\mathrm{M} 1)$ or $\mathrm{VO}_{2}$ (B) from the water- or ozone-grown films, respectively. Similarly, Peter et at linked the density of the as-deposited films to either close to $\mathrm{VO}_{2}$ or $\mathrm{V}_{2} \mathrm{O}_{5}$, resulting in much smoother $\mathrm{VO}_{2}$ films using optimized conditions at $1.6 \mathrm{~Pa} \mathrm{O}_{2},[69]$.

Furthermore, as not all ALD chemistry is able to deposit a 'clean' vanadium oxide film, impurities such as carbon or hydrogen can often be incorporated into the films. Musschoot et al. showed that this carbon content in the films can delay the crystallisation of amorphous ALD vanadium oxides. They examined VTOP as an ALD vanadium source with thermal and PE-ALD. While water plasma enhanced the growth rate compared to thermal ALD, the carbon content was higher. Both films were amorphous as deposited, but crystallisation was delayed. The water-grown film crystallized between $400-450^{\circ} \mathrm{C}$ to $\mathrm{V}_{3} \mathrm{O}_{7}$, and further oxidized to $\mathrm{V}_{2} \mathrm{O}_{5}$ between $450-500^{\circ} \mathrm{C}$, while the higher C-content PE-ALD grown film only crystallized at $500^{\circ} \mathrm{C}$ to $\mathrm{V}_{2} \mathrm{O}_{5},[37,89]$.

\subsubsection{Influence of substrate}

The crystallisation and oxidation/reduction behaviour is sensitive to the oxygen content in the films (section 4.1.2) and to the oxygen partial pressure during post-annealing (section 4.1.1). Both parameters retain particular attention during the design of the post-deposition annealing process. However, the effect of the substrate on which the films are deposited 
is often overlooked. An easily oxidizable substrate, such as copper or titanium nitride, can scavenge oxygen from the vanadium oxide film, some substrates can donate oxygen to the films and act as an oxygen source, while a third class of substrates can be classified as oxygen-indifferent, such as Pt films which neither donate nor scavenge oxygen from the ALD films during anneal. Permkumar et al. studied the crystallisation behaviour of $\mathrm{VO}_{2}$ from amorphous ALD $\mathrm{VO}_{x}$ films grown from TEMAV $+\mathrm{O}_{3}$ at $150^{\circ} \mathrm{C}$. It was observed that $\mathrm{VO}_{2}$ could be crystallised at $500^{\circ} \mathrm{C}$ in oxygen partial pressures up to $11 \mathrm{~Pa} \mathrm{O}_{2}$ on a $1 \mathrm{~nm} \mathrm{SiO}_{2}$ on Si substrate. In contrast, further oxidation to mixed-phase $\mathrm{VO}_{2} / \mathrm{V}_{3} \mathrm{O}_{7}$ was observed already at $\geq 6 \mathrm{~Pa} \mathrm{O}_{2}$ on $90 \mathrm{~nm} \mathrm{SiO}_{2}$, indicating an oxygen loss from the amorphous film through the thin $\mathrm{SiO}_{2}$ layer into the silicon substrate, which was prevented using a thicker $\mathrm{SiO}_{2}$ barrier, [68].

In the same way, the difference between $\mathrm{SiO}_{2}$, TiN or Pt/TiN substrates was examined by Mattelaer et al. The phase formation diagrams on the $\mathrm{SiO}_{2}$ substrates in Figure 10 can be compared to those in Figure 12, where the same annealing conditions were applied on TiN or TiN capped with Pt. Besides the larger number of phases that are formed on $\mathrm{SiO}_{2}$ substrate, the oxidation of the vanadium oxide films to higher oxides was delayed on both TiN and Pt/TiN substrates. This was related to oxygen scavenging from TiN in both cases, demonstrating a clear influence of substrate, [65].

Besides the influence on the oxygen content of the vanadium oxide film, crystallisation is also influenced by the underlying surface. When studying the crystallisation of TEMAV $+\mathrm{O}_{3}$ grown amorphous ALD vanadium oxides, it was found that on alumina the formation of the meta-stable $\mathrm{VO}_{2}(\mathrm{~B})$ phase was possible using mild annealling conditions, while only the monoclinic $\mathrm{VO}_{2}(\mathrm{M})$ phase was found using $\mathrm{SiO}_{2}$ substrates. Permkumar ascribed this behaviour to different reactive sites available on these different surfaces, facilitating a preferential crystalline state during the post-deposition annealing, [68].

\subsection{Influence of post-deposition annealing on the surface morphology}

\subsubsection{Thickness and temperature}

As highlighted in the previous section, an excellent control over the crystallinity and oxidation state of vanadium oxide films can be achieved by post-deposition annealing of ALD-made films. However, besides crystallinity, film and surface morphology also play a paramount role in device characteristics, as wll be shown in the following sections on applications of ALD $\mathrm{VO}_{x}$ films in energy storarage (section 5), micro-electronics (section 6 ) and thermochromic glazing (section 7). For example, electrical devices, such as the electrochromic films discussed in section 7, can only be operated if they are continuous, while for catalysis the enhanced surface area is beneficial. Rampelberg et al. investigated the morphology evolution upon the conversion to $\mathrm{VO}_{2}(\mathrm{M} 1)$ and revealed a significant sensitivity to the annealing step, as shown in Figure 13. While the crystallisation behaviour was thickness insensitive $\left(\sim 450^{\circ} \mathrm{C}\right.$ in $\left.1 \mathrm{~Pa} \mathrm{O}_{2}\right)$, lowering the film thickness or further increasing the thermal budget resulted in faster agglomeration of the films to form isolated particles, and films below $11 \mathrm{~nm}$ fell outside the processing window to obtain a closed $\mathrm{VO}_{2}(\mathrm{M} 1)$ film, [66]. 
(a) TiN substrate

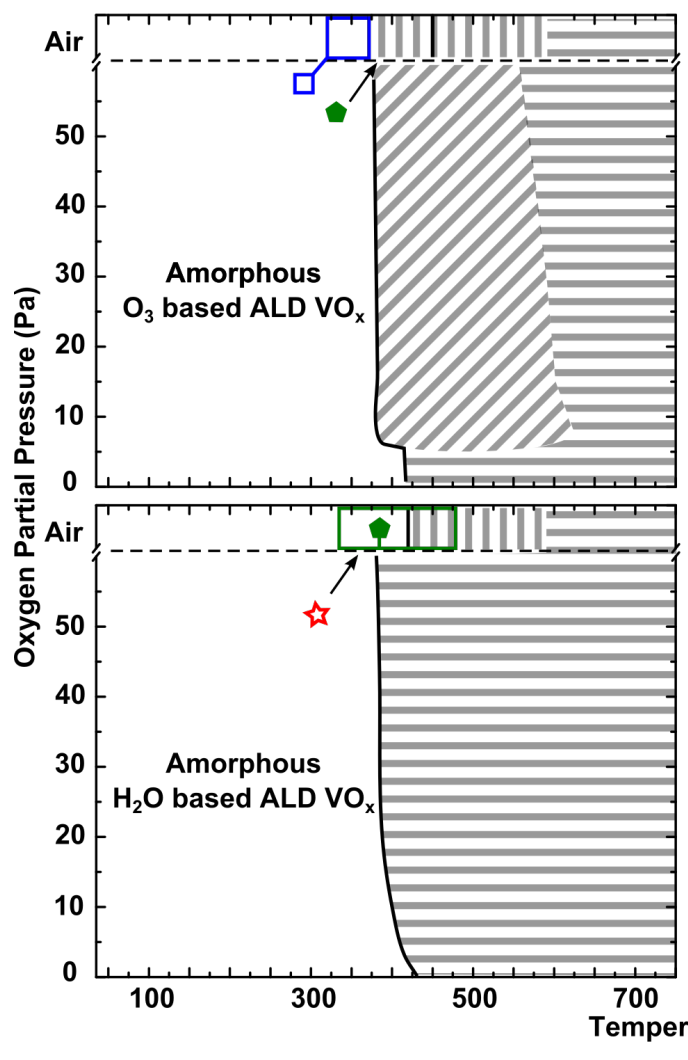

(b) Pt substrate

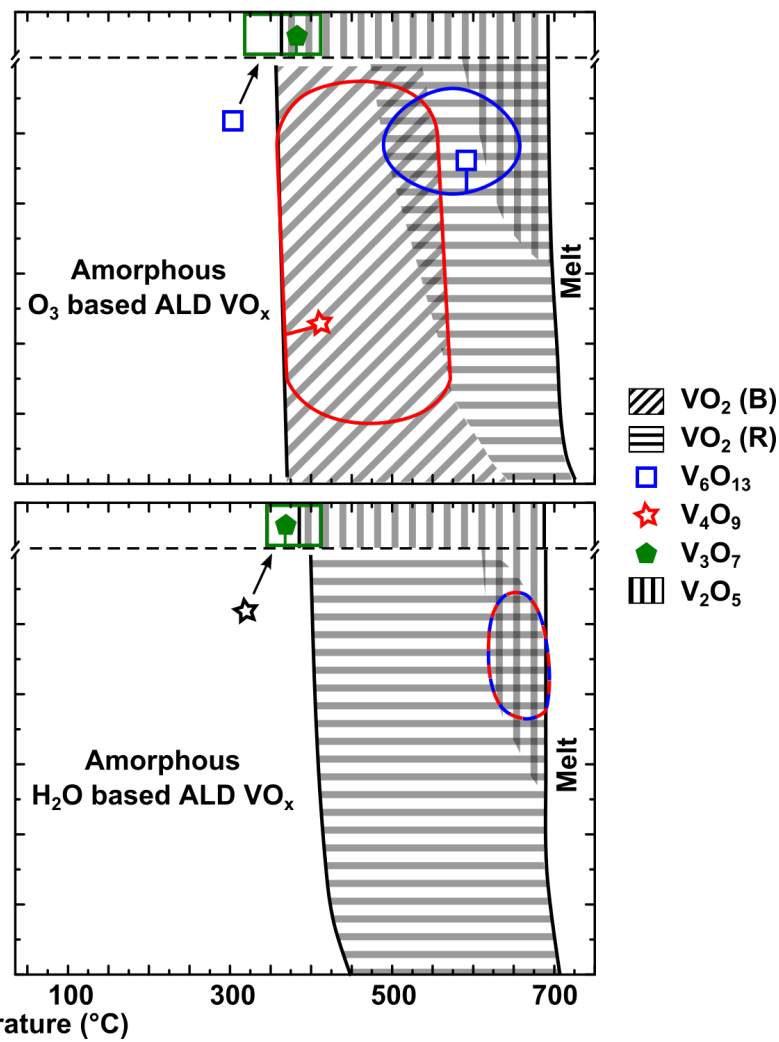

Figure 12: Phase formation diagrams of the $\mathrm{VO}_{x}$ crystal states $(2<\mathrm{x}<2.5)$ on TiN substrates (left) and on $\mathrm{Pt} / \mathrm{TiN}$ substrates (right), at $0.25^{\circ} / \mathrm{s}$ for He ambients with oxygen partial pressure of 3.7, 7.4, 14.8, 29.6 and $48.1 \mathrm{~Pa}$, and in ambient air. The absence of the melt-line on the left figure is related to the presence of rutile $\mathrm{TiO}_{2}$ from the substrate, complicating the analysis of the $\mathrm{VO}_{2}(\mathrm{R})$ phase on the TiN substrate at high temperatures. Reproduced from, [65] with permission from the Royal Society of Chemistry.

\subsubsection{Surface and ambient}

Peter et al further showed that, besides film thickness and temperature, the presence of oxygen in the annealing ambient, and the nature of the substrate, also played a role in agglomeration of films, more specifically of $\mathrm{VO}_{2}$ films. They suggested that post-deposition annealing, especially in the case when a valence change is necessary to obtain stoichiometric $\mathrm{VO}_{2}$, is typically accompanied by rough morphology and agglomeration on dielectric substrates, [69]. These were attributed to dewetting of the dielectric surfaces by the metallic $\mathrm{VO}_{2}$ and is strongly enhanced by the volume change during the heat treatment, [69]. A systematic coarsening of vanadium oxide was reported on fused silica substrates upon annealing in pure $\mathrm{N}_{2},[78]$. When very similar films were annealed by $\mathrm{Lv}$ et al in inert ambient (pure Ar in their case), film cracking was observed, but no agglomeration was seen, indicating a better adhesion to the Si surface compared to the fused silica, [80]. The interplay between the presence of oxygen in the ambient and the nature of the substrate is not yet completely understood, and requires further research. 

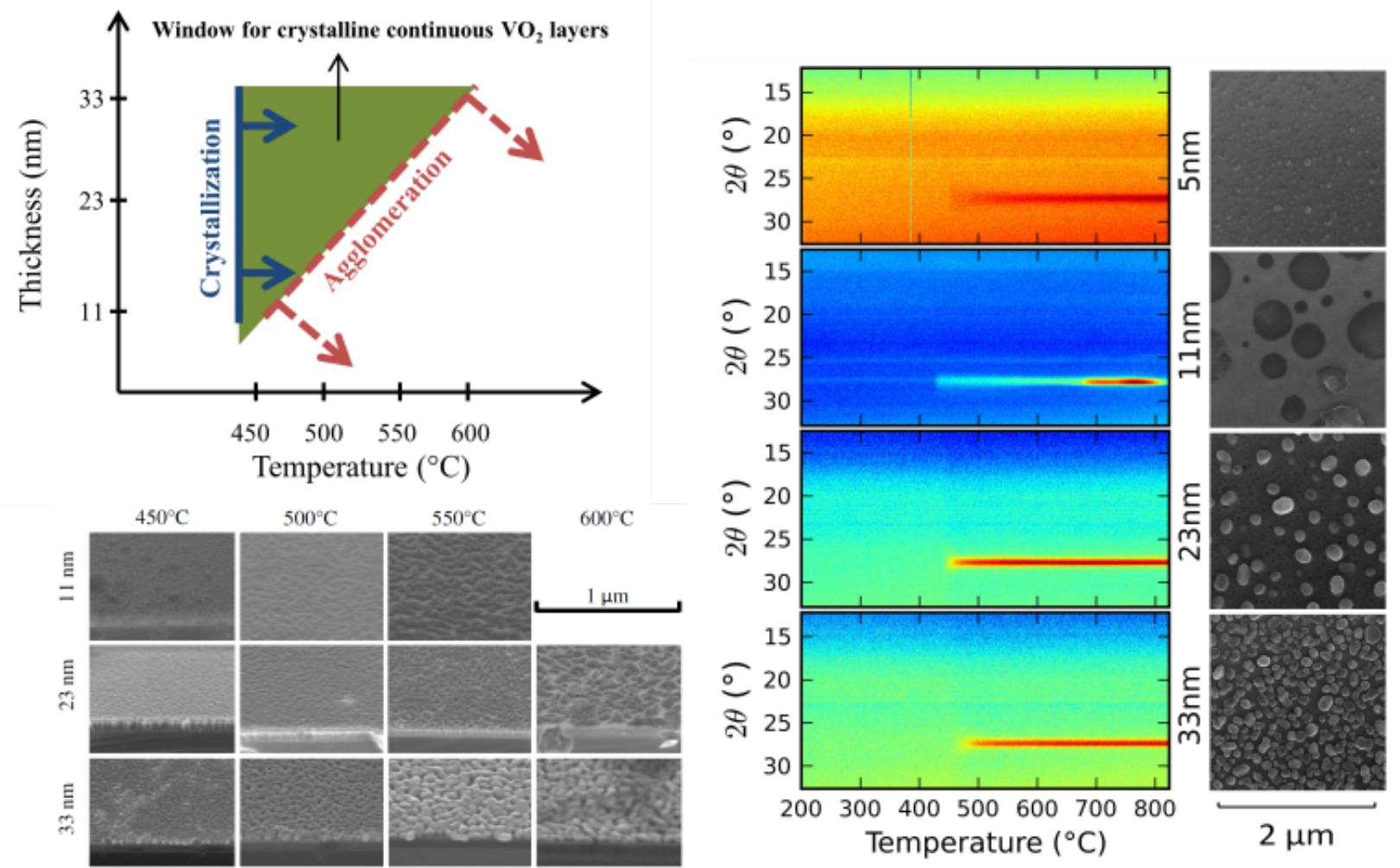

Figure 13: (top left) Process window for the crystallisation of amorphous vanadium oxide films grown from TEMAV and $\mathrm{O}_{3}$ in a $1 \mathrm{~Pa}_{2}$ ambient, illustrating the effect of thickness and temperature on the morphology. (bottom left) SEM images of 11, 23 and $23 \mathrm{~nm}$ films after isothermal anneal for 30 minutes in $1 \mathrm{~Pa}_{2}$ at 450 , 500,550 or $600^{\circ} \mathrm{C}$, (right) in-situ XRD demonstrating the independence of thickness on the crystallisation temperature under the same conditions (same precursors, reactant and an annealing ambient of $1 \mathrm{~Pa} \mathrm{O}_{2}$ ) Reprinted from [66], Copyright 2014, with permission from Elsevier.
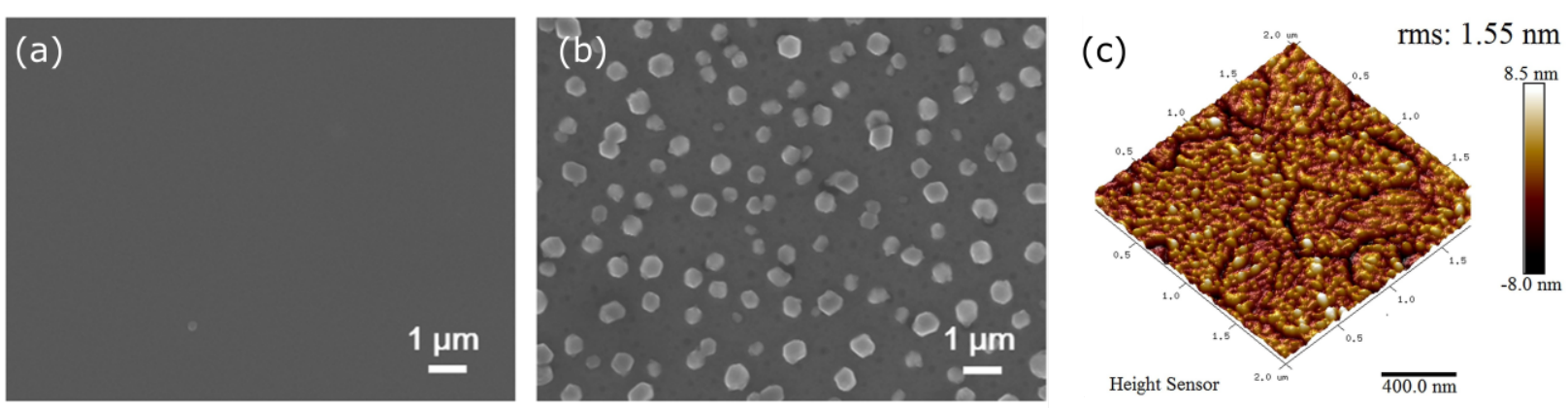

Figure 14: SEM top-view images comparatively showing the accompanying morphological change of a TDMAV $+\mathrm{H}_{2} \mathrm{O}$-grown $\mathrm{VO}_{x}$ film (a) before and (b) after the annealing process in pure $\mathrm{N}_{2}$ at $600^{\circ} \mathrm{C}$ on fused silica substrates, reproduced with permission from, [78]. (c) AFM image of a TDMAV $+\mathrm{H}_{2} \mathrm{O}$-grown $\mathrm{VO}_{x}$ film on n-type silicon after anneal at $425^{\circ} \mathrm{C}$ in Ar, Reprinted from [80], Copyright 2017, with permission from Elsevier. 


\section{Applications of Vanadium Oxides in Energy Storage}

The global energy scarcity and environment deterioration have compelled an intensive exploration of sustainable and clean energy storage. Rechargeable batteries and supercapacitors are considered as the most favourable options among various energy storage technologies. Hereinto, the choice of electrode materials is of vital importance for the electrochemical performance. Typically, materials of interest are found amongst those with an open crystal structure and a relatively low density. The vanadium oxides in the Wadsley series, i.e. $\mathrm{VO}_{2}, \mathrm{~V}_{6} \mathrm{O}_{13}, \mathrm{~V}_{4} \mathrm{O}_{9}, \mathrm{~V}_{3} \mathrm{O}_{7}$ and $\mathrm{V}_{2} \mathrm{O}_{5}$, are known as the layered vanadium oxides, and have attracted a continuous and fervent attention as promising electrode materials for nextgeneration advanced electrochemical energy storage owing to their high specific capacity, abundant resource and low cost, [95-97]. Therefore, many synthesis methods for vanadium oxides electrode have been shown to exhibit excellent electrochemical performance, including wet-chemical approaches, [98, 99], CVD, [100], and (ALD), [30, 50, 65, 87, 94, 101, 102]. Vanadium oxides prepared by ALD as electrodes have delivered remarkable properties for energy storage.

\subsection{Lithium-ion batteries}

Among various energy storage technologies, lithium ion batteries (LIBs) are one of the most attractive rechargeable batteries due to their high energy density, long cycling life, no to little memory effect, and reduced environmental impact, [103-107]. The layered vanadium oxides allow the insertion of ions, which makes them high capacity cathode materials for LIBs as shown in Figure 15, [108]. The conformal nature of ALD allows the construction of very thin electrodes on highly structured 3D electrodes, such as (MW-)CNTs and silicon etch-based structures as pillars or trenches. This enables a very fast charging thanks to the reduced diffusion length in thin film and a considerable capacity attributed to the area enhancement factor of the substrate compared to the footprint area, [87], ultimately allowing the integration into 3D all-solid-state thin-film batteries, [109]. On the other hand, the excellent phase control and high quality of the films allows for the study of ALD vanadium oxides as 'model system' electrodes.

Despite the phase-richness of vanadium oxides, most research was concentrated on the lithium-ion insertion into $\mathrm{V}_{2} \mathrm{O}_{5}$, [86]. Theoretically, the specific capacity of $\mathrm{V}_{2} \mathrm{O}_{5}$ can reach $147 \mathrm{~mA} \mathrm{~h} \mathrm{~g}^{-1}$ with 1 Li-ion inserted per $\mathrm{V}_{2} \mathrm{O}_{5}$ unit, $294 \mathrm{~mA} \mathrm{~h} \mathrm{~g}^{-1}$ with 2 Li-ions inserted per $\mathrm{V}_{2} \mathrm{O}_{5}$, and $440 \mathrm{~mA} \mathrm{~h} \mathrm{~g}{ }^{-1}$ with $3 \mathrm{Li}$-ions inserted per $\mathrm{V}_{2} \mathrm{O}_{5}$, i.e. full lithiation to $\mathrm{Li}_{3} \mathrm{~V}_{2} \mathrm{O}_{5}$.

The theoretical capacity of the complete lithiation of $\mathrm{V}_{2} \mathrm{O}_{5}$ is much greater than the typically commercialized materials such as $\mathrm{LiMn}_{2} \mathrm{O}_{4}\left(148 \mathrm{~mA} \mathrm{~h} \mathrm{~g}{ }^{-1}\right)$, [110], $\mathrm{LiFePO}_{4}(170 \mathrm{~mA} \mathrm{~h}$ $\left.\mathrm{g}^{-1}\right)$, [111], and $\mathrm{LiCoO}_{2}\left(274 \mathrm{~mA} \mathrm{~h} \mathrm{~g}^{-1)}\right.$, [112], as shown in Figure 15. When one lithium per unit cell is stored (charging to $\mathrm{LiV}_{2} \mathrm{O}_{5}$ ), the original lattice structure is maintained, causing $\mathrm{V}_{2} \mathrm{O}_{5}$ to be extremely reversible (over 1000 cycles without capacity loss, [30, 113], and to display an excellent kinetics thanks to the high electronic conductivity in this range [114]. However, charging beyond 1 lithium per $\mathrm{V}_{2} \mathrm{O}_{5}$ unit cell is accompanied by irreversible lattice changes from up-up-down-down alternations of $\mathrm{VO}_{4}$-pyramids to up-down-up-down alternations, [115]. This structure transformation, along with lowered conductivity and poor 


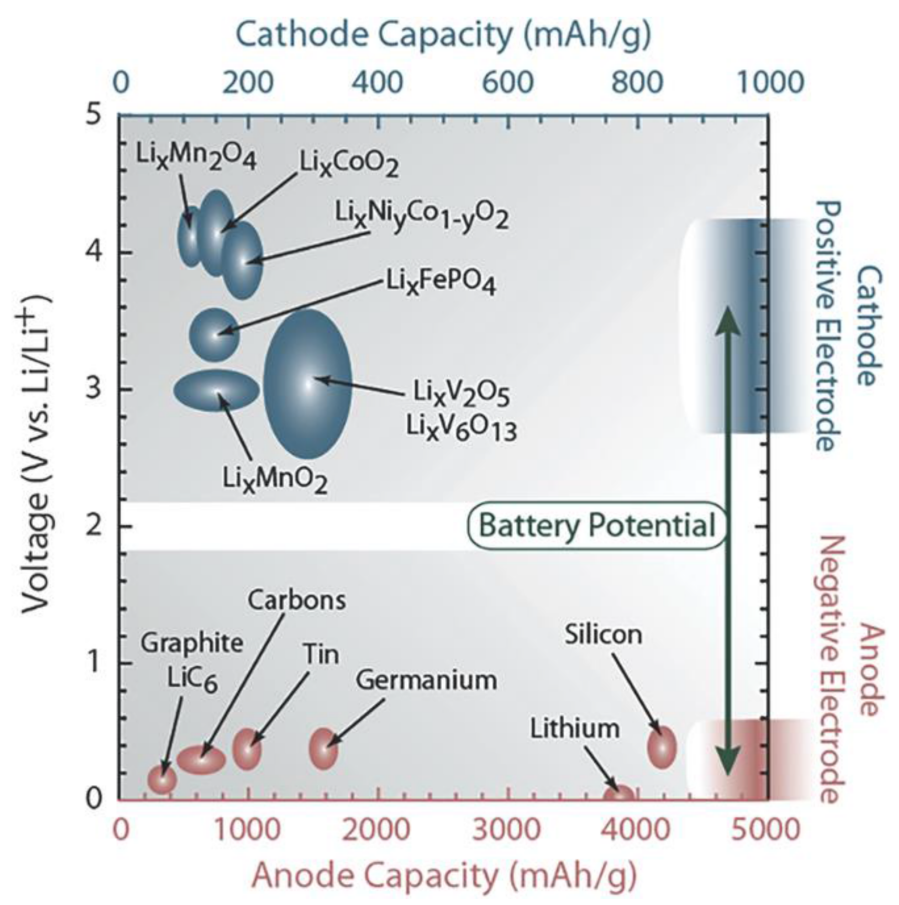

Figure 15: Diagram illustrating the lithium-ion capacity and electrochemical reduction potentials of conventional anode and cathode materials, [108].

structural stability (solubility of $\mathrm{V}^{3+}$ and $\mathrm{V}^{4+}$ species), leads to inferior electrochemical performance, [116-118].

Constructing nanostructures for $\mathrm{V}_{2} \mathrm{O}_{5}$ by $\mathrm{ALD}$ is one of the most attractive strategies to overcome these drawbacks and thus further optimize its property in LIBs, [30, 50, 53, $56,57,94]$. For example, Østreng et al. deposited nano-structured cathodes of $\mathrm{V}_{2} \mathrm{O}_{5}$ with different thicknesses, particle sizes, and morphologies using ALD. A cathode layer of $10 \mathrm{~nm}$ (500 ALD-cycles) delivered a superior electrochemical performance relative to other cathodes thicknesses. This sample delivered a high specific capacity of $118 \mathrm{~mA} \mathrm{~h} \mathrm{~g}^{-1}$ at $1 \mathrm{C}$ within the potential window of $2.75-3.8 \mathrm{~V}$. It even handled discharge rates of up to $960 \mathrm{C}$ and showed stable capacity up to 650 cycles with a modest capacity fading that remained within $80 \%$ of the original capacity after 1530 cycles and endured up to 4000 cycles without failure at 120 C. This remarkable performance is due to good contact with the current collector and the electrolyte, along with small particle size, [30]. Chen et al. reported a detailed study of ALD $\mathrm{V}_{2} \mathrm{O}_{5}$ as a high capacity cathode material, using VTOP precursor (see section 3.2 for details of ALD process) and comparing two oxidants, $\mathrm{O}_{3}$ and $\mathrm{H}_{2} \mathrm{O} \cdot \mathrm{O}_{3}$-based films were crystalline and exhibited an improved electrochemical performance, compared to $\mathrm{H}_{2} \mathrm{O}$-grown film, which was amorphous. This crystalline film showed a high capacity of $127 \mathrm{~mA} \mathrm{~h} \mathrm{~g}{ }^{-1}$ for $1 \mathrm{Li} / \mathrm{V}_{2} \mathrm{O}_{5}$, $283 \mathrm{~mA} \mathrm{~h} \mathrm{~g}^{-1}$ for $2 \mathrm{Li} / \mathrm{V}_{2} \mathrm{O}_{5}$, and $389 \mathrm{~mA} \mathrm{~h} \mathrm{~g}^{-1}$ for $3 \mathrm{Li} / \mathrm{V}_{2} \mathrm{O}_{5}$ at $1 \mathrm{C}$, [50]. In addition, the hybridization of $\mathrm{V}_{2} \mathrm{O}_{5}$ with other materials such as carbon, CNTs, and $\mathrm{TiO}_{2}$, has also proven to be extremely effective for enhancing the electrochemical performance, [53, 56, 94, 119]. Chen et al. successfully fabricated MWCNT $/ \mathrm{V}_{2} \mathrm{O}_{5}$ sponges for LIBs cathode by ALD as 
shown in Figure 16. This cathode delivered a high initial area capacity of $1.284 \mathrm{~mA} \mathrm{~h}$ $\mathrm{cm}^{-2}$ for $3 \mathrm{Li}$ transfer $(4.0-1.5 \mathrm{~V})$, although cyclability was poor. In the 4.0-2.1V range for $2 \mathrm{Li} / \mathrm{V}_{2} \mathrm{O}_{5}$, the initial area capacity was $0.818 \mathrm{~mA} \mathrm{~h} \mathrm{~cm}^{-2}$ at $1 \mathrm{C}$ and the cycling stability was largely improved. Furthermore, the capacity of $0.155 \mathrm{~mA} \mathrm{~h} \mathrm{~cm} \mathrm{~cm}^{-2}$ was maintained with $50 \mathrm{C}$ rate, giving an outstanding rate property. The excellent electrochemical performance of this hybrid cathode can be ascribed to its unique nanostructure. The sponge structure exhibited a high surface area, allowing for a high amount of active material loading while the multiwall carbon nanotubes (MWCNTs) offer fast electrons transport channels. Furthermore, the thin uniform layer of $\mathrm{V}_{2} \mathrm{O}_{5}(<16 \mathrm{~nm})$ enables fast (de)/ lithiation of the active material. Finally, the high porosity of the sponge provides an easy access of electrolyte to the active storage material, [94].

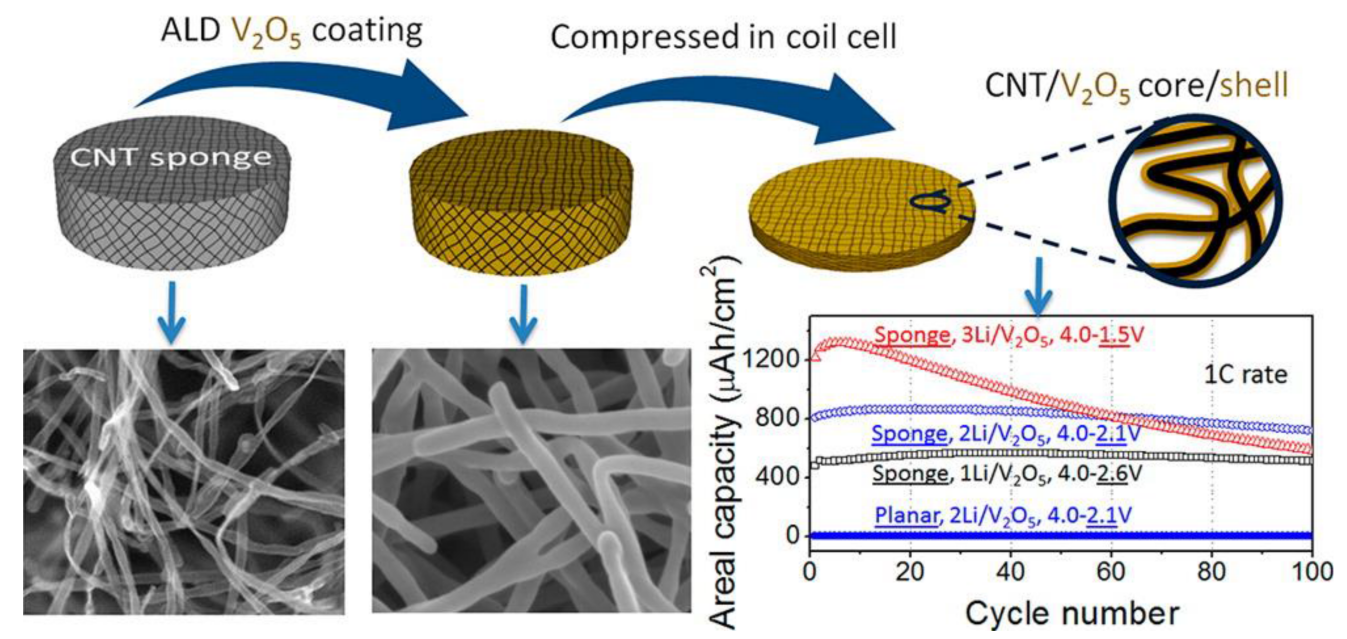

Figure 16: The synthesis schematic and electrochemical performance of $\mathrm{V}_{2} \mathrm{O}_{5}$-coated MWCNT sponge, [94].

However, the cycling stability of two lithium ions into $\mathrm{V}_{2} \mathrm{O}_{5}$ is still not perfect, as the lower oxidation state vanadium can still dissolve in the liquid electrolyte. Kurttepeli et al. constructed a heterogeneous $\mathrm{TiO}_{2} / \mathrm{V}_{2} \mathrm{O}_{5} /$ MWCNT structure to tackle this issue, as shown in Figure 17. Here, it was shown that the core-shell-shell structure still enabled all the excellent properties found by Chen et al, but the addition of a lithium-conductive protective coatings prevented V-dissolution and further stabilized the electrode, as shown in Figure 17, [119].

Despite the main focus on $\mathrm{V}_{2} \mathrm{O}_{5}$, ALD also allows the study of model system electrodes. On the one hand, the excellent phase control shown in the previous sections on ALD films also allows the study of all other vanadium oxides in the Wadsley series as potential electrodes. Mattelaer et al. found that all phases, i.e. $\mathrm{VO}_{2}(\mathrm{~B})$ up to $\mathrm{V}_{2} \mathrm{O}_{5}$, were able to store lithium. $\mathrm{VO}_{2}(\mathrm{~B})$ was found to exhibit good cyclability along with storage of one lithium into $\mathrm{V}_{2} \mathrm{O}_{5}$, while $\mathrm{V}_{4} \mathrm{O}_{9}$ exhibited the highest initial capacity $\left(1380 \mathrm{mAh} / \mathrm{cm}^{3}\right)$. Their rate performance is summarised in Figure 18, [87].

Besides crystalline phases, the low-temperature nature of ALD also allows the study of amorphous vanadium oxides. Le Van et al synthesized amorphous $\sim 200 \mathrm{~nm} \mathrm{VO}_{x}$ films using ALCVD, resulting in good cyclability and much higher capacity than the crystalline 

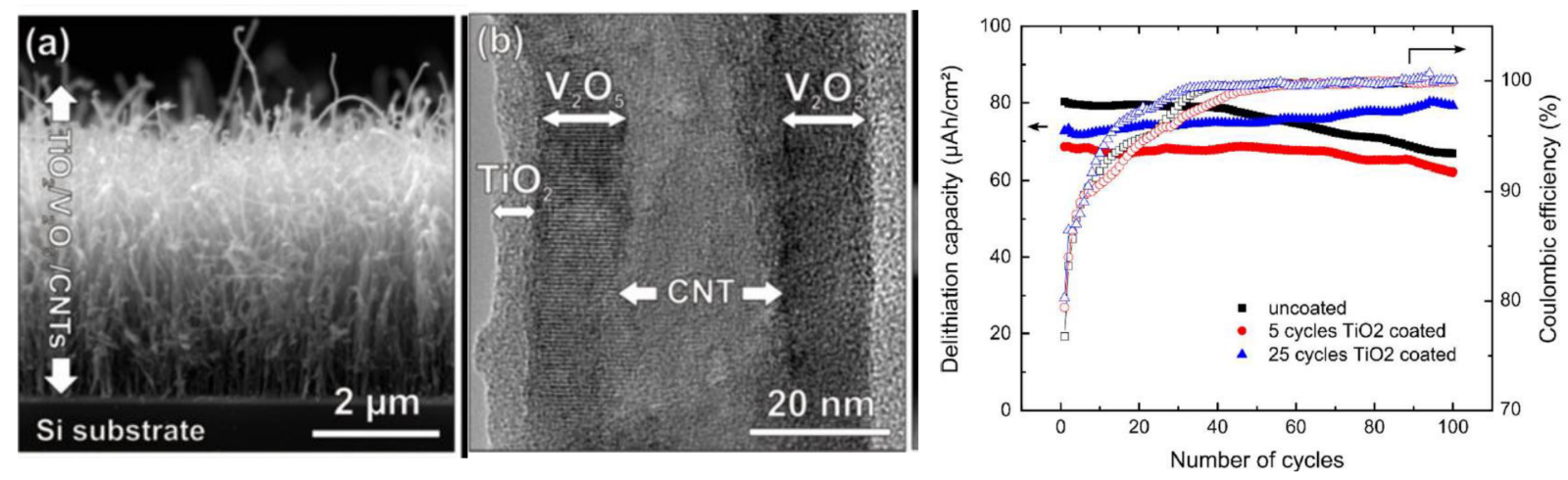

Figure 17: Cross-section SEM image (left) and HRTEM image (middle) of 25 ALD cycles $\mathrm{TiO}_{2}$-coated $\mathrm{V}_{2} \mathrm{O}_{5} /$ CNTs. (right) Cyclability testing of uncoated $\mathrm{V}_{2} \mathrm{O}_{5} / \mathrm{CNTs}$ and of 5 and 25 ALD cycles $\mathrm{TiO}_{2}$ on $\mathrm{V}_{2} \mathrm{O}_{5} / \mathrm{CNTs}$ samples at a current corresponding to $2 \mathrm{C}$ between 2.0 and $4.0 \mathrm{~V}$ vs $\mathrm{Li}+/ \mathrm{Li}$. Reprinted with permission from [119]. Copyright 2017 American Chemical Society.

counterparts (455 mAh/g), [43]. Similarly, Mattelaer et al were able to obtain amorphous $\mathrm{VO}_{2}$ and $\mathrm{V}_{2} \mathrm{O}_{5}$ by tuning the process conditions using the TEMAV precursor (refer to sections 3.3.1 and 4.1 for more details). As can be seen in Figure 18, very high capacities up to $1.4 \mathrm{Ah} / \mathrm{cm}^{3}$ were found for amorphous $\mathrm{VO}_{2}(\sim 20 \mathrm{~nm})$, alongside excellent capacity retention at high rates $(80 \%$ at $100 \mathrm{C})$, related to both higher lithium diffusion coefficients compared to their crystalline counterparts and the thin-film nature of the electrodes, [87].
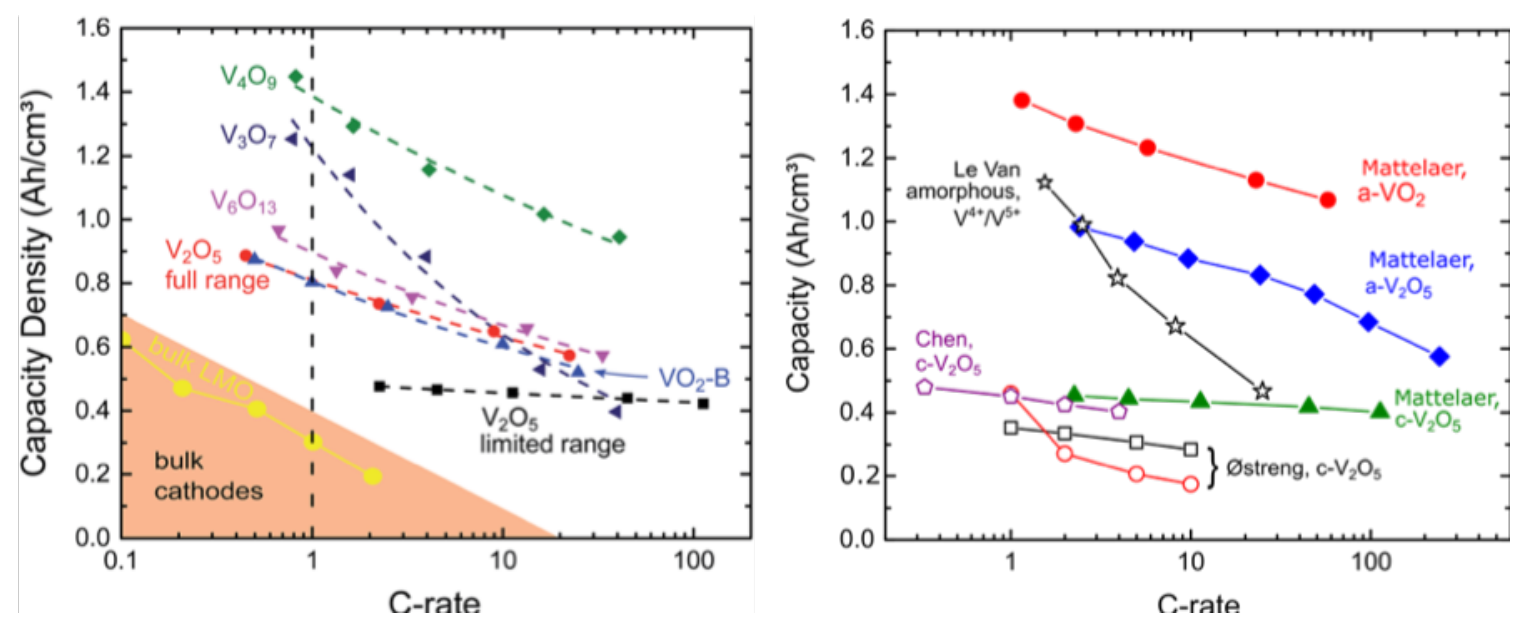

Figure 18: (left) comparison of the performance of various ALD-derived crystalline vanadium oxides (Published by The Royal Society of Chemistry) and (right) benchmarking of amorphous to crystalline vanadium oxides, [30] [43] [87] [65].

\subsection{Supercapacitors}

In addition to LIBs, supercapacitors are also promising for energy storage because they are able to deliver high power density which is also important for practical applications, [120]. 
Therefore, vanadium oxides used for supercapacitors have also been explored due to the broad range of their oxidation states and low cost, [47, 51, 52, 121]. Surprisingly, the aforementioned unique hybrid nanoarchitecture composed of vanadium oxides and MWNTs prepared by ALD also showed excellent performance when used as supercapacitor electrode, see Figure 19. A very high capacitance of up to $1550 \mathrm{~F} \mathrm{~g}^{-1}$ was achieved at the current density of $1 \mathrm{~A} \mathrm{~g}^{-1}$. Such high capacitance values are unprecedented for supercapacitor electrodes measured in a symmetrical two-electrode configuration in aqueous electrolytes. Its capacitance can reach up to above $1550 \mathrm{~F} \mathrm{~g}^{-1}$ even at a current density as high as $20 \mathrm{~A}$ $\mathrm{g}^{-1}$. Furthermore, it also showed an excellent cycling performance. The capacitance loss was only $8 \%$ at a current density of $5 \mathrm{~A} \mathrm{~g}^{-1}$ after 5000 cycles. This striking performance of such hybrid nanomaterial makes it an ideal candidate as electrode material for supercapacitors in real applications, [121]. Hybrid nanostructures resulting from the incorporation of vanadium oxides with carbon or other conductive materials have also been used as electrode materials for supercapacitors with enhanced performance [47, 51].
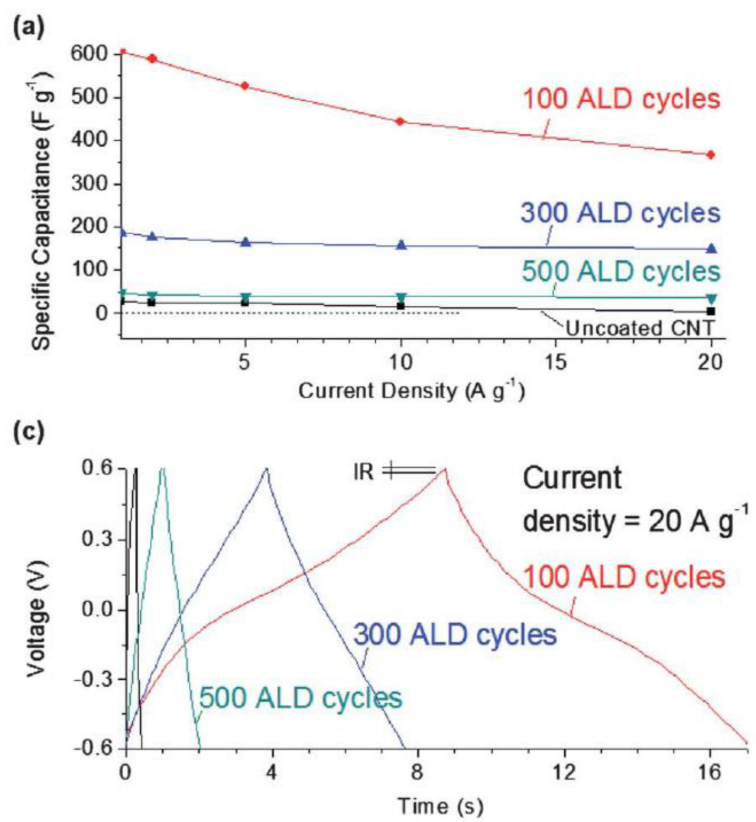

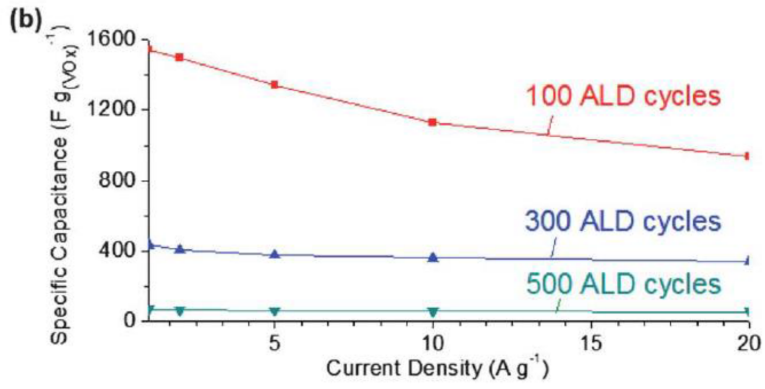

(d)

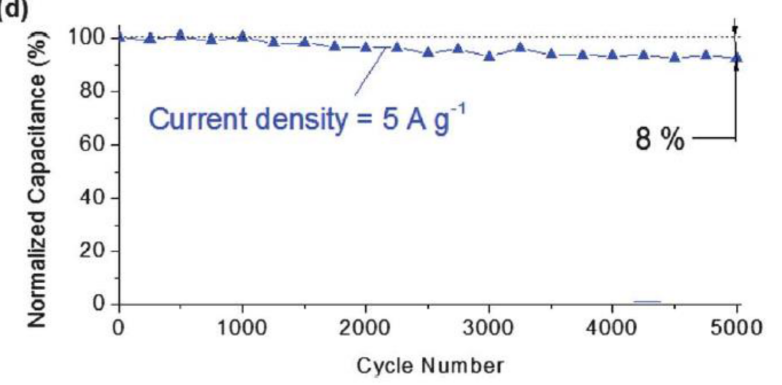

Figure 19: Changes in the specific capacitance of the produced electrode samples for: (a) composite electrode and (b) contribution of $\mathrm{VO}_{x}$ coating as a function of current density. (c) Charge-discharge profiles of the produced electrodes at the current density of $20 \mathrm{~A} / \mathrm{g}$. (d) A typical capacitance retention of $\mathrm{VO}_{x}$ coating as a function of charge-discharge cycle numbers, [121].

Interestingly, Daubert et al found an intrinsic limit to the potential improvements of carbon-based supercapacitive performance. Due to the excellent conformality of ALD, pore sealing can occur in nanoporous carbon electrodes. They found that, using VTOP as a precursor, pores with diameters below $13 \AA$, i.e. close to the precursor diameter $(9.6 \AA)$ are closed during deposition as shown in Figure 20. Counter-intuitively, they found much larger increases in coated macroscopic carbon black or activated carbon, compared to microscopic 
carbon-based electrodes, as this pore-sealing fraction was much smaller [52].

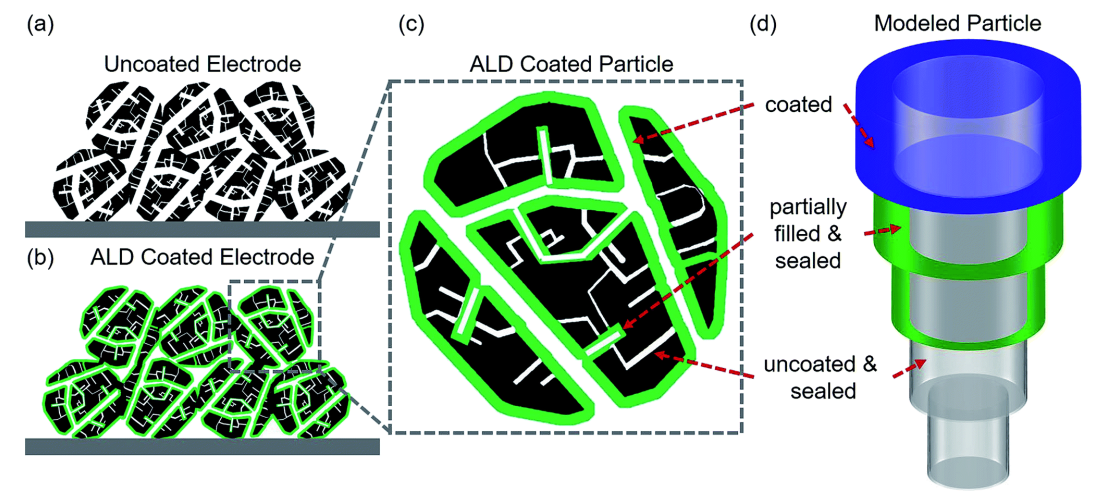

Figure 20: (a-c) Illustration of pore sealing that can occur by deposition of a pseudocapacitive material using ALD, and (d) a model used to study this pore sealing, based on a series of narrowing tubes. Reprinted from [52].

\section{Electronic phase control of $\mathrm{VO}_{2}$}

To allow either electronic or photonic applications, electronic phase control of $\mathrm{VO}_{2}$ is key. By controlling the phase of $\mathrm{VO}_{2}$ to be either the metal or insulator, one can switch electronic current or voltage signals for nanoelectronics applications, or modulate electromagnetic waves, in photonics applications. A memory function arises if both phases, or memory states, can be maintained for a sufficiently long time at the same device operating conditions (input signals, temperature and other). Now, how can $\mathrm{VO}_{2}$ be switched between its phases electronically? We will treat the current understanding of the electronic switching of $\mathrm{VO}_{2}$ 's phase. This allows to deduce challenges and opportunities for ALD $\mathrm{VO}_{2}$ thin films for electronics and photonics.

In recent years, ALD has become a prominent technique for the deposition of dielectric, [122] and metallic thin-films for nanoelectronic applications, [123-125]. The self-limiting surface reactions of ALD enable a precise control over film thickness and stoichiometry which are essential for the (deca)nanometer thin films employed in nanoelectronics. In addition, the high conformality allows deposition onto three-dimensional (3D) structures, as increasingly required for advanced nanoelectronic applications. ALD of $\mathrm{VO}_{2}$ presents a manufacturing friendly technique for potential $\mathrm{VO}_{2}$ applications.

The direct way to switch $\mathrm{VO}_{2}$ is to heat or cool it across its MIT electrically by means of Joule heating either by a nearby heater element by running a current through the $\mathrm{VO}_{2}$ itself or by the Peltier effect. In section 6.1 the switching of $\mathrm{VO}_{2}$ 2-terminal devices is discussed. In such devices a current is run through $\mathrm{VO}_{2}$ itself. The switching mechanism of such devices has been a subject of recent discussion in literature. The use of $\mathrm{ALD} \mathrm{VO}_{2}$ films, which have become available very recently and which are suitable for manufacturing of nano-sized and $3 \mathrm{D}$ devices, has been reported in such device research. 
Heating however, requires a significant amount of power, which is an impediment for some contemporary applications. Low power is very important, for example, in highly mobile Internet of Things (IoT) applications. Researchers have explored alternative switching mechanisms and have attempted to switch $\mathrm{VO}_{2}$ at constant temperature, looking for a socalled field-induced MIT in Field Effect Transistor devices (FET), which can be considered a holy grail in the field. In the second section an overview is given of this $\mathrm{VO}_{2} \mathrm{FET}$ research. In 3-terminal FET devices a channel current runs through $\mathrm{VO}_{2}$ between source and drain terminals. This channel current is controlled by a third, gate terminal. Most of this research has a fundamental character and has not been done with techniques suitable for manufacturing such as ALD, however, the ALD deposition of dielectric thin films has played a key role in this work and has allowed the fabrication of $\mathrm{VO}_{2}$ FETs with high quality gate dielectrics.

\subsection{Switching of $\mathrm{VO}_{2}$ 2-terminal devices}

Two-terminal thin film $\mathrm{VO}_{2}$ devices show an abrupt decrease of resistance when the current or voltage applied exceeds a threshold value. Investigations of few-micron-sized thin film $\mathrm{VO}_{2}$ two terminal devices have widely reported that the observed steep decrease of resistance at a critical current or voltage is related to a field-induced metal-insulator transition, [126-133]. However, recent work, [134-141], has found the switching to be induced by Joule heating rather than directly by the applied electric field.

The fabrication of $\mathrm{VO}_{2}$ coplanar two terminal devices (20-100 $\mu \mathrm{m}$ length) by Duchene et al, [142], allowed measurements of the pre-transition region and the transition parameters of the current-voltage (I-V) characteristic. It is proposed that when a voltage is applied between the electrodes, the internal temperature rises and the device switches to the "on" state. Threshold voltage and current were investigated versus ambient temperature. Below about $10^{\circ} \mathrm{C}$, switching was proposed to be a pure thermistor effect; above this point, application of voltage was proposed to cause the device temperature to rise to the phase transition temperature, when the conductivity increased sharply. The I-V characteristics in the pretransition region and the $\mathrm{I}-\mathrm{V}$ thermal transition phenomena were explained by means of a theoretical model.

Zimmers et al, [135], used fluorescence spectra of rare-earth doped micron sized particles as local temperature sensors on $\mathrm{VO}_{2}$ two terminal devices $(10,20 \mu \mathrm{m}$ length). As the insulator-metal transition was induced by a dc voltage or dc current, the local temperature reached the transition temperature indicating that Joule heating played a predominant role.

Freeman et al, [137], examined the structural evolution of tensile strained vanadium dioxide thin film devices $\left(6 \times 9.4 \mu \mathrm{m}^{2}\right)$ across the electrically driven insulator-to-metal transition by nanoscale hard X-ray diffraction. A metallic filament with rutile $(\mathrm{R})$ structure was found to be the dominant conduction pathway for an electrically driven transition, while the majority of the channel area remained in the monoclinic M1 phase. The filament dimensions were estimated using simultaneous electrical probing and nanoscale X-ray diffraction.

Nano-scale $\mathrm{VO}_{2}$ two terminal devices were fabricated with different electrode separations down to $100 \mathrm{~nm}$ and the dc switching voltage and current dependence on device size and temperature were studied, [140]. The nanoscale devices allowed the evaluation of $\mathrm{VO}_{2}$ as 
an electronic switching material at a relevant scale for future nanoelectronics applications. Redicung the electrode separation to the $\mathrm{VO}_{2}$ grain size is used as an approach to limit the occurrence of inhomogeneous (filamentary) and cascaded switching, since the current will traverse less or no grain boundaries between the electrodes. This allows to study the transition in devices more closely approximating intrinsic single-crystal behavior. Studying the origins of geometrically uniform switching which is expected to show the most straightforward behavior and is most relevant for nanoscale devices. The observations of the geometrical and temperature dependence, and hysteresis of switching were found to be consistent with a Joule heating mechanism governing the switching. The power at which a device switched decreased linearly with increasing temperature, characteristic for a Joule-heating induced transition. Pulsed measurements showed a switching time to the high resistance state of the order of one hundred nanoseconds, consistent with heat dissipation time. In spite of the Joule heating mechanism which was expected to induce device degradation, devices can be switched for more than 1000 cycles.

The work by Tadjer et al, [141], reported on two terminal switching devices making use of an ALD deposited vanadium oxide layer. Amorphous vanadium oxide $\left(\mathrm{VO}_{2}\right)$ films were crystallized with an ex situ annealing at $660-670^{\circ} \mathrm{C}$ for $1-2 \mathrm{~h}$ under a low oxygen pressure $\left(10^{-4}\right.$ to $10^{-5}$ Torr $)$. Under these conditions the crystalline $\mathrm{VO}_{2}$ phase was maintained, while formation of the $\mathrm{V}_{2} \mathrm{O}_{5}$ phase was suppressed. Electrical transition from the insulator to the metallic phase was observed in the $37-60^{\circ} \mathrm{C}$ range, with an $\mathrm{R}_{O F F} / \mathrm{R}_{O N}$ ratio of up to about 750 . The lateral electric field applied across two terminal device structures induced a reversible phase change. Both the width and slope of the field induced MIT I-V hysteresis were dependent upon the $\mathrm{VO}_{2}$ crystalline quality.

The power needed for reaching a MIT decreased linearly with temperature, confirming Joule heating was the predominant switching mechanism for that sample. However, this was not the case for partially crystallized $\mathrm{VO}_{2}$ film and a soft (non-abrupt) transition profile was measurable even near room temperature in the $1.8-2.5 \mathrm{~V}$ range. The behavior in this "soft-MIT" region was attributed to the fact that the thermal conductivity of $\mathrm{VO}_{2}$ is also phase dependent and could change by as much as 60 percent over the course of the MIT, ultimately leading to a non-abrupt field switching profile as the critical temperature is approached during measurement.

\subsection{The Transverse Field-induced Metal-Insulator Transition and the Transverse Field Ef- fect in $\mathrm{VO}_{2}$ Field Effect Transistor devices}

A question which has instigated both fundamental and applied research is whether $\mathrm{VO}_{2}$ could possess an electrostatic field induced metal-insulator transition - or not. More specifically, the switching of a strongly correlated material such as $\mathrm{VO}_{2}$ between a metallic and an insulating phase by means of applying an electric field transverse to the material's interface with a gate electrode evokes the possibility of a switch device outperforming the present Metal Oxide Semiconductor Field Effect Transistor (MOSFET). Such a device is also referred to as Mott transistor or an MIT FET. The MOSFET is the dominant switching device in contemporary nanoelectronics and relies on the modulation of the surface conductivity of a semiconductor by a transverse field applied with a gate electrode. A metallic on-state in 
an MIT FET would allow a much lower on-resistance and a significantly higher transistor drive current.

It is important to rule out electrochemically and thermally driven effects (e.g. Joule heating) before ascribing certain encountered characteristics to Metal-Insulator Transitions induced by electrostatic charging as in the aforementioned hypothetical MIT FET. In some work in literature, Joule heating has not been satisfactorily ruled out for transitions occurring at a certain drain-source bias or for gate voltage dependence of such a transition. Electrochemically induced phase transitions are typically induced at significantly longer time scales than electronic effects. Electrochemically switched devices (e.g. Resistive RAM) tend to have lower cyclability, the amount of repeated switching possible before device failure occurs. However, electrochemical switching might enable memory applications. Crucial as well is to work with high quality and well-characterized $\mathrm{VO}_{2}$ films, to assure that the intended phase is obtained while also assuring a well-insulating gate insulator on top or below the $\mathrm{VO}_{2}$ film. At present, MIT or Mott FET behavior not induced by Joule heating or electrochemical effects has not been rigorously proven to exist in correlated oxide FETs. For $\mathrm{VO}_{2}$, the basic understanding of the field effect, the change in surface conductance with an applied transverse electric field is of fundamental and applied interest as well, and is not yet fully understood.

Ruzmetov's work, [143], emphasized that the quality of the gate dielectric layer and its interface with $\mathrm{VO}_{2}$ were critical factors for detecting the field effect in 3-terminal $\mathrm{VO}_{2}$ devices. For this reason the authors explored a number of ways of synthesizing the gate dielectric within the device: e-beam evaporation of $\mathrm{SiO}_{2}$ and $\mathrm{Al}_{2} \mathrm{O}_{3}$, RF sputtering of $\mathrm{SiO}_{2}$ and $\mathrm{Si}_{3} \mathrm{~N}_{4}$, and atomic layer deposition of $\mathrm{HfO}_{2}$ and $\mathrm{Al}_{2} \mathrm{O}_{3}$. It was found for the gate-on-toptype devices with non-ALD dielectric that, while the high quality of $\mathrm{VO}_{2}$ can be preserved within the hetero-structure, the devices suffered from large leakage through the gate dielectric and poor dielectric $/ \mathrm{VO}_{2}$ interfaces. These devices showed gate voltage modulation of drain current which was history dependent and of which the resistance continued to increase for some time $(\sim 10 \mathrm{~min})$ even after the gate voltage was removed.

However, it was found that the devices with the gate below the $\mathrm{VO}_{2}$ film offered better quality of the gate dielectric layer and its interface as opposed to the gate-on-top devices. For the better quality bottom gate devices, a highly uniform $25 \mathrm{~nm}$ thick $\mathrm{Al}_{2} \mathrm{O}_{3}$ insulating layer was deposited by ALD on top of n-Si conducting substrate which served as a base for 60-150 nm $\mathrm{VO}_{2}$ growth by means of $\mathrm{RF}$ sputtering from a $\mathrm{V}_{2} \mathrm{O}_{5}$ target. The ALD-grown gate insulator $/ \mathrm{VO}_{2}$ interfaces exhibited reproducible electrical response to applied gate voltages, with no time dependence or persistence beyond removal of the gate voltage. At $\mathrm{T}=60^{\circ} \mathrm{C}$ applying gate voltages of $0.5 \mathrm{~V}$ led to a systematic, reversible and low drop in the channel resistance of about $-0.26 \%$. Gate leakage was ruled out as a possible cause of the modulation and no modulation was detected at lower temperatures or at the inverse bias.

The authors ascribe the subdued gate field modulation to $\mathrm{VO}_{2}$ 's small Debye length which at $300 \mathrm{~K}$ is of the order of a few $\mathrm{nm}$, assuming the carrier density to be $\mathrm{n}=2 \times 10^{18} \mathrm{~cm}^{-3}$. The density was deduced from Hall measurements which assumed itinerant carriers, an assumption not necessarily valid for $\mathrm{VO}_{2}$. Nevertheless, at the quoted carrier density it is expected that, if $\mathrm{VO}_{2}$ were to behave like a conventional semiconductor, a significant portion 
of a $100 \mathrm{~nm}$ film should be depletable and some modulation ought to have been observed. The authors suggested the future use of ultrathin films of $\mathrm{VO}_{2}$ to avoid shunting by bulk $\mathrm{VO}_{2}$ of the gate modulated interfacial $\mathrm{VO}_{2}$.

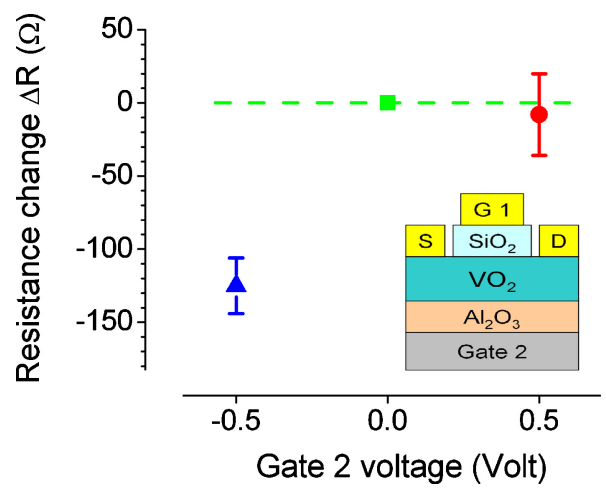

Figure 21: The gate voltage modulation of source-drain resistance of the $\mathrm{VO}_{2}$ channel as observed by Ruzmetov et al. The inset shows the device diagram. Reprinted from [143] with the permission of AIP publishing.

Ji et al, [144], attempted to modulate the $\mathrm{VO}_{2}$ MIT in single-crystal $\mathrm{VO}_{2}$ nanowires via electrochemical gating using an ionic liquid. Individual single-crystal $\mathrm{VO}_{2}$ nanobeams grown by vapor phase transport were used with a width and thickness of a few $100 \mathrm{~nm}$. To attain high charge densities by applying a static electric field, a nanowire electric-doublelayer transistor (EDLT) was used involving an organic ionic liquid (DEME-TFSI) as gate electrode. Stray water contamination in the ionic liquid was found to lead to large, slow, hysteretic conductance responses to changes in the gate potential applied by means of the ionic liquid. It was suggested that these changes were the result of electrochemical doping via hydrogen. In the absence of this chemical effect, gate response was found to be minimal. The authors suggested that significant field-effect modulation of the metal-insulator transition is not possible, along the crystallographic directions of the reported nanowires.

Using an ionic liquid as an electrolytic gating medium, induced surface charge densities of $\sim 10^{14} / \mathrm{cm}^{2}$ at the liquid- $\mathrm{VO}_{2}$ interface are expected. The absence of any detectable gating effect in the insulating state was found to be surprising. Certainly some gate response would be expected for a conventional semiconductor with a band gap of $\sim 0.5 \mathrm{eV}$. Surface states were asserted to be a possible impediment, but Ji et al. note that surface states had not been a problem for field effect modulation in a number of oxide systems.

Nakano et al., [145], reported that semiconducting $\mathrm{VO}_{2}$ can be rendered metallic by applying a strong electric field transverse to the $\mathrm{VO}_{2}$ interface with an ionic liquid (DEMETFSI) in an EDLT device. In these devices no gate dielectric was present and $\mathrm{VO}_{2}$ was in direct contact with the ionic liquid. These field-effect transistors consisted of $\mathrm{VO}_{2}(001)$ epitaxially grown on monocrystalline rutile $\mathrm{TiO}_{2}(001)$ substrates by means of pulsed laser deposition. They reported the temperature dependence of resistance of the $\mathrm{VO}_{2}$ devices for different gate biases. At high bias they observed that the temperature dependence of channel resistance and the MIT were suppressed. The gate bias dependence of channel resistance at 260K showed hysteretic switching. 
a

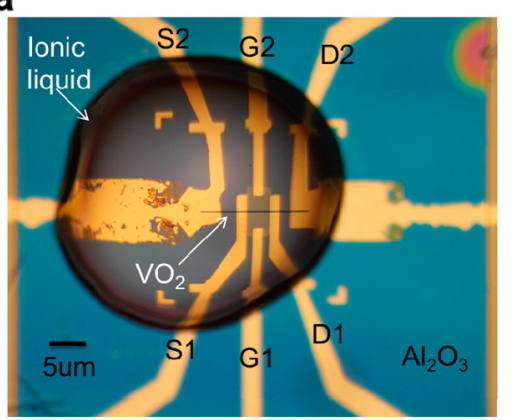

b

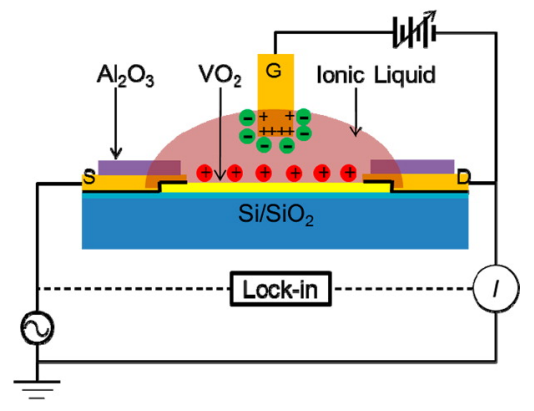

Figure 22: a) Optical micrograph of an ionic liquid gated EDLT device. B) Schematic cross section of an EDLT device. Adapted with permission from [144]. Copyright 2012 American Chemical Society.

The authors proposed that electrostatic charging at a surface drives all the previously localized charge carriers in the bulk $\mathrm{VO}_{2}$ material into motion giving rise to collective carrier delocalization, leading to the emergence of a three-dimensional metallic ground state.
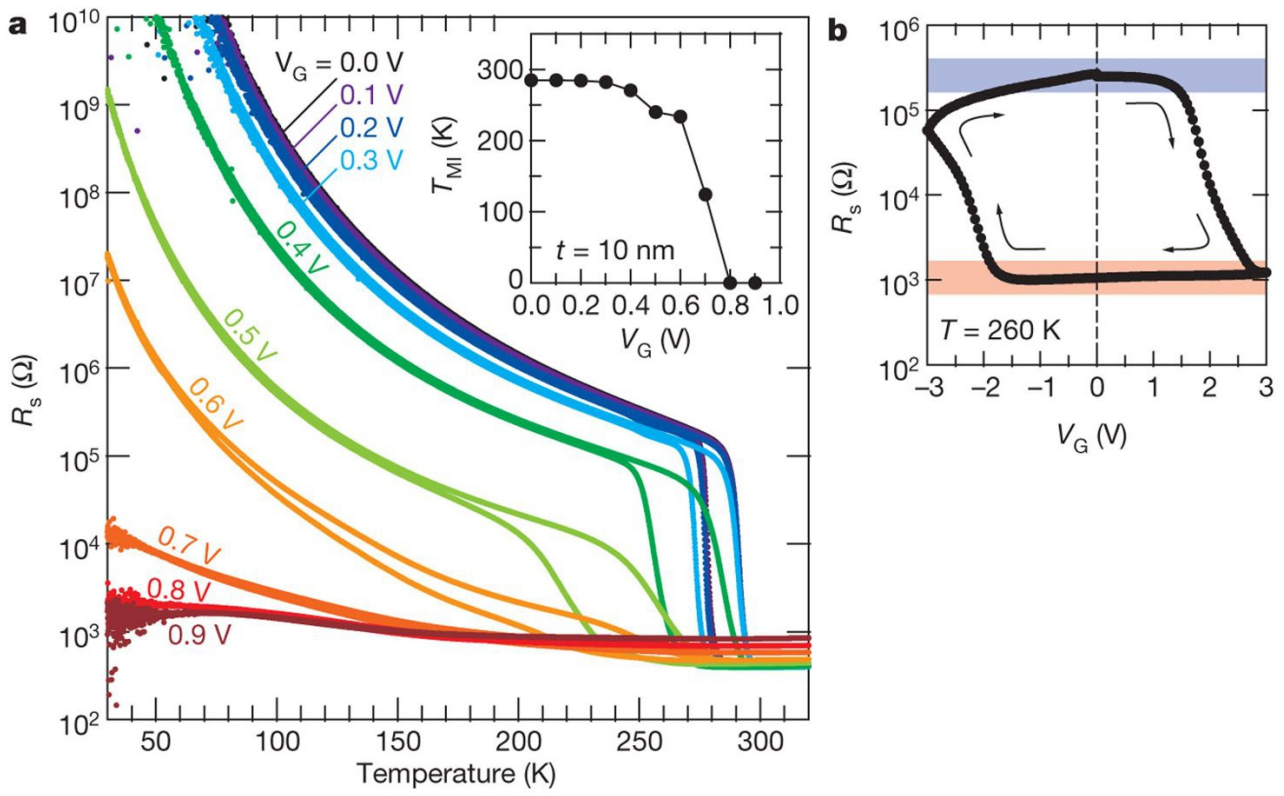

Figure 23: a) Temperature dependence of channel resistance of a $\mathrm{VO}_{2}$ EDLT device for different gate biases and b) gate bias dependence at 260K. Reprinted with permission from Nature, [145].

Jeong et al., [146], showed similar temperature dependence of resistivity for different ionic liquid gate biases and similar hysteretic gate bias dependence at constant temperature in similar devices as in [145]. The hysteretic gate bias dependence was reported in [144] as well, in which the modulation was ascribed to water contamination. Jeong et al. argued that electrolyte gating of $\mathrm{VO}_{2}$ leads not to electrostatically induced bulk carriers as proposed in [145] but instead, to the electric field-induced creation of oxygen vacancies, with migration of oxygen from the oxide film into the ionic liquid. The devices were gated to the metallic 
state in vacuum and reverse-gated to recover to the insulating state in an ${ }^{18} \mathrm{O}_{2}$ ambient. The ${ }^{18} \mathrm{O}_{2}$ was found to be incorporated in the $\mathrm{VO}_{2}$ films by means of SIMS. XPS observations indicated a reduction in the oxidation state of $\mathrm{V}$ from $\mathrm{V}^{+}$toward $\mathrm{V}^{+}$after gating. It was also observed that the gate bias dependence of conductance depends on oxygen pressure, with gating absent at higher oxygen pressure. Jeong et al. showed that oxygen migration occurs during ionic liquid gating.

Belyaev et al. deposited $100 \mathrm{~nm}$ of amorphous vanadium oxide at room temperature by magnetron sputtering, on a $\mathrm{Si}$ substrate with a $100 \mathrm{~nm} \mathrm{SiO}_{2}$ gate dielectric followed by a $10 \mathrm{~m}$ Torr, $520^{\circ} \mathrm{C}$ post deposition anneal, [147]. These solid gated FET structures showed a temperature-induced MIT with a resistivity jump of about 2 orders of magnitude. The $\mathrm{VO}_{2}$ channel resistance was found to weakly depend on gate bias, showing a change with only tenths of a percent when the gate voltage reaches a value of about $120 \mathrm{~V}$, corresponding to an oxide field strength of $107 \mathrm{~V} / \mathrm{cm}$. As the temperature increased, the resistance change under the applied electric field was found to decrease.

Martens et al investigated the field effect on devices with ultrathin layers of $\mathrm{VO}_{2}$ epitaxially deposited by pulsed laser deposition on single crystalline $\mathrm{TiO}_{2}$, [148]. These films were combined with ultrathin high quality gate dielectrics, amongst which $\mathrm{ALD} \mathrm{HfO}_{2}$. These structures allowed the measurement of the $\mathrm{VO}_{2}$ field effect. The 3-9 nm thick single crystalline $\mathrm{VO}_{2}$ films avoided large unmodulated "bulk" conduction which has made measuring the small $\mathrm{VO}_{2}$ field effect problematic. Due to the high dielectric breakdown strength and high-k value of the $\mathrm{ALD} \mathrm{HfO}_{2}$ films, $\mathrm{VO}_{2}$ FET devices could attain a charge density of $\sim 5 \times 10^{13} \mathrm{~cm}^{-2}$, which is similar to the density quoted in [145] for ionic liquid gating, $5.6 \times 10^{13} \mathrm{~cm}^{-2}$ at $0.9 \mathrm{~V}$.

The gate bias modulation of channel conductance was found to be low $(<0.6 \% / \mathrm{V})$ and no gate bias induced MITs were observed. Depletion behavior was found to be strongly suppressed, as observed in both subdued field effect modulation of channel current and capacitance. No signatures of defect dominated behavior were encountered in admittance spectroscopy of gate capacitance and channel conductance, and STM. The mobility of the field-induced carriers was derived at $80 \mathrm{~K}-400 \mathrm{~K}$. Based on the low, thermally activated fieldinduced carrier mobility $\left(\sim 1 \times 10^{-3} \mathrm{~cm}^{2} / \mathrm{Vs}\right.$ at $\left.300 \mathrm{~K}\right)$ these excess carriers were concluded to be strongly localized. The excess charge mobility was in agreement with that of small polarons described by an adiabatic Holstein polaron model with an extracted optical phonon frequency of the expected magnitude, $\hbar \omega=8-22 \mathrm{meV}$ for hopping distances of $\mathrm{a}=0.3-0.5$ $\mathrm{nm}$, fitted to the observed activation energy $\mathrm{Ea}=0.11 \mathrm{eV}$. The low mobility of the fieldinduced carriers provides an explanation for the strongly subdued field effect found in $\mathrm{VO}_{2}$.

Yajima et al used single-crystalline niobium-doped $\mathrm{TiO}_{2}$, an N-type semiconductor, as a back-gate electrode, [149]. $\mathrm{VO}_{2}$ was grown on top of this $\mathrm{Nb} \mathrm{TiO}_{2}$ substrate with PLD. The depleted single-crystalline $\mathrm{Nb}: \mathrm{TiO}_{2}$ at the interface with $\mathrm{VO}_{2}$ can be regarded as a gate dielectric for a $\mathrm{VO}_{2} \mathrm{FET}$ channel, enabling a high permittivity as well as high breakdown voltage. As an 'inverse-Schottky gate', the $\mathrm{VO}_{2}$ channel was regarded as a metal electrode and $\mathrm{TiO}_{2}$ as a semiconductor. The inverse-Schottky gate geometry allows electron densities of more than $1 \times 10^{14} \mathrm{~cm}^{-2}$ to accumulate in $\mathrm{VO}_{2}$ at the $\mathrm{VO}_{2} / \mathrm{Nb}: \mathrm{TiO}_{2}$ interface.

The hysteretic temperature dependence of channel conductivity across the MIT was 
measured for different gate biases. A gate bias dependence of the derived transition temperatures is observed. Accumulating $\sim 9.0 \times 10^{13} \mathrm{~cm}^{-2}$ gate induced carriers results in an observed change in TMIT of $\sim 1 \mathrm{~K}$. The gate bias dependence of conductivity at constant temperature was studied as well. Outside of the transition temperature region this gate bias dependence was found to be small $(\sim 10 \%$ at $306 \mathrm{~K})$ and was found to occur fast $(<100 \mathrm{~ms})$. Near the transition region starting in the highly resistive state, it was found that applying gate bias resulted in a significant 2 order of magnitude increase in conductivity. This larger change was found to occur slowly in about $\sim 10 \mathrm{~s}$. The authors ascribed this slow change to a possible nucleation mechanism. Reverse voltage induced switching from low to high resistive was not reported. Small transition temperature shifts observed, were found to be inconsistent with Joule heating. It was argued that the current modulation was taking place not only in the vicinity of the interface, but in the whole $\mathrm{VO}_{2}$ film, and hence that a carrier delocalization effect is taking place as proposed in [145].

Wei et al found that the modulation of $\mathrm{VO}_{2}$ nanowire channel resistance near the metalinsulator transition temperature by a gate was significantly larger than that of larger thin film based FETs, [150]. The authors proposed that the enhanced resistance modulation of the nanowire channels was primarily due to the expansion of metallic nano-fractions in an insulating matrix by applying gate bias especially at the edge parts of channel where the electric field was higher.

There is plenty left to be learned and confirmed about the field effect in $\mathrm{VO}_{2}$. A significant modulation of $\mathrm{VO}_{2}$ by means of a transverse electric field has been observed in ionic liquid gated devices and was ascribed to oxygen migration. Cyclability and speed of this effect remain to be further investigated for applications. The field effect in solid gated devices has so far largely appeared to be subdued. Improvements in film quality and defect content, especially near the gate dielectric- $\mathrm{VO}_{2}$ interface, the careful avoidance or control of Joule heating, gate leakage and electrochemical effects, and the use of advanced characterization techniques may lead to further understanding of the physics and the development of the application potential of the $\mathrm{VO}_{2}$ field effect.

\section{3. $\mathrm{VO}_{2}$ applications and $A L D \mathrm{VO}_{2}$ challenges}

Electronic switching applications for $\mathrm{VO}_{2}$ that have been proposed so far include: selector elements for cross bar array memories [140, 151-155], RF switches [156-158], steep threshold devices [159], non-Boolean computing [160, 161], reconfigurable photonic devices [162-166], plasmonics [167, 168], terahertz applications [169-172], metamaterials [173-175] and others.

A key challenge across $\mathrm{VO}_{2}$ based electronics and photonics is the compatibility with commercial and industrial operating temperature range requirements $\left(70-85^{\circ} \mathrm{C}\right)$ and the even more challenging range of military and automotive applications. To comply with these requirements the $\mathrm{VO}_{2}$ film transition temperature would need to be sufficiently above the operating temperature range, in order to avoid switching all $\mathrm{VO}_{2}$ when the chip temperature is at the higher end of the operating range. During electronic switching the local device temperature is then brought above the operating temperature range in order to switch the device. A workaround would be to provide temperature control of the nanoelectronics or photonics chip which keeps global chip temperature below the transition temperature. This 
might be feasible for some specific applications, but not for all, especially when competing with alternatives that do not require such temperature control. To address the operating temperature range challenge ALD $\mathrm{VO}_{2}$ films might be strained [176] or doped to raise the transition temperature. Ti doping has been reported by some to lead to higher transition temperature [177] or to have little influence on the transition temperature by others [178, 179]. While raising the transition temperature sufficiently, the abruptness and magnitude of the resistivity change across the transition should be maintained, or even improved.

Another key ALD challenge is improving the $\mathrm{VO}_{2}$ ALD film quality to reach similar magnitudes of resistivity change across the transition as those obtained in the best reported $\mathrm{VO}_{2}$ material. Control of crystallinity, stoichiometry, and defects in $\mathrm{VO}_{2}$ films are key to obtain the desired electronic properties.

Atomic Layer Deposition forms an attractive technology to deposit thin $(<50 \mathrm{~nm}) \mathrm{VO}_{2}$ films suitable for mass manufacturing, and further progress in film quality, change in conductivity across the transition, and transition temperature tuning, could enable $\mathrm{VO}_{2}$ applications.

\section{Thermochromic windows - principle of operation.}

Approximately half of the energy that reaches the surface of the Earth from the Sun is in invisible to humans, near-infrared wavelengths, [180]. Developing adaptive coatings that modulate this particular part of the terrestrial solar spectrum, is presenting us with an excellent opportunity to balance the energy needs for the heating and cooling of buildings, without affecting the visual perception and comfort of their inhabitants, [181]. In this regard, the purpose of a smart thermochromic coating is to regulate the amount of solar radiation that is transmitted through the windows of a building, depending upon the ambient temperature. During hot weather (hot-state), a smart window should ideally reject the majority of the Sun's infrared radiation and pass all or part (in cases where a diming effect is desirable) of the incident visible radiation; thus, the need for air-conditioning is limited. During cooler weather (cold-state), both infrared and visible radiation should fully be transmitted, minimising heating and lighting energy loads, Figure 24. Vanadium dioxide is the prime material choice for thermochromic window applications due to its favourable intrinsic properties, summarised below; i) the material exhibits a substantial change to its optical properties when switching from one phase to the other (see also discussion on $\mathrm{VO}_{2}$ refractive index in the following section). This change is more prominent in the infrared wavelengths $(>700 \mathrm{~nm}$ ), inducing a large modulation to the transmittance of NIR radiation between the cold and hot states; ii) the transition temperature of $\mathrm{VO}_{2}$ can be tuned over a broad range and hence, the properties of thermochromic coatings can be tailored to the specific climatic conditions of a particular geographic location; iii) a large number of deposition methods and precursor materials for $\mathrm{VO}_{2}$ thin-films are already available, some compatible with widely deployed, scalable manufacturing processes. This promises a short path from research to the market; and finally, iv) vanadium is a relatively abundant material and is already in use on industrial scale. There are largely two lines of research in association with $\mathrm{VO}_{2}$ smart window technologies under intense investigation at present. The first employs 
thin-films of $\mathrm{VO}_{2}$ to control NIR radiation, most commonly via modulation of a window's reflectance, [182]. The second, exploits the changes in the absorption cross-section of $\mathrm{VO}_{2}$ nanoparticles to regulate the solar heat gain through a window's surface. The latter area, frequently termed nanothermochromics, [183], will not be the subject of this review as there is no evidence of conjunction with atomic layer deposition processes in the literature. Instead, we will focus on the former area, where we believe that most of the breakthroughs may come about by application of ALD methods.

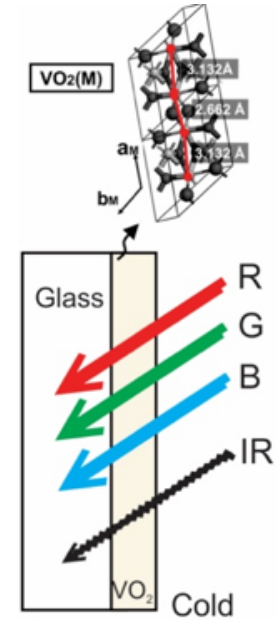

(a)

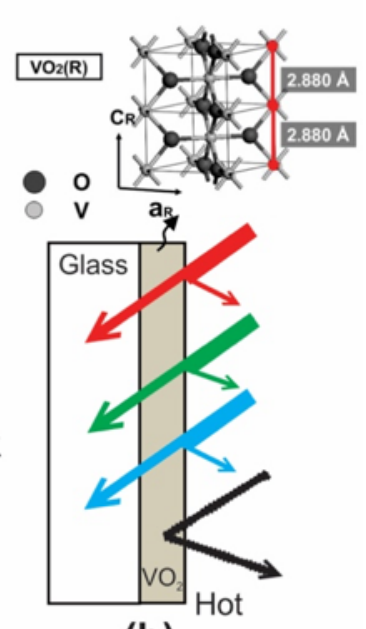

(b)

Figure 24: Illustration of thermochromic window functionality: (a) Cold-state enabling both visible and infrared radiation to be transmitted through. (b) Hot-state that cuts off infrared radiation and part of visible radiation.

\subsection{Optical constants in hot and cold state.}

As mentioned in previous sections of this review, $\mathrm{VO}_{2}$ behaves as a semiconductor with monoclinic crystalline structure below the transition temperature $T t,(T<T t)$, while it transforms into a rutile-like, semi-metallic phase for $T>T t$. We therefore expect the real and imaginary parts, $(n, k)$, of its refractive index to vary quite distinctly between these two states. It is, in fact, the drastic variation in the optical constants of $\mathrm{VO}_{2}$ that is responsible for its striking properties that make it a suitable material for smart window applications. In spite of numerous studies having been devoted to the evaluation of the wavelength dependent $\mathrm{VO}_{2}$ refractive index, [73, 184-186], the literature has yet to converge to an accurate and commonly agreed set of values. This is primarily because the quality of the measurements is affected by deviations on the density and morphology of the produced films, as well as the concurrent presence of other oxide polymorphs. The inherent anisotropic nature of crystalline $\mathrm{VO}_{2}$ may imply at first that the complete refractive index tensor needs be quantified. Nonetheless, most films produced in practice consist of polycrystalline domains, giving rise to an isotropic effective index over sufficiently long range. While substantial discrepancies between the absolute values of the reported optical constants are met among different studies, all published data still share the same qualitative characteristics. Figure 25, shows the 
values for both hot and cold states, obtained by spectrometric ellipsometry [186]. The cold state is consistent with a semiconductor structure with a bandgap of $2.5 \mathrm{eV}(\sim 495 \mathrm{~nm})$, arising from the separation between the oxygen $2 \mathrm{p}$-orbitals and the vanadium $3 \mathrm{~d}$-bands in the monoclinic phase and additional absorption peaks at around $3 \mathrm{eV}$ and $4 \mathrm{eV}$ due to interband transitions within the vanadium 3d-bands, [184]. These features manifest as an abrupt increase in the extinction coefficient for wavelengths $<500 \mathrm{~nm}$, which accounts for increased losses in this region. This is undesirable, as it is responsible for the yellow-brownish coloration of typical $\mathrm{VO}_{2}$ films, which is generally considered unattractive for commercial purposes. The relatively large values $(>2.3)$ of the refractive index across the whole visible spectrum contribute to high reflectance in this spectral region, which is also undesirable as natural light is equally blocked in hot and cold states. An additional absorption peak is observed at $\sim 1.2-1.3 \mathrm{eV}$, consistent with the literature [73, 184, 185], which is responsible for the milder and broader peak in the extinction coefficient around $1000 \mathrm{~nm}$. In the hot state, purely metallic behaviour is observed for energies higher than $2 \mathrm{eV}(\sim 620 \mathrm{~nm})$ and a stark increase in the free-carrier absorption with a concomitant increase in the extinction coefficient in the infrared occurs. The consequence of this behaviour is dramatic, as far as smart window applications are concerned. Vanadium-dioxide thin-films exhibit a surge in their reflectivity [182], while $\mathrm{VO}_{2}$ nanoparticles exhibit acute enhancement to their absorption cross-section [183], as the temperature increases past the transition threshold and the material undergoes the SMT. Thereupon, the amount of radiation that is transmitted through a smart window can substantially be modulated, with this effect being more prominent for NIR wavelengths, as already mentioned before.
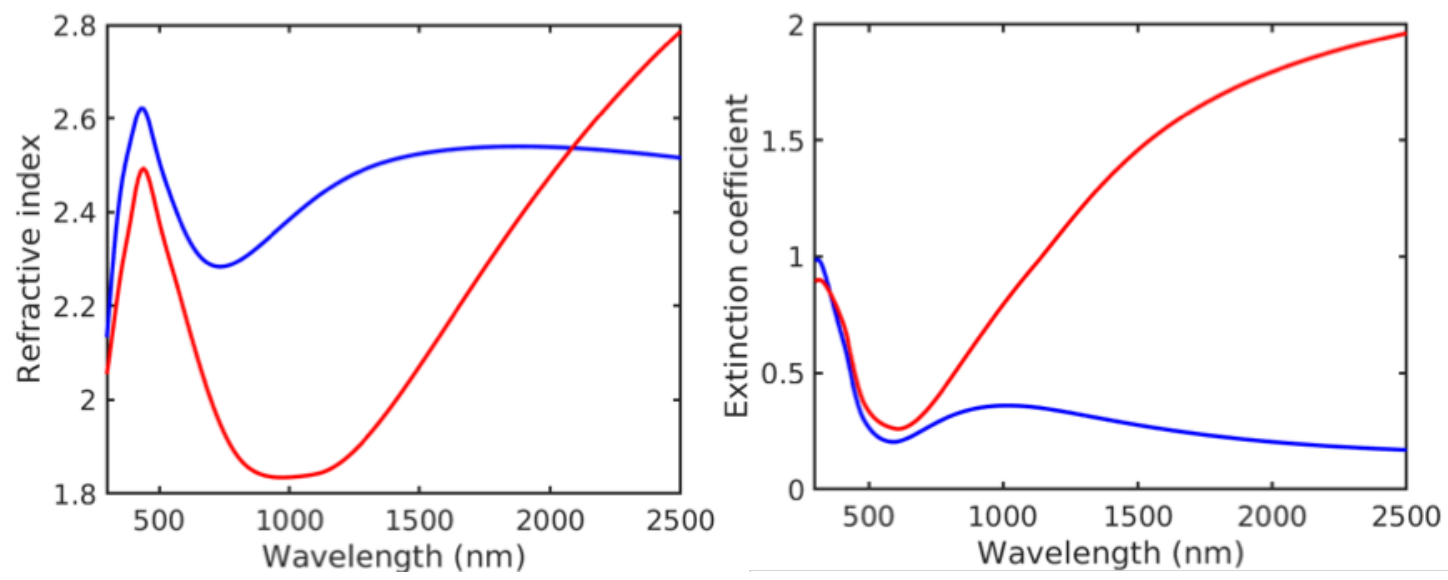

Figure 25: Spectroscopic analysis of $\mathrm{VO}_{2}$ refractive index: (a) Real part. (b) Imaginary part. Data reproduced from [186].

\subsection{Metrics for Thermochromic Window Performance.}

Before discussing the synergies between thermochromic coating research and atomic layer deposition in more detail, it is useful to introduce some key metrics that are used extensively 
to characterise the performance of smart windows, [181-183]. It is customary to use spectrally weighted average transmission quantities and assess the performance of the window in the visible wavelengths, associated with human comfort aspects, separately. Consequently, the luminous transmittance $T_{\text {lum }}^{c, h}$ and solar transmittance $T_{\text {sol }}^{c, h}$ metrics are defined in the cold and hot states as following:

$$
T_{\text {lum }, \text { sol }}^{c, h}=\frac{\int \phi_{\text {lum }, \text { sol }}(\lambda) T^{c, h}(\lambda) \mathrm{d} \lambda}{\int \phi_{\text {lum }, \text { sol }}(\lambda) \mathrm{d} \lambda},
$$

where, $T^{c}(\lambda)$ is the transmittance at wavelength $\lambda$ in the cold state and $T^{h}(\lambda)$ in the hot state correspondingly, $\phi_{\text {lum }}$ is the photopic spectral sensitivity of the light-adapted eye (CIE 2008, $380 \mathrm{~nm}<\lambda<780 \mathrm{~nm})$ and $\phi_{\text {sol }}$ is the solar irradiance spectrum for air mass 1.5 standard $(280 \mathrm{~nm}<\lambda<2500 \mathrm{~nm})$. The solar transmittance modulation $\left(\Delta T_{\text {sol }}\right)$ can then be deduced from the above as $\Delta T_{\text {sol }}=\left(T_{\text {sol }}^{c}-T_{\text {sol }}^{h}\right) / T_{\text {sol }}^{c}$. This parameter, outlines the potential of a thermochromic coating to regulate the admitted solar radiation in the summer and winter months. As a general rule of thumb, efficient thermochromic coatings should be designed to simultaneously maximize $T_{\text {lum }}^{c, h}$ and $\Delta T_{\text {sol }}$. We mention in passing that the transmittance based metrics presented above are not the only parameters that smart window researchers need to consider when developing next generation coatings. Equally important, albeit broadly overlooked in the literature, are the hysteresis width and gradient of the coatings, which need to be tightly controlled or otherwise the performance of the windows may be inexorably compromised [187].

\subsection{Key challenges of thermochromic window research}

After several decades of research and a smart window product has yet to appear in the market, unveiling the hurdles still needed to be overcome for the commercial translation of the work in this area. The key and often conflicting challenges facing thermochromic coating research are; (a) The refractive index of $\mathrm{VO}_{2}$ admits large values across the entire solar spectrum, as already discussed in the previous section. This results in high reflectance in both hot and cold states, limiting $T_{\text {lum }}^{c, h}$ and suppressing $\Delta T_{\text {sol }}$; (b) The solution that usually is advanced to improve $\Delta T_{\text {sol }}$, is to increase the thickness of $\mathrm{VO}_{2}$ layers. This has the adverse effect of diminishing $T_{\text {lum }}^{c, h}$, pointing to a critical trade-off between $T_{\text {lum }}^{c, h}$ and $\Delta T_{\text {sol }}$ the difficulty in concurrently maximizing both; (c) The native transition temperature of $\mathrm{VO}_{2}$ is $68^{\circ} \mathrm{C}$, which is impractical for real life applications and needs to be brought closer to room temperature; (d) Steep switching promotes higher energy savings and hence, the hysteresis and the gradient of the transition curve have to be kept to a minimum; (e) The unappealing coloration of $\mathrm{VO}_{2}$ coatings needs to be addressed to produce aesthetically desirable products; (f) Durability is an issue of prime importance, as coatings need to survive harsh conditions over prolonged periods of time. The two most common threats encountered by $\mathrm{VO}_{2}$ coatings are oxidation when exposed to air and weak adhesion to substrates; (g) As a final remark, we note that additional multifunctionality (for example, self-cleaning, oil-repellence, high-conductivity, scratch resistance, ice nucleation delay, photocatalytic and antimicrobial activity and other) is desirable for add on value and creation of high-end products. 


\subsection{Role of $A L D$ in smart window research and future outlook.}

Atomic layer deposition is emerging as a promising technology platform to address some or all of the key challenges encountered in smart window research. As a first example, ultrathin layers of amorphous $\mathrm{Al}_{2} \mathrm{O}_{3}$ were deposited atop $\mathrm{VO}_{2}$ films by Wang et al in, [188], as protective layers. In this study, it was found that $\mathrm{Al}_{2} \mathrm{O}_{3}$ layers as thin as $5 \mathrm{~nm}$ were sufficient to prevent oxidation of $\mathrm{VO}_{2}$, even when samples were heated up to $350^{\circ} \mathrm{C}$ for over 1h. This was in complete contrast with the control sample that was fully oxidised to $\mathrm{V}_{2} \mathrm{O}_{5}$ and lost its thermochromic properties when subjected to the same heat treatment. Such protective layers can, in the future, be used as barriers to prevent oxidation but also to improve the durability and wearability of thermochromic films, [189]. As far as the issues associated with the transition temperature and aesthetics of the $\mathrm{VO}_{2}$ coatings are concerned, researchers have traditionally sought solutions in elemental doping. This is a very vibrant area of work and over 60 elements have been investigated by theory or experiment at present, as potential dopants to improve the optical properties of $\mathrm{VO}_{2}$ films, [190]. The complete coverage of the subject is outside the scope of this review but the general strategies to lower by doping aim to increase the carrier concentration and to induce directed internal strain, both of which have shown to decrease the energy barrier for the SMT. The prototypical dopant is $\mathrm{W}$, a higher valency $(+5)$ transition metal, which was shown to lower the transition temperature by $\sim 20 \mathrm{~K} /$ at $\%$, [191]. On the other hand, doping with $\mathrm{Mg}$ was employed to widen (blue-shift) the bandgap of $\mathrm{VO}_{2}$ to $2.32 \mathrm{eV}$ [192], which had a beneficial effect on the hue and the $T_{\text {lum }}^{c, h}$ of the films. Atomic layer deposition can play an important role as a means to controlled and precise doping, as has been demonstrated with the nanolaminate technique, [193]. According to this method, ultrathin nanolaminates of different materials are alternately deposited by successive ALD cycles and doping is facilitated upon high temperature annealing via interlayer diffusion. A first attempt in the context of smart windows was made by Lv et al in, [194], where doping with Mo up to levels of 10 at\% was examined and results were encouraging.

A popular method to surpass the trade-off barrier between luminous transmittance and solar modulation is by employing multilayer, antireflective films [197-199]. By carefully optimising the optical path in each layer, constructive interference conditions can be attained for the transmitted field suppressing reflections and thus, enhancing $T_{\text {lum }}^{c, h}$ and $\Delta T_{\text {sol }}$. A triplelayer $\mathrm{TiO}_{2} / \mathrm{VO}_{2} / \mathrm{TiO}_{2}$ made by magnetron sputtering in [197] reported $T_{\text {lum }}^{c}=63 \%$ and $T_{\text {lum }}^{h}=57 \%$, compared with $T_{\text {lum }}^{c}=47 \%$ and $T_{\text {lum }}^{h}=42.5 \%$, for a single $\mathrm{VO}_{2}$ layer deposited under identical conditions and on a similar substrate. Another triple layer $\mathrm{SiO}_{2} / \mathrm{VO}_{2} / \mathrm{TiO}_{2}$ structure [199], demonstrated additional photocatalytic activity, showcasing the possibility of combining thermochromicity with extra functionalities. The broadband and incoherent nature of sunlight pose a great challenge to the design and fabrication of multilayer structures for thermochromic applications. Any system designed needs to maintain steady performance over a broad range of wavelengths and, crucially, be insensitive to the incident polarisation as well as the angle of incidence. Such demanding design rules can only be met by systems comprising a large number of layers [200], the thickness of each one of which needs to very precisely be controlled as even miniscule errors aggregate rapidly across the full stack. This imposes stringent requirements to the fabrication processes. Atomic layer deposition is a 

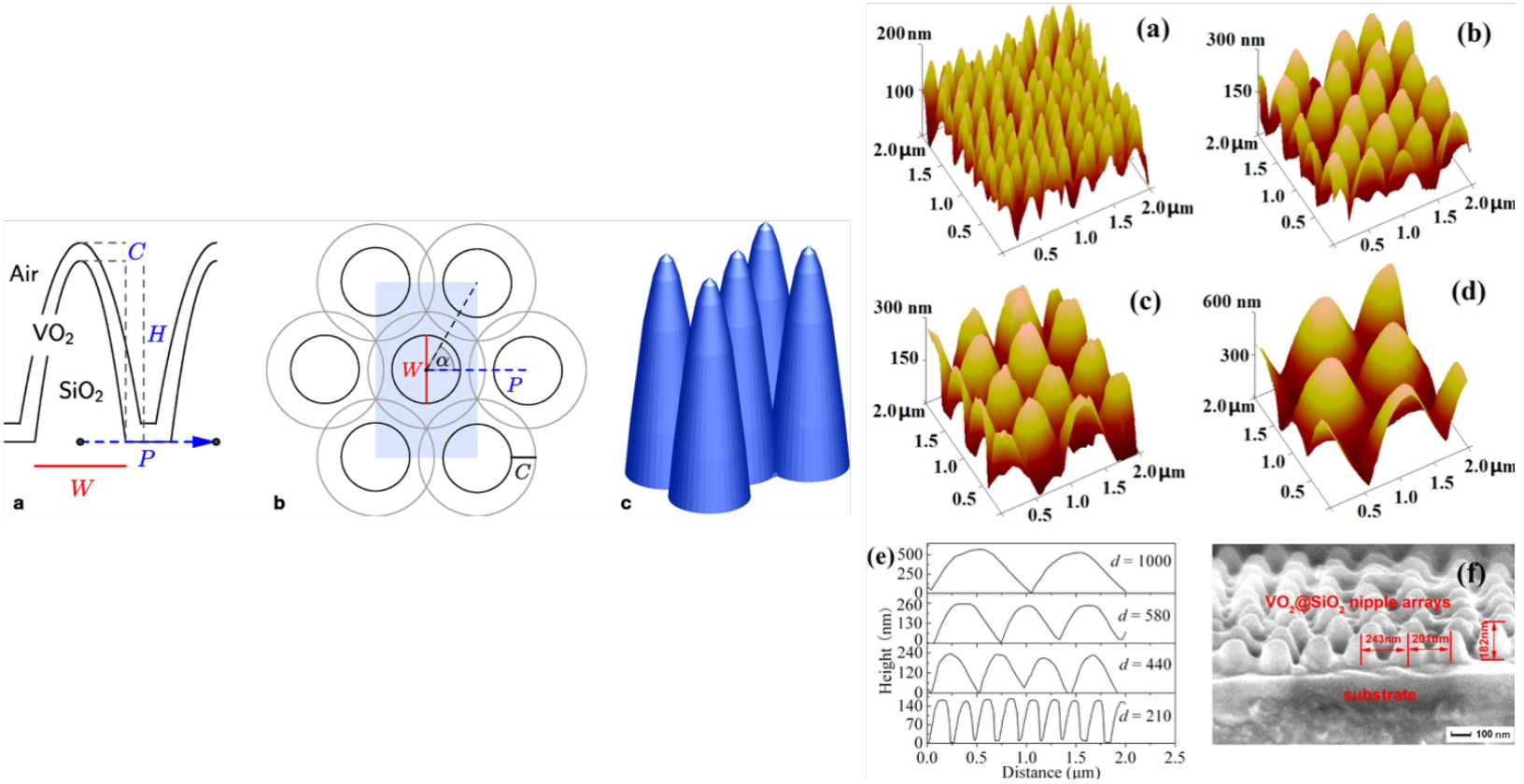

Figure 26: Bioinspired, antireflective, superhydrophobic thermochromic concept. (A) Side and top elevations of nanotextured surfaces with hexagonally arranged paraboloid cones that were simulated in [195]. (C) 2013 Optical Society of America. (B) Fabricated moth-eye $\mathrm{VO}_{2}$ structures. Adapted with permission from [196]. Copyright 2014 American Chemical Society.

very attractive method for this purpose, as it provides with a highly repeatable, accurate, scalable and automated route for the uniform deposition of multiple material layers in a single batch [201].

The outlook of atomic layer deposition in thermochromic window research is bright, as argued in the previous paragraphs. It is our belief however, that the full potential of ALD will truly be harnessed only when it combines with the rapid advances in nanotechnology and nanofabrication. The first step to merge the worlds of smart windows and nanotechnology was taken by Taylor et al, [195], with the design shown in Figure 26(A). In their paper, it was shown theoretically that $T_{\text {lum }}^{c}>70 \%$ and $\Delta T_{\text {sol }}>15 \%$. are achievable by using bioinspired, anti-reflective structures in a glass substrate, conformally coated with ultrathin layers (10$20 \mathrm{~nm}$ ) of $\mathrm{VO}_{2}$. Moreover, this design satisfies the requirements for broadband operation, is agnostic to the polarization and angle of the incident light and introduces virtually no haze to the smart window. Finally, such moth-eye structures are well known to induce extreme superhydrophobicity, ice formation delay, omniphobicity and other functionalities when their surface energy is lowered by silanization or other processes, [204, 205]. Along similar lines, Liu et al proposed [202], a design, whereby a $\mathrm{SiO}_{2}$ substrate patterned on a nanogrid array showed theoretical values of $T_{\text {lum }}^{c}>78 \%$ and $\Delta T_{\text {sol }}>15 \%$, when coated with $\mathrm{VO}_{2}$ layers of $\sim 300 \mathrm{~nm}$, Figure 27(A). Thermochromic coatings were also combined with 

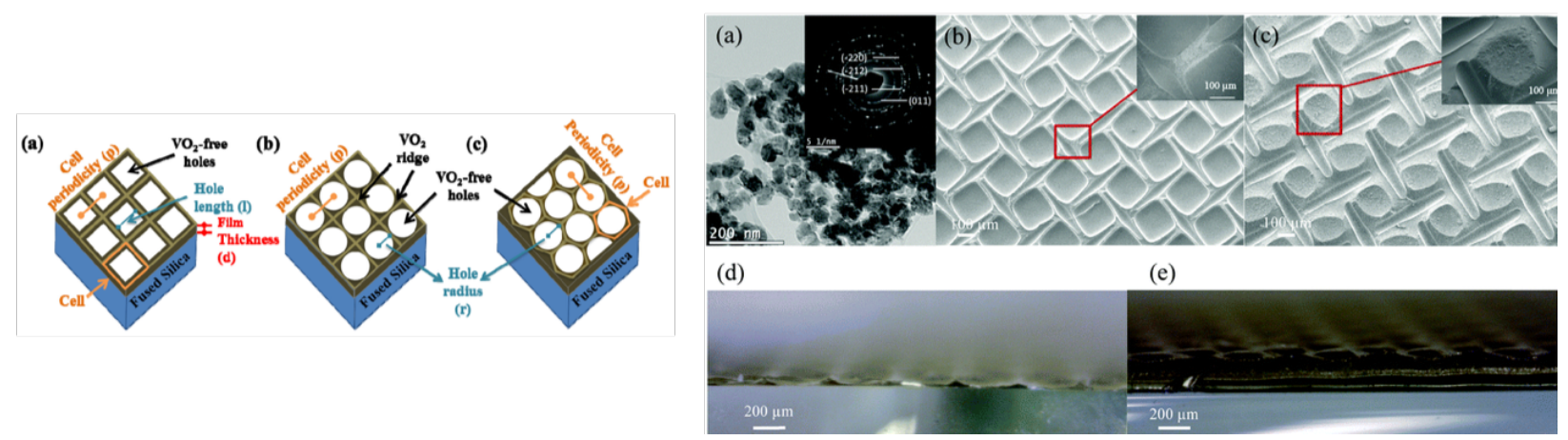

Figure 27: (A) Nanogrid thermochromic modelled in [202]. (C) 2015 Optical Society of America. Fabricated microgrid patterns in [203] - Published by the Royal Society of Chemistry.

opal photonic crystals in [206] where theoretical results of $T_{\text {lum }}^{c}>49 \%$ and $\Delta T_{\text {sol }}>11 \%$ were obtained. However, the real strength of photonic crystals lies in the ability to tune their photonic bandgap, which can be leveraged to achieve virtually any desired tint, as was demonstrated in this publication, Figure 28. Some attempts to fabricate the above structures were made in the literature [196, 203] where in all cases, sol-gel processes were used to deposit the $\mathrm{VO}_{2}$ coatings. In spite of best efforts, all experimental systems exhibited suboptimal results compared to their theoretical counterparts, mainly because the fabricated structures could not match the explicit design requirements arose from modelling. The above reveal the unique opportunity for ALD, as the only known process that can provide ultrathin, carefully doped, conformal and high-aspect ratio coatings, to meet the demanding requirements of nanotechnology and produce highly efficient, multifunctional thermochomic coatings that can outperform almost any other design.

\section{Conclusions}

The ALD of vanadium oxide has been addressed from various perspectives. A close look at the processing chemistry reveals the availability of vanadium precursors where the cation features the oxidation state III, IV and V. Considering the volatility of these precursors near room temperature and their thermal stability, two precursors can be distinguished in terms of reaction with various typical reactants. Thermal ALD using water vapour or ozone as a reactant and plasma-enhanced ALD using molecular oxygen are readily enabled using TEMAV and VTOP. The ALD-required saturating chemisorption of these precursors was reported. The absence of a consensus regarding the thermolysis temperature of VTOP and the growth per cycle at saturation with TEMAV is noteworthy. Nonetheless, VTOP presents clear handling advantage and high volatility at room temperature while TEMAV features a conveniently high thermolysis temperature. A considerable number of commercially available volatile vanadium compounds were not reported so far as ALD precursors. 


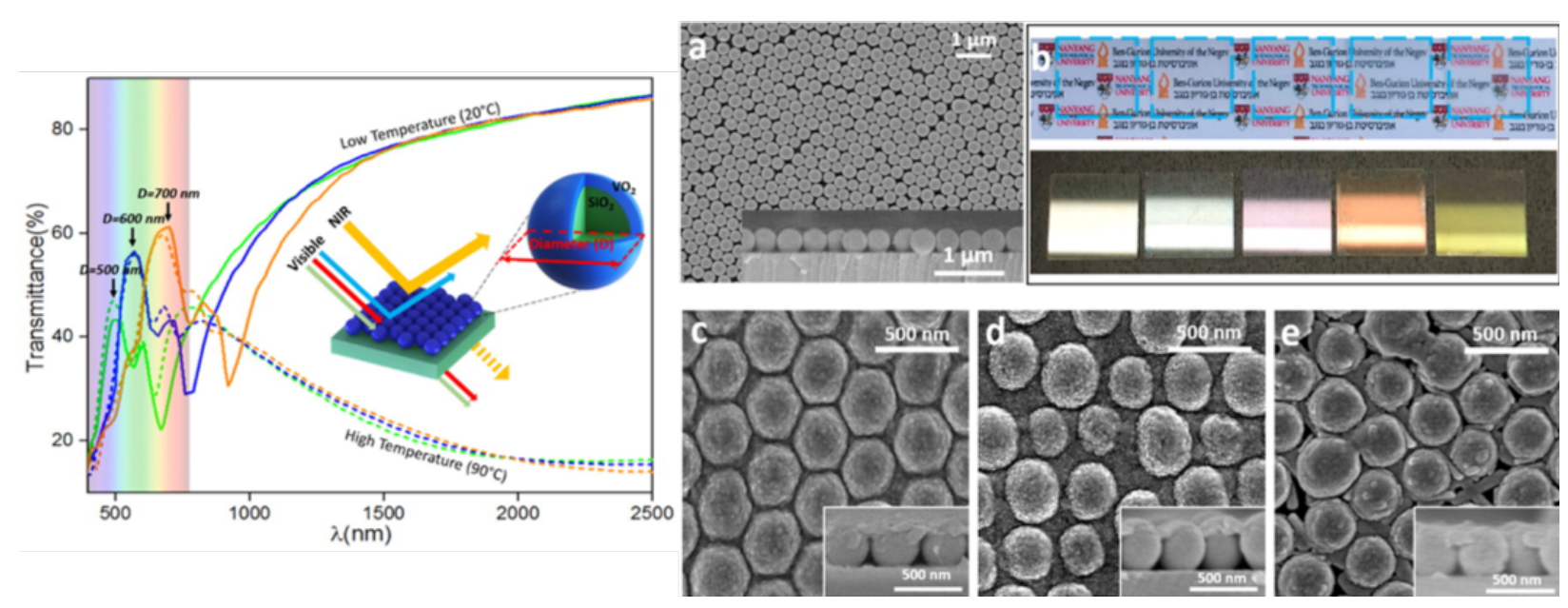

Figure 28: Photonic crystal based thermochromic windows. Adapted with permission from [206]. Copyright 2016 American Chemical Society.

The ALD-made vanadium oxide layers are typically amorphous and the post-deposition treatment is essential for the attainment of a single crystalline phase. A thorough review in this respect shows a tight dependence of the crystallization kinetics on the nature of the substrate, gas-phase composition, pressure, temperature, content and nature of contaminants in the film and the film thickness. In situ monitoring has played a major role for the establishment of phase-formation diagrams to rationalize the processing of the various vanadium oxide phases. The processing-induced morphological impact is substantial and it its complexity is worth of dedicated investigations. Among vanadium oxides phases, the Wadsley series presents a particular interest for the electrochemical energy storage. The implementation of ALD leverages the potential of these coatings by the possibility to target amorphous, nano-crystalline or polycrystalline oxides; uniformly coating powders or CNTs; and by the possibility to engineer core/shell architectures. The reported investigations display improved performance and stability. The interest towards $\mathrm{VO}_{2}$ that features a semiconductor to metal transition was reviewed for microelectronics and thermochromic windows. This near roomtemperature transition, $68^{\circ} \mathrm{C}$, finds pertinent application for switching and light modulation. For microelectronic applications, an understanding of the electronic control of the transition with its thermal shifting above $85^{\circ} \mathrm{C}$ is suitable. In contrast, decreasing it around $30^{\circ} \mathrm{C}$ is essential for glazing applications. The ALD-based development for thermochromic $\mathrm{VO}_{2}$ windows is emphasized by the introduction of bioinspired surface structuration.

\section{Acknowledgements}

This article is based upon work from COST Action MP1402 'Hooking together European research in atomic layer deposition (HERALD)', supported by COST (European Coopera- 
tion in Science and Technology). Vasu Prasad Prasadam and Naoufal Bahlawane would like to acknowledge funding through the MASSENA Pride program of the Luxembourg National Research Fund (FNR). Ioannis Papakonstantinou acknowledges support from the European Research Council for Starting Grant Intelglazing, Project ID: 679891 and from Horizon H2020 for project EENSULATE grant No. 723868. Felix Mattelaer, Geert Rambelberg and Christophe Detavernier would like to thank BOF-UGent for GOA funding and FWOVlaanderen for project funding. Y.Z. Jiang would like to thank the National Natural Science Foundation of China (Grant no. 51722105), Zhejiang Provincial Natural Science Foundation of China (LR18B030001) and the Fundamental Research Funds for the Central Universities (2018XZZX002-08) for their support. Koen Martens would like to thank FWO-Vlaanderen for project funding.

\section{References}

[1] M. Liu, B. Su, Y. Tang, X. Jiang, A. Yu, Recent Advances in Nanostructured Vanadium Oxides and Composites for Energy Conversion, Advanced Energy Materials. URL 10.1002/aenm.201700885

[2] J. B. Goodenough, Anomalous Properties of the Vanadium Oxides, Annual Review of Materials Science 1 (1971) 101-138. URL 10.1146/annurev.ms.01.080171.000533

[3] S. Surnev, M. G. Ramsey, F. P. Netzer, Vanadium oxide surface studies, Progress in Surface Science 73 (2003) 117-165. URL 10.1016/j.progsurf.2003.09.001

[4] K. Kosuge, The phase diagram and phase transition of the V2O3-V2O5, system, Journal of Physics and Chemistry of Solids 28 (1967) 1613-1621. URL https://doi.org/10.1016/0022-3697(67)90293-4

[5] Z. Yang, C. Y. Ko, S. Ramanathan, Oxide Electronics Utilizing Ultrafast Metal-Insulator Transitions, Annual Review of Materials Research, Vol 4141 (2011) 337-367. URL 10.1146/annurev-matsci-062910-100347

[6] M. Brahlek, L. Zhang, J. Lapano, H. T. Zhang, R. Engel-Herbert, N. Shukla, S. Datta, H. Paik, D. G. Schlom, Opportunities in vanadium-based strongly correlated electron systems, Mrs Communications 7 (2017) $27-52$. URL $10.1557 / \mathrm{mrc} .2017 .2$

[7] C. Z. Wu, F. Feng, Y. Xie, Design of vanadium oxide structures with controllable electrical properties for energy applications, Chemical Society Reviews 42 (2013) 5157-5183. URL $10.1039 / \mathrm{c} 3 \operatorname{cs} 35508 \mathrm{j}$

[8] T. C. Chang, X. Cao, S. H. Bao, S. D. Ji, H. J. Luo, P. Jin, Review on thermochromic vanadium dioxide based smart coatings: from lab to commercial application, Advances in Manufacturing 6 (2018) $1-19$.

URL 10.1007/s40436-017-0209-2

[9] T. A. Kainulainen, M. K. Niemela, A. O. I. Krause, Ethene hydroformylation on Co/SiO2 catalysts, Catalysis Letters 53 (1998) 97-101.

[10] M. Kamalisarvestani, R. Saidur, S. Mekhilef, F. S. Javadi, Performance, materials and coating technologies of thermochromic thin films on smart windows, Renewable \& Sustainable Energy Reviews 26 (2013) 353-364.

URL 10.1016/j.rser.2013.05.038

[11] B. M. Weckhuysen, D. E. Keller, Chemistry, spectroscopy and the role of supported vanadium oxides in heterogeneous catalysis, Catalysis Today 78 (2003) 25-46.

URL 10.1016/s0920-5861(02)00323-1 
[12] L. Zhang, Y. J. Zhou, L. Guo, W. W. Zhao, A. Barnes, H. T. Zhang, C. Eaton, Y. X. Zheng, M. Brahlek, H. F. Haneef, N. J. Podraza, M. H. W. Chan, V. Gopalan, K. M. Rabe, R. EngelHerbert, Correlated metals as transparent conductors, Nature Materials 15 (2016) 204-+. URL 10.1038/nmat4493

[13] H. T. Zhang, M. Brahlek, X. Y. Ji, S. M. Lei, J. Lapano, J. W. Freeland, V. Gopalan, R. EngelHerbert, High-Quality LaVO3 Films as Solar Energy Conversion Material, Acs Applied Materials \& Interfaces 9 (2017) 12556-12562.

URL 10.1021/acsami.6b16007

[14] N. Bahlawane, D. Lenoble, Vanadium Oxide Compounds: Structure, Properties, and Growth from the Gas Phase, Chemical Vapor Deposition 20 (2014) 299-311. URL 10.1002/cvde.201400057

[15] S. Beke, A review of the growth of V2O5 films from 1885 to 2010, Thin Solid Films 519 (2011) 17611771. URL 10.1016/j.tsf.2010.11.001

[16] S. F. Wang, M. S. Liu, L. B. Kong, Y. Long, X. C. Jiang, A. B. Yu, Recent progress in VO2 smart coatings: Strategies to improve the thermochromic properties, Progress in Materials Science 81 (2016) $1-54$. URL 10.1016/j.pmatsci.2016.03.001

[17] R. L. Puurunen, A Short History of Atomic Layer Deposition: Tuomo Suntolaś Atomic Layer Epitaxy, Chemical Vapor Deposition 20 (2014) 332-344.

URL 10.1002/cvde.201402012

[18] E. Ahvenniemi, A. R. Akbashev, S. Ali, M. Bechelany, M. Berdova, S. Boyadjiev, D. C. Cameron, R. Chen, M. Chubarov, V. Cremers, A. Devi, V. Drozd, L. Elnikova, G. Gottardi, K. Grigoras, D. M. Hausmann, C. S. Hwang, S. H. Jen, T. Kallio, J. Kanervo, I. Khmelnitskiy, D. H. Kim, L. Klibanov, Y. Koshtyal, A. O. I. Krause, J. Kuhs, I. Karkkanen, M. L. Kaariainen, T. Kaariainen, L. Lamagna, A. A. Lapicki, M. Leskela, H. Lipsanen, J. Lyytinen, A. Malkov, A. Malygin, A. Mennad, C. Militzer, J. Molarius, M. Norek, C. Ozgit-Akgun, M. Panov, H. Pedersen, F. Piallat, G. Popov, R. L. Puurunen, G. Rampelberg, R. H. A. Ras, E. Rauwel, F. Roozeboom, T. Sajavaara, H. Salami, H. Savin, N. Schneider, T. E. Seidel, J. Sundqvist, D. B. Suyatin, T. Torndahl, J. R. van Ommen, C. Wiemer, O. M. E. Ylivaara, O. Yurkevich, Recommended reading list of early publications on atomic layer deposition-Outcome of the "Virtual Project on the History of ALD", Journal of Vacuum Science \& Technology A 35. URL 10.1116/1.4971389

[19] S. M. George, Atomic Layer Deposition: An Overview, Chemical Reviews 110 (2010) 111-131. URL $10.1021 / \operatorname{cr} 900056 b$

[20] R. L. Puurunen, Surface chemistry of atomic layer deposition: A case study for the trimethylaluminum/water process, Journal of Applied Physics 97 (2005) 121301. URL $10.1063 / 1.1940727$

[21] M. P. L. R. M. V.; Leskela, M.; Titala, Crystallinity of inorganic films grown by atomic layer deposition: Overview and general trends, Journal of Applied Physics 113 (2013) 021301. URL 10.1063/1.4757907

[22] C. Detavernier, J. Dendooven, S. P. Sree, K. F. Ludwig, J. A. Martens, Tailoring nanoporous materials by atomic layer deposition, Chemical Society Reviews 40 (2011) 5242-5253. URL $10.1039 / \mathrm{c} 1 \mathrm{cs} 15091 \mathrm{j}$

[23] U. K. Urs, K. C. Anitha, K. L. Raghunathan, S. A. Shivashankar, W. T. Robinson, T. N. G. Row, Low-temperature oxobis(2,2,6,6-tetramethyl-3,5-heptanedionato)vanadium(IV), Acta Crystallographica Section E-Structure Reports Online 57 (2001) m242-m243. URL $10.1107 / \mathrm{s} 1600536801007760$

[24] M. A. K. Ahmed, H. Fjellvag, A. Kjekshus, B. Klewe, New oxovanadium(IV) complexes with mixed ligands synthesis, thermal stability, and crystal structure of $(\mathrm{VO})(2)(\mathrm{acac})(2)(\mathrm{mu}-\mathrm{OEt})(2)$ and $(\mathrm{VO})(2)(\mathrm{thd})(2)(\mathrm{mu}-\mathrm{OEt})(2)$, Zeitschrift Fur Anorganische Und Allgemeine Chemie 630 (2004) 2311- 
2318.

URL $10.1002 /$ zaac. 200400369

[25] I. P. Malkerova, A. M. Makarevich, A. S. Alikhanyan, N. P. Kuz'mina, Volatility and thermal stability of vanadyl $\beta$-diketonate complexes, Russian Journal of Inorganic Chemistry 62 (2017) 818-821. URL 10.1134/S0036023617060134

[26] T. Moeller, Vanadium(IV) Oxy(acetylacetonate), 1957. URL 10.1002/9780470132364.ch30

[27] J. Keranen, A. Auroux, S. Ek-Harkonen, L. Niinisto, Calorimetric measurements of the acidity of supported vanadium oxides prepared by ALE and impregnation, Thermochimica Acta 379 (2001) $233-239$. URL 10.1016/s0040-6031(01)00621-9

[28] P. Dagur, A. U. Mane, S. A. Shivashankar, Thin films of VO2 on glass by atomic layer deposition: microstructure and electrical properties, Journal of Crystal Growth 275 (2005) E1223-E1228. URL 10.1016/j.jcrysgro.2004.11.144

[29] J. Keranen, A. Auroux, S. Ek, L. Niinisto, Preparation, characterization and activity testing of vanadia catalysts deposited onto silica and alumina supports by atomic layer deposition, Applied Catalysis a-General 228 (2002) 213-225.

URL 10.1016/s0926-860x (01)00975-9

[30] E. Ostreng, K. B. Gandrud, Y. Hu, O. Nilsen, H. Fjellvag, High power nano-structured V2O5 thin film cathodes by atomic layer deposition, Journal of Materials Chemistry A 2 (2014) 15044-15051. URL $10.1039 / \mathrm{c} 4$ ta00694a

[31] E. Ostreng, O. Nilsen, H. Fjellvag, Optical Properties of Vanadium Pentoxide Deposited by ALD, Journal of Physical Chemistry C 116 (2012) 19444-19450. URL 10.1021/jp304521k

[32] H. Kanai, T. Yoshikawa, T. Sone, Y. Nishimura, Preparation and characterization of highly dispersed V2O5/SiO2prepared by a CVD method, Reaction Kinetics and Catalysis Letters 75 (2002) 213-224. URL 10.1023/A:1015282409268

[33] J. C. Badot, S. Ribes, E. B. Yousfi, V. Vivier, J. P. Pereira-Ramos, N. Baffier, D. Lincot, Atomic layer epitaxy of vanadium oxide thin films and electrochemical behavior in presence of lithium ions, Electrochemical and Solid State Letters 3 (2000) 485-488.

[34] Safety Data Sheet Vanadium triisopropoxide oxide, Material Safety Data Sheet 4 (2015) 7.

[35] W. Priebsch, D. Rehder, OXOVANADIUM ALKOXIDES - STRUCTURE, REACTIVITY, AND V-51 NMR CHARACTERISTICS - CRYSTAL AND MOLECULAR-STRUCTURES OF VO(OCH2CH2CL)3 AND VOCL2(THF)2H2O, Inorganic Chemistry 29 (1990) 3013-3019. URL 10.1021/ic00341a032

[36] H. Langbein, A. Polte, On the Hydrolysis of Trisalkoxyvanadyl Compounds, Zeitschrift fur Naturforschung - Section B Journal of Chemical Sciences 46 (1991) 1509-1514. URL 10.1515/znb-1991-1109

[37] J. Musschoot, D. Deduytsche, H. Poelman, J. Haemers, R. L. V. Meirhaeghe, S. V. den Berghe, C. Detavernier, Comparison of Thermal and Plasma-Enhanced ALD/CVD of Vanadium Pentoxide, Journal of the Electrochemical Society 156 (2009) P122-P126. URL 10.1149/1.3133169

[38] X. Chen, E. Pomerantseva, P. Banerjee, K. Gregorczyk, R. Ghodssi, G. Rubloff, Ozone-Based Atomic Layer Deposition of Crystalline V2O5 Films for High Performance Electrochemical Energy Storage, Chemistry of Materials 24 (2012) 1255-1261.

URL 10.1021/cm202901z

[39] A. Mantoux, J. C. Badot, N. Baffier, J. Farcy, J. P. Pereira-Ramos, D. Lincot, H. Groult, Structural and Electrochemical Properties of V2O5 Thin Films Obtained by Atomic Layer Chemical Vapor Deposition (ALCVD), 2002. URL 10.1007/978-94-010-0389-6 42

[40] R. Baddour-Hadjean, V. Golabkan, J. P. Pereira-Ramos, A. Mantoux, D. Lincot, A Raman study of 
the lithium insertion process in vanadium pentoxide thin films deposited by atomic layer deposition, Journal of Raman Spectroscopy 33 (2002) 631-638.

URL $10.1002 /$ jrs. 893

[41] H. Groult, E. Balnois, A. Mantoux, K. L. Van, D. Lincot, Two-dimensional recrystallisation processes of nanometric vanadium oxide thin films grown by atomic layer chemical vapor deposition (ALCVD) evidenced by AFM, Applied Surface Science 252 (2006) 5917-5925.

URL 10.1016/j.apsusc.2005.08.014

[42] J. C. Badot, A. Mantoux, N. Baffier, O. Dubrunfaut, D. Lincot, Submicro- and nanostructural eff ects on electrical properties of Li0.2V2O5 thin films obtained by atomic layer deposition (ALD), Journal of Physics and Chemistry of Solids 67 (2006) 1270-1274.

URL 10.1016/j.jpcs.2006.01.098

[43] K. L. Van, H. Groult, A. Mantoux, L. Perrigaud, F. Lantelme, R. Lindstrom, R. Badour-Hadjean, S. Zanna, D. Lincot, Amorphous vanadium oxide films synthesised by ALCVD for lithium rechargeable batteries, Journal of Power Sources 160 (2006) 592-601.

URL 10.1016/j.jpowsour.2006.01.049

[44] J. C. Badot, A. Mantoux, N. Baffier, O. Dubrunfaut, D. Lincot, Electrical properties of V2O5 thin films obtained by atomic layer deposition (ALD), Journal of Materials Chemistry 14 (2004) 3411-3415. URL 10.1039/b410324f

[45] G. Y. Song, C. Oh, S. Sinha, J. Son, J. Heo, Facile Phase Control of Multivalent Vanadium Oxide Thin Films (V2O5 and VO2) by Atomic Layer Deposition and Postdeposition Annealing, Acs Applied Materials \& Interfaces 9 (2017) 23909-23917.

URL 10.1021/acsami.7b03398

[46] A. M. Johnson, B. R. Quezada, L. D. Marks, P. C. Stair, Influence of the Metal Oxide Substrate Structure on Vanadium Oxide Monomer Formation, Topics in Catalysis 57 (2014) 177-187. URL 10.1007/s11244-013-0174-3

[47] I. E. Rauda, V. Augustyn, L. C. Saldarriaga-Lopez, X. Chen, L. T. Schelhas, G. W. Rubloff, B. Dunn, S. H. Tolbert, Nanostructured Pseudocapacitors Based on Atomic Layer Deposition of V2O5 onto Conductive Nanocrystal-based Mesoporous ITO Scaffolds, Advanced Functional Materials 24 (2014) 6717-6728.

URL 10.1002/adfm.201401284

[48] S. Fleischmann, A. Tolosa, M. Zeiger, B. Kruner, N. J. Peter, I. Grobelsek, A. Quade, A. Kruth, V. Presser, Vanadia-titania multilayer nanodecoration of carbon onions via atomic layer deposition for high performance electrochemical energy storage, Journal of Materials Chemistry A 5 (2017) 27922801

URL $10.1039 / \mathrm{c} 6$ ta09890h

[49] P. Banerjee, X. Y. Chen, K. Gregorczyk, L. Henn-Lecordier, G. W. Rubloff, Mixed mode, ionicelectronic diode using atomic layer deposition of $\mathrm{V} 2 \mathrm{O} 5$ and $\mathrm{ZnO}$ films, Journal of Materials Chemistry 21 (2011) 15391-15397.

URL $10.1039 / \mathrm{c} 1 \mathrm{jm} 12595 \mathrm{~h}$

[50] X. Chen, E. Pomerantseva, K. Gregorczyk, R. Ghodssi, G. Rubloff, Cathodic ALD V2O5 thin films for high-rate electrochemical energy storage, Rsc Advances 3 (2013) 4294-4302. URL $10.1039 / \mathrm{c} 3 \mathrm{ra} 23031 \mathrm{~g}$

[51] J. S. Daubert, N. P. Lewis, H. N. Gotsch, J. Z. Mundy, D. N. Monroe, E. C. Dickey, M. D. Losego, G. N. Parsons, Effect of Meso- and Micro-Porosity in Carbon Electrodes on Atomic Layer Deposition of Pseudocapacitive V2O5 for High Performance Supercapacitors, Chemistry of Materials 27 (2015) 6524-6534, internal-pdf://2459727014/daubert2015.pdf .

URL 10.1021/acs.chemmater.5b01602

[52] J. S. Daubert, R. C. Wang, J. S. Ovental, H. F. Barton, R. Rajagopalan, V. Augustyn, G. N. Parsons, Intrinsic limitations of atomic layer deposition for pseudocapacitive metal oxides in porous electrochemical capacitor electrodes, Journal of Materials Chemistry A 5 (2017) 13086-13097, internal-pdf: //3362911818/daubert2017.pdf . 
URL $10.1039 / \mathrm{c} 7 \mathrm{ta} 02719 \mathrm{~b}$

[53] S. Fleischmann, N. Jaeckel, M. Zeiger, B. Kruener, I. Grobelsek, P. Formanek, S. Choudhury, D. Weingarth, V. Presser, Enhanced Electrochemical Energy Storage by Nanoscopic Decoration of Endohedral and Exohedral Carbon with Vanadium Oxide via Atomic Layer Deposition, Chemistry of Materials 28 (2016) 2802-2813.

URL 10.1021/acs.chemmater.6b00738

[54] T. Singh, S. Wang, N. Aslam, H. Zhang, S. Hoffmann-Eifert, S. Mathur, Atomic Layer Deposition of Transparent VOx Thin Films for Resistive Switching Applications, Chemical Vapor Deposition 20 (2014) 291-297.

URL $10.1002 /$ cvde. 201407122

[55] X. Sun, C. Zhou, M. Xie, T. Hu, H. Sun, G. Xin, G. Wang, S. M. George, J. Lian, Amorphous vanadium oxide coating on graphene by atomic layer deposition for stable high energy lithium ion anodes, Chemical Communications 50 (2014) 10703-10706. URL $10.1039 / \mathrm{c} 4 \mathrm{cc} 04580 \mathrm{~g}$

[56] M. Xie, X. Sun, H. Sun, T. Porcelli, S. M. George, Y. Zhou, J. Lian, Stabilizing an amorphous $\mathrm{V} 2 \mathrm{O} 5 /$ carbon nanotube paper electrode with conformal $\mathrm{TiO} 2$ coating by atomic layer deposition for lithium ion batteries, Journal of Materials Chemistry A 4 (2016) 537-544.

URL $10.1039 / \mathrm{c} 5 \mathrm{ta} 01949 \mathrm{~d}$

[57] S. Fleischmann, D. Leistenschneider, V. Lemkova, B. Kruener, M. Zeiger, L. Borchardt, V. Presser, Tailored Mesoporous Carbon/Vanadium Pentoxide Hybrid Electrodes for High Power Pseudocapacitive Lithium and Sodium Intercalation, Chemistry of Materials 29 (2017) 8653-8662. URL 10.1021/acs.chemmater.7b02533

[58] B.-C. Kan, J.-H. Boo, I. Lee, F. Zaera, Thermal Chemistry of Tetrakis(ethylmethylamido)titanium on $\mathrm{Si}(100)$ Surfaces, Journal of Physical Chemistry A 113 (2009) 3946-3954. URL $10.1021 /$ jp8102172

[59] I. J. Raaijmakers, LOW-TEMPERATURE METAL-ORGANIC CHEMICAL-VAPOR-DEPOSITION OF ADVANCED BARRIER LAYERS FOR THE MICROELECTRONICS INDUSTRY, Thin Solid Films 247 (1994) 85-93. URL 10.1016/0040-6090(94)90479-0

[60] H. Park, B. Kim, S. H. Lee, H. Kim, Study of a Vanadium Precursor for VO2 Thin-Film Growth in the Atomic Layer Deposition Process by Multiscale Simulations, Journal of Physical Chemistry C 120 (2016) 28193-28203. URL 10.1021/acs.jpcc.6b06347

[61] D. C. Bradley, M. H. Chisholm, Transition-Metal Dialkylamides and Disilylamides, Accounts of Chemical Research 9 (1976) 273-280. URL 10.1021/ar50103a005

[62] D. C. Bradley, R. H. Moss, K. D. Sales, Electron spin resonance studies on quadrivalent vanadium compounds, Journal of the Chemical Society D: Chemical Communications (1969) 1255-1256. URL 10.1039/C29690001255

[63] T. Blanquart, J. Niinisto, M. Gavagnin, V. Longo, M. Heikkila, E. Puukilainen, V. R. Pallem, C. Dussarrat, M. Ritala, M. Leskela, Atomic layer deposition and characterization of vanadium oxide thin films, Rsc Advances 3 (2013) 1179-1185.

URL $10.1039 / \mathrm{c} 2 \mathrm{ra} 22820 \mathrm{c}$

[64] P. Bonnefond, R. Feurer, A. Reynes, F. Maury, B. Chansou, R. Choukroun, P. Cassoux, Thermal decomposition of $\mathrm{V}(\mathrm{NEt}(2))(4)$ in an MOCVD reactor: A low-temperature route to vanadium carbonitride coatings, Journal of Materials Chemistry 6 (1996) 1501-1506. URL 10.1039/jm9960601501

[65] F. Mattelaer, K. Geryl, G. Rampelberg, T. Dobbelaere, J. Dendooven, C. Detavernier, Atomic layer deposition of vanadium oxides for thin-film lithium-ion battery applications, Rsc Advances 6 (2016) $114658-114665$.

URL 10.1039/c6ra25742a 
[66] G. Rampelberg, D. Deduytsche, B. D. Schutter, P. A. Premkumar, M. Toeller, M. Schaekers, K. Martens, I. Radu, C. Detavernier, Crystallization and semiconductor-metal switching behavior of thin VO2 layers grown by atomic layer deposition, Thin Solid Films 550 (2014) 59-64. URL 10.1016/j.tsf.2013.10.039

[67] G. Rampelberg, M. Schaekers, K. Martens, Q. Xie, D. Deduytsche, B. D. Schutter, N. Blasco, J. Kittl, C. Detavernier, Semiconductor-metal transition in thin VO2 films grown by ozone based atomic layer deposition, Applied Physics Letters 98, internal-pdf://0744364709/2011-APL-Rampelberg-Semicond uctor-metaltransit.pdf . URL $10.1063 / 1.3579195$

[68] P. A. Premkumar, M. Toeller, I. P. Radu, C. Adelmann, M. Schaekers, J. Meersschaut, T. Conard, S. V. Elshocht, Process Study and Characterization of VO2 Thin Films Synthesized by ALD Using TEMAV and O-3 Precursors, Ecs Journal of Solid State Science and Technology 1 (2012) P169-P174. URL $10.1149 / 2.009204 \mathrm{jss}$

[69] A. P. Peter, K. Martens, G. Rampelberg, M. Toeller, J. M. Ablett, J. Meersschaut, D. Cuypers, A. Franquet, C. Detavernier, J.-P. Rueff, M. Schaekers, S. V. Elshocht, M. Jurczak, C. Adelmann, I. P. Radu, Metal-Insulator Transition in ALD VO2 Ultrathin Films and Nanoparticles: Morphological Control, Advanced Functional Materials 25 (2015) 679-686. URL 10.1002/adfm.201402687

[70] F. Cerbu, H. S. Chou, I. P. Radu, K. Martens, A. P. Peter, V. V. Afanasév, A. Stesmans, Band alignment and effective work function of atomic-layer deposited VO2 and V2O5 films on $\mathrm{SiO} 2$ and Al2O3, Physica Status Solidi C: Current Topics in Solid State Physics, Vol 12, No 1-2 12 (2015) $238-241$.

URL $10.1002 /$ pssc. 201400037

[71] M. J. Tadjer, V. D. Wheeler, B. P. Downey, Z. R. Robinson, D. J. Meyer, J. E. Charles R., F. J. Kub, Temperature and electric field induced metal-insulator transition in atomic layer deposited VO2 thin films, Solid-State Electronics 136 (2017) 30-35.

URL 10.1016/j.sse.2017.06.018

[72] B. P. Downey, V. D. Wheeler, D. J. Meyer, Localized phase change of VO2 films grown by atomic-layer deposition on InAlN/AlN/GaN heterostructures, Applied Physics Express 10. URL 10.7567/apex.10.061101

[73] M. Currie, M. A. Mastro, V. D. Wheeler, Characterizing the tunable refractive index of vanadium dioxide, Optical Materials Express 7 (2017) 1697-1707. URL 10.1364/ome.7.001697

[74] A. C. Kozen, H. Joress, M. Currie, V. R. Anderson, J. E. Charles R., V. D. Wheeler, Structural Characterization of Atomic Layer Deposited Vanadium Dioxide, Journal of Physical Chemistry C 121 (2017) 19341-19347.

URL 10.1021/acs.jpcc.7b04682

[75] M. Tangirala, K. Zhang, D. Nminibapiel, V. Pallem, C. Dussarrat, W. Cao, T. N. Adam, C. S. Johnson, H. E. Elsayed-Ali, H. Baumgart, Physical Analysis of VO2 Films Grown by Atomic Layer Deposition and RF Magnetron Sputtering, Ecs Journal of Solid State Science and Technology 3 (2014) N89-N94. URL $10.1149 / 2.006406 \mathrm{jss}$

[76] K. Zhang, M. Tangirala, D. Nminibapiel, W. Cao, V. Pallem, C. Dussarrat, H. Baumgart, Synthesis of VO2 thin Films by Atomic Layer Deposition with TEMAV as Precursor, Atomic Layer Deposition Applications 850 (2012) 175-182.

URL $10.1149 / 05013.0175$ ecst

[77] H. H. Park, T. J. Larrabee, L. B. Ruppalt, J. C. Culbertson, S. M. Prokes, Tunable Electrical Properties of Vanadium Oxide by Hydrogen-Plasma-Treated Atomic Layer Deposition, Acs Omega 2 (2017) $1259-1264$. URL 10.1021/acsomega.7b00059

[78] X. Wang, Z. Guo, Y. Gao, J. Wang, Atomic layer deposition of vanadium oxide thin films from tetrakis(dimethylamino)vanadium precursor, Journal of Materials Research 32 (2017) 37-44. 
URL 10.1557/jmr.2016.303

[79] Y. Gao, Y. Shao, L. Yan, H. Li, Y. Su, H. Meng, X. Wang, Efficient Charge Injection in Organic Field-Effect Transistors Enabled by Low-Temperature Atomic Layer Deposition of Ultrathin VOx Interlayer, Advanced Functional Materials 26 (2016) 4456-4463. URL 10.1002/adfm.201600482

[80] X. Lv, Y. Cao, L. Yan, Y. Li, L. Song, Atomic layer deposition of VO2 films with Tetrakis-dimethylamino vanadium (IV) as vanadium precursor, Applied Surface Science 396 (2017) 214-220. URL 10.1016/j.apsusc.2016.10.044

[81] B. S. Lim, A. Rahtu, J. S. Park, R. G. Gordon, Synthesis and characterization of volatile, thermally stable, reactive transition metal amidinates, Inorganic Chemistry 42 (2003) 7951-7958. URL $10.1021 /$ ic0345424

[82] R. G. Gordon, Introduction to ALD Precursors and Reaction Mechanisms, Proceedings of the AVS Atomic Layer Deposition Conference.

[83] M. S., K. I. Soo, G. Peijun, S. R. D., M. A. B. F., H. A. S. Weimer, Oxidation State Discrimination in the Atomic Layer Deposition of Vanadium Oxides, Chemistry of Materials 29 (2017) 6238-6244. URL 10.1021/acs.chemmater.7b01130

[84] R. F. McCarthy, M. S. Weimer, R. T. Haasch, R. D. Schaller, A. S. Hock, A. B. F. Martinson, VxIn(2$\mathrm{x})$ S3 Intermediate Band Absorbers Deposited by Atomic Layer Deposition, Chemistry of Materials 28 (2016) 2033-2040.

URL 10.1021/acs.chemmater.5b04402

[85] S. Passerini, J. J. Ressler, D. B. Le, B. B. Owens, W. H. Smyrl, High rate electrodes of V2O5 aerogel, Electrochimica Acta 44 (1999) 2209-2217. URL 10.1016/s0013-4686(98)00346-6

[86] D. B. Le, S. Passerini, J. Guo, J. Ressler, B. B. Owens, W. H. Smyrl, High surface area V2O5 aerogel intercalation electrodes, Journal of the Electrochemical Society 143 (1996) 2099-2104. URL 10.1149/1.1836965

[87] F. Mattelaer, K. Geryl, G. Rampelberg, J. Dendooven, C. Detavernier, Amorphous and Crystalline Vanadium Oxides as High-Energy and High-Power Cathodes for Three-Dimensional Thin-Film Lithium Ion Batteries, Acs Applied Materials \& Interfaces 9 (2017) 13121-13131. URL 10.1021/acsami.6b16473

[88] F. J. Morin, Oxides which show a metal-to-insulator transition at the neel temperature, Physical Review Letters 3 (1959) 34-36. URL 10.1103/PhysRevLett.3.34

[89] J. Musschoot, D. Deduytsche, R. L. V. Meirhaeghe, C. Detavernier, ALD of Vanadium Oxide, Atomic Layer Deposition Applications 525 (2009) 29-37. URL 10.1149/1.3205040

[90] R. Geert, B. D. Schutter, W. Devulder, M. Schaekers, K. Martens, C. Dussarrat, C. Detavernier, Semiconductor-metal Transition in ALD Deposited Vanadium Oxide Thin Films and Nanoparticles (2016).

[91] H. A. Wriedt, The O-V (Oxygen-Vanadium) System, Bulletin of Alloy Phase Diagrams 10 (1989) 271-277.

[92] Y.-B. Kang, Critical evaluation and thermodynamic optimization of the VO-VO2.5 system, Journal of the European Ceramic Society 32 (2012) 3187-3198. URL 10.1016/j.jeurceramsoc.2012.04.045

[93] G. Rampelberg, B. D. Schutter, W. Devulder, K. Martens, I. Radu, C. Detavernier, In situ X-ray diffraction study of the controlled oxidation and reduction in the V-O system for the synthesis of VO2 and V2O3 thin films, Journal of Materials Chemistry C 3 (2015) 11357-11365. URL $10.1039 / \mathrm{c} 5$ tc02553b

[94] X. Chen, H. Zhu, Y.-C. Chen, Y. Shang, A. Cao, L. Hu, G. W. Rubloff, MWCNT/V2O5 Core/Shell Sponge for High Areal Capacity and Power Density Li-Ion Cathodes, Acs Nano 6 (2012) 7948-7955, internal-pdf://1021881756/chen2012.pdf . 
URL $10.1021 / \mathrm{nn} 302417 \mathrm{x}$

[95] A. Pan, H. B. Wu, L. Yu, X. W. Lou, Template-Free Synthesis of VO2 Hollow Microspheres with Various Interiors and Their Conversion into V2O5 for Lithium-Ion Batteries, Angewandte ChemieInternational Edition 52 (2013) 2226-2230.

URL 10.1002/anie.201209535

[96] R. J. Cava, A. Santoro, D. W. Murphy, S. M. Zahurak, R. M. Fleming, P. Marsh, R. S. Roth, THE STRUCTURE OF THE LITHIUM-INSERTED METAL-OXIDE DELTA-LIV2O5, Journal of Solid State Chemistry 65 (1986) 63-71.

URL 10.1016/0022-4596(86)90089-7

[97] X.-F. Zhang, K.-X. Wang, X. Wei, J.-S. Chen, Carbon-Coated V2O5 Nanocrystals as High Performance Cathode Material for Lithium Ion Batteries, Chemistry of Materials 23 (2011) 5290-5292. URL $10.1021 / \mathrm{cm} 202812 \mathrm{z}$

[98] Z. Chen, V. Augustyn, J. Wen, Y. Zhang, M. Shen, B. Dunn, Y. Lu, High-Performance Supercapacitors Based on Intertwined CNT/V2O5 Nanowire Nanocomposites, Advanced Materials 23 (2011) 791-+. URL 10.1002/adma.201003658

[99] B. Yan, X. Li, Z. Bai, Y. Zhao, L. Dong, X. Song, D. Li, C. Langford, X. Sun, Crumpled reduced graphene oxide conformally encapsulated hollow V2O5 nano/microsphere achieving brilliant lithium storage performance, Nano Energy 24 (2016) 32-44.

URL 10.1016/j.nanoen.2016.04.002

[100] S. Guan, Y. Wei, J. Zhou, J. Zheng, C. Xu, A Method for Preparing Manganese-Doped V2O5 Films with Enhanced Cycling Stability, Journal of the Electrochemical Society 163 (2016) H541-H545. URL 10.1149/2.0761607jes

[101] C. Liu, N. Kim, G. W. Rubloff, S. B. Lee, High performance asymmetric V2O5-SnO2 nanopore battery by atomic layer deposition, Nanoscale 9 (2017) 11566-11573. URL $10.1039 / \mathrm{c} 7 \mathrm{nr} 02151 \mathrm{~h}$

[102] R. Carter, L. Oakes, N. Muralidharan, A. P. Cohn, A. Douglas, C. L. Pint, Polysulfide Anchoring Mechanism Revealed by Atomic Layer Deposition of V2O5 and Sulfur-Filled Carbon Nanotubes for Lithium-Sulfur Batteries, Acs Applied Materials \& Interfaces 9 (2017) 7185-7192. URL 10.1021/acsami.6b16155

[103] J. M. Tarascon, M. Armand, Issues and challenges facing rechargeable lithium batteries, Nature 414 (2001) 359-367.

URL $10.1038 / 35104644$

[104] M. Armand, J. M. Tarascon, Building better batteries, Nature 451 (2008) 652-657. URL 10.1038/451652a

[105] Y.-M. Chiang, Building a Better Battery, Science 330 (2010) 1485-1486. URL 10.1126/science.1198591

[106] J. B. Goodenough, Y. Kim, Challenges for Rechargeable Li Batteries, Chemistry of Materials 22 (2010) 587-603. URL 10.1021/cm901452z

[107] P. G. Bruce, S. A. Freunberger, L. J. Hardwick, J.-M. Tarascon, Li-O-2 and Li-S batteries with high energy storage, Nature Materials 11 (2012) 19-29.

URL 10.1038/nmat3191

[108] B. J. Landi, M. J. Ganter, C. D. Cress, R. A. DiLeo, R. P. Raffaelle, Carbon nanotubes for lithium ion batteries, Energy \& Environmental Science 2 (2009) 638-654. URL $10.1039 /$ b904116h

[109] A. Pearse, T. Schmitt, E. Sahadeo, D. M. Stewart, A. Kozen, K. Gerasopoulos, A. A. Talin, S. B. Lee, G. W. Rubloff, K. E. Gregorczyk, Three-Dimensional Solid-State Lithium-Ion Batteries Fabricated by Conformal Vapor-Phase Chemistry, Acs Nano 12 (2018) 4286-4294. URL 10.1021/acsnano.7b08751

[110] H. Xia, Z. Luo, J. Xie, Nanostructured LiMn2O4 and their composites as high-performance cathodes for lithium-ion batteries, Progress in Natural Science-Materials International 22 (2012) 572-584. 
URL 10.1016/j.pnsc.2012.11.014

[111] L.-H. Hu, F.-Y. Wu, C.-T. Lin, A. N. Khlobystov, L.-J. Li, Graphene-modified LiFePO4 cathode for lithium ion battery beyond theoretical capacity, Nature Communications 4.

URL $10.1038 /$ ncomms2705

[112] X. Dai, A. Zhou, J. Xu, Y. Lu, L. Wang, C. Fan, J. Li, Extending the High-Voltage Capacity of LiCoO2 Cathode by Direct Coating of the Composite Electrode with Li2CO3 via Magnetron Sputtering, Journal of Physical Chemistry C 120 (2016) 422-430.

URL 10.1021/acs.jpcc.5b10677

[113] S. Zhou, X. G. Yang, Y. J. Lin, J. Xie, D. W. Wang, A Nanonet-Enabled Li Ion Battery Cathode Material with High Power Rate, High Capacity, and Long Cycle Lifetime, Acs Nano 6 (2012) 919-924. URL 10.1021/nn204479n

[114] K. West, B. Zachauchristiansen, M. J. L. Ostergard, T. Jacobsen, VANADIUM-OXIDES AS ELECTRODE MATERIALS FOR RECHARGEABLE LITHIUM CELLS, Journal of Power Sources 20 (1987) $165-172$.

URL 10.1016/0378-7753(87)80107-6

[115] C. Delmas, H. Cognacauradou, J. M. Cocciantelli, M. Menetrier, J. P. Doumerc, THE LIXV2O5 SYSTEM - AN OVERVIEW OF THE STRUCTURE MODIFICATIONS INDUCED BY THE LITHIUM INTERCALATION, Solid State Ionics 69 (1994) 257-264.

URL 10.1016/0167-2738(94)90414-6

[116] C. Leger, S. Bach, P. Soudan, J. P. Pereira-Ramos, Structural and electrochemical properties of omega$\mathrm{Li}(\mathrm{x}) \mathrm{V}(2) \mathrm{O}(5)(0.4<=\mathrm{x}<=3)$ as rechargeable cathodic material for lithium batteries, Journal of the Electrochemical Society 152 (2005) A236-A241.

URL 10.1149/1.1836155

[117] J.-Y. Luo, W.-J. Cui, P. He, Y.-Y. Xia, Raising the cycling stability of aqueous lithium-ion batteries by eliminating oxygen in the electrolyte, Nature Chemistry 2 (2010) 760-765.

URL 10.1038/nchem.763

[118] N. A. Chernova, M. Roppolo, A. C. Dillon, M. S. Whittingham, Layered vanadium and molybdenum oxides: batteries and electrochromics, Journal of Materials Chemistry 19 (2009) 2526-2552.

URL $10.1039 / \mathrm{b} 819629 \mathrm{j}$

[119] M. Kurttepeli, S. Deng, F. Mattelaer, D. J. Cott, P. Vereecken, J. Dendooven, C. Detavernier, S. Bals, Heterogeneous TiO2/V2O5/Carbon Nanotube Electrodes for Lithium Ion Batteries, Acs Applied Materials \& Interfaces 9 (2017) 8055-8064.

URL 10.1021/acsami.6b12759

[120] A. Gonzalez, E. Goikolea, J. A. Barrena, R. Mysyk, Review on supercapacitors: Technologies and materials, Renewable \& Sustainable Energy Reviews 58 (2016) 1189-1206. URL 10.1016/j.rser.2015.12.249

[121] S. Boukhalfa, K. Evanoff, G. Yushin, Atomic layer deposition of vanadium oxide on carbon nanotubes for high-power supercapacitor electrodes, Energ Environ Sci 2012 (5) 6872-6879.

[122] M. Ritala, Atomic Layer Deposition of Oxide Thin Films with Metal Alkoxides as Oxygen Sources, Science 288 (5464) (2000) 319-321. doi:10.1126/science.288.5464.319.

[123] R. Chau, B. Doyle, S. Datta, J. Kavalieros, K. Zhang, Integrated nanoelectronics for the future, Nature Materials 6 (11) (2007) 810-812. doi:10.1038/nmat2014.

[124] D.-H. Kwon, K. M. Kim, J. H. Jang, J. M. Jeon, M. H. Lee, G. H. Kim, X.-S. Li, G.-S. Park, B. Lee, S. Han, M. Kim, C. S. Hwang, Atomic structure of conducting nanofilaments in TiO2 resistive switching memory, Nature Nanotechnology 5 (2) (2010) 148-153. doi:10.1038/nnano.2009.456.

[125] A. Javey, H. Kim, M. Brink, Q. Wang, A. Ural, J. Guo, P. McIntyre, P. McEuen, M. Lundstrom, H. Dai, High- $\kappa$ dielectrics for advanced carbon-nanotube transistors and logic gates, Nature Materials 1 (4) (2002) 241-246. doi:10.1038/nmat769.

[126] C. Ko, S. Ramanathan, Observation of electric field-assisted phase transition in thin film vanadium oxide in a metal-oxide-semiconductor device geometry, Applied Physics Letters 93 (25) (2008) 252101. doi:10.1063/1.3050464. 
[127] H.-T. Kim, B.-G. Chae, D.-H. Youn, S.-L. Maeng, G. Kim, K.-Y. Kang, Y.-S. Lim, Mechanism and observation of Mott transition in VO 2 -based two- and three-terminal devices, New Journal of Physics 6 (2004) 52. doi:10.1088/1367-2630/6/1/052.

[128] G. Gopalakrishnan, D. Ruzmetov, S. Ramanathan, On the triggering mechanism for the metal-insulator transition in thin film VO2 devices: electric field versus thermal effects, Journal of Materials Science 44 (19) (2009) 5345-5353. doi:10.1007/s10853-009-3442-7.

[129] Z. Yang, S. Hart, C. Ko, A. Yacoby, S. Ramanathan, Studies on electric triggering of the metalinsulator transition in VO 2 thin films between $77 \mathrm{~K}$ and $300 \mathrm{~K}$, Journal of Applied Physics 110 (3) (2011) 33725. doi:10.1063/1.3619806.

[130] G. Stefanovich, A. Pergament, D. Stefanovich, Electrical switching and Mott transition in VO 2, Journal of Physics: Condensed Matter 12 (41) (2000) 8837-8845. doi:10.1088/0953-8984/12/41/310.

[131] J. Leroy, A. Crunteanu, A. Bessaudou, F. Cosset, C. Champeaux, J.-C. Orlianges, High-speed metalinsulator transition in vanadium dioxide films induced by an electrical pulsed voltage over nano-gap electrodes, Applied Physics Letters 100 (21) (2012) 213507. doi:10.1063/1.4721520.

[132] Y. Zhang, S. Ramanathan, Analysis of "on" and "off" times for thermally driven VO2 metalinsulator transition nanoscale switching devices, Solid-State Electronics 62 (1) (2011) 161-164. doi:10.1016/j.sse.2011.04.003.

[133] A. Joushaghani, J. Jeong, S. Paradis, D. Alain, J. Stewart Aitchison, J. K. S. Poon, Voltage-controlled switching and thermal effects in VO 2 nano-gap junctions, Applied Physics Letters 104 (22) (2014) 221904. doi:10.1063/1.4881155.

[134] T. S. Jordan, S. Scott, D. Leonhardt, J. O. Custer, C. T. Rodenbeck, S. Wolfley, C. D. Nordquist, Model and Characterization of $\mathrm{VO}_{2}$ Thin-Film Switching Devices, IEEE Transactions on Electron Devices 61 (3) (2014) 813-819. doi:10.1109/TED.2014.2299549.

[135] A. Zimmers, L. Aigouy, M. Mortier, A. Sharoni, S. Wang, K. G. West, J. G. Ramirez, I. K. Schuller, Role of Thermal Heating on the Voltage Induced Insulator-Metal Transition in VO 2, Physical Review Letters 110 (5). doi:10.1103/PhysRevLett.110.056601.

[136] S. Kumar, M. D. Pickett, J. P. Strachan, G. Gibson, Y. Nishi, R. S. Williams, Local Temperature Redistribution and Structural Transition During Joule-Heating-Driven Conductance Switching in VO 2, Advanced Materials 25 (42) (2013) 6128-6132. doi:10.1002/adma.201302046.

[137] E. Freeman, G. Stone, N. Shukla, H. Paik, J. A. Moyer, Z. Cai, H. Wen, R. Engel-Herbert, D. G. Schlom, V. Gopalan, S. Datta, Nanoscale structural evolution of electrically driven insulator to metal transition in vanadium dioxide, Applied Physics Letters 103 (26) (2013) 263109. doi:10.1063/1.4858468.

[138] D. Li, A. A. Sharma, D. K. Gala, N. Shukla, H. Paik, S. Datta, D. G. Schlom, J. A. Bain, M. Skowronski, Joule Heating-Induced Metal-Insulator Transition in Epitaxial VO 2 /TiO 2 Devices, Acs Applied Materials \& Interfaces 8 (20) (2016) 12908-12914. doi:10.1021/acsami.6b03501.

[139] M. A. Belyaev, P. P. Boriskov, A. A. Velichko, A. L. Pergament, V. V. Putrolainen, D. V. Ryabokon', G. B. Stefanovich, V. I. Sysun, S. D. Khanin, Switching Channel Development Dynamics in Planar Structures on the Basis of Vanadium Dioxide, Physics of the Solid State 60 (3) (2018) 447-456. doi:10.1134/S1063783418030046.

[140] I. P. Radu, B. Govoreanu, S. Mertens, X. Shi, M. Cantoro, M. Schaekers, M. Jurczak, S. De Gendt, A. Stesmans, J. A. Kittl, M. Heyns, K. Martens, Switching mechanism in two-terminal vanadium dioxide devices, Nanotechnology 26 (16) (2015) 165202. doi:10.1088/0957-4484/26/16/165202.

[141] M. J. Tadjer, V. D. Wheeler, B. P. Downey, Z. R. Robinson, D. J. Meyer, C. R. Eddy, F. J. Kub, Temperature and electric field induced metal-insulator transition in atomic layer deposited vo2 thin films, Solid-State Electronics 136 (2017) 30 - 35, selected Papers from ISDRS 2016. doi:https://doi.org/10.1016/j.sse.2017.06.018.

URL http://www.sciencedirect.com/science/article/pii/S0038110117304264

[142] J. C. Duchene, M. M. Terraillon, M. Pailly, G. B. Adam, Initiation of switching in VO 2 coplanar devices, IEEE Transactions on Electron Devices 18 (12) (1971) 1151-1155. doi:10.1109/TED.1971.17347. 
[143] D. Ruzmetov, G. Gopalakrishnan, C. Ko, V. Narayanamurti, S. Ramanathan, Three-terminal field effect devices utilizing thin film vanadium oxide as the channel layer, Journal of Applied Physics 107 (11) (2010) 114516. doi:10.1063/1.3408899.

[144] H. Ji, J. Wei, D. Natelson, Modulation of the Electrical Properties of VO 2 Nanobeams Using an Ionic Liquid as a Gating Medium, Nano Letters 12 (6) (2012) 2988-2992. doi:10.1021/nl300741h.

[145] M. Nakano, K. Shibuya, D. Okuyama, T. Hatano, S. Ono, M. Kawasaki, Y. Iwasa, Y. Tokura, Collective bulk carrier delocalization driven by electrostatic surface charge accumulation, Nature 487 (2012) 459.

URL https://doi.org/10.1038/nature11296http://10.0.4.14/nature11296https://www.nature.com/ articles/nature11296\{\\#\}supplementary-information

[146] J. Jeong, N. Aetukuri, T. Graf, T. D. Schladt, M. G. Samant, S. S. P. Parkin, Suppression of MetalInsulator Transition in VO2 by Electric Field-Induced Oxygen Vacancy Formation, Science 339 (6126) (2013) 1402-1405. doi:10.1126/science.1230512.

[147] M. A. Belyaev, V. V. Putrolaynen, A. A. Velichko, G. B. Stefanovich, A. L. Pergament, Field-effect modulation of resistance in VO 2 thin film at lower temperature, Japanese Journal of Applied Physics 53 (11) (2014) 111102. doi:10.7567/JJAP.53.111102.

[148] K. Martens, J. Jeong, N. Aetukuri, C. Rettner, N. Shukla, E. Freeman, D. Esfahani, F. Peeters, T. Topuria, P. Rice, A. Volodin, B. Douhard, W. Vandervorst, M. Samant, S. Datta, S. Parkin, Field Effect and Strongly Localized Carriers in the Metal-Insulator Transition Material VO 2, Physical Review Letters 115 (19). doi:10.1103/PhysRevLett.115.196401.

[149] T. Yajima, T. Nishimura, A. Toriumi, Positive-bias gate-controlled metal-insulator transition in ultrathin VO2 channels with $\mathrm{TiO} 2$ gate dielectrics, Nature Communications 6 (1). doi:10.1038/ncomms10104.

[150] T. Wei, T. Kanki, M. Chikanari, T. Uemura, T. Sekitani, H. Tanaka, Enhanced electronic-transport modulation in single-crystalline VO2 nanowire-based solid-state field-effect transistors, Scientific Reports 7 (1). doi:10.1038/s41598-017-17468-x.

[151] M.-J. Lee, Y. Park, D.-S. Suh, E.-H. Lee, S. Seo, D.-C. Kim, R. Jung, B.-S. Kang, S.-E. Ahn, C. Lee, D. Seo, Y.-K. Cha, I.-K. Yoo, J.-S. Kim, B. Park, Two Series Oxide Resistors Applicable to High Speed and High Density Nonvolatile Memory, Advanced Materials 19 (22) (2007) 3919-3923. doi:10.1002/adma.200700251.

[152] C.-R. Cho, S. Cho, S. Vadim, R. Jung, I. Yoo, Current-induced metal-insulator transition in VOx thin film prepared by rapid-thermal-annealing, Thin Solid Films 495 (1-2) (2006) 375-379. doi:10.1016/j.tsf.2005.08.241.

[153] M. Son, J. Lee, J. Park, J. Shin, G. Choi, S. Jung, W. Lee, S. Kim, S. Park, H. Hwang, Excellent Selector Characteristics of Nanoscale $\mathrm{VO}_{2}$ for High-Density Bipolar ReRAM Applications, Ieee Electron Device Letters 32 (11) (2011) 1579-1581. doi:10.1109/LED.2011.2163697.

[154] K. Martens, I. P. Radu, S. Mertens, X. Shi, L. Nyns, S. Cosemans, P. Favia, H. Bender, T. Conard, M. Schaekers, S. De Gendt, V. Afanas'ev, J. A. Kittl, M. Heyns, M. Jurczak, The VO 2 interface, the metal-insulator transition tunnel junction, and the metal-insulator transition switch On-Off resistance, Journal of Applied Physics 112 (12) (2012) 124501. doi:10.1063/1.4767473.

[155] I. P. Radu, B. Govoreanu, K. Martens, M. Toeller, A. P. Peter, M. R. Ikram, L. Q. Zhang, H. Hody, W. Kim, P. Favia, T. Conard, H. Y. Chou, B. Put, V. V. Afanasiev, A. Stesmans, M. Heyns, S. De Gendt, M. Jurczak, (Invited) Vanadium Dioxide for Selector Applications, ECS Transactions 58 (7) (2013) 249-258. doi:10.1149/05807.0249ecst.

[156] A. Crunteanu, J. Givernaud, J. Leroy, D. Mardivirin, C. Champeaux, J.-C. Orlianges, A. Catherinot, P. Blondy, Voltage- and current-activated metal-insulator transition in VO 2 -based electrical switches: a lifetime operation analysis, Science and Technology of Advanced Materials 11 (6) (2010) 65002. doi:10.1088/1468-6996/11/6/065002.

[157] C. Hillman, P. A. Stupar, Z. Griffith, VO2 Switches for Millimeter and Submillimeter-Wave Applications, in: 2015 IEEE Compound Semiconductor Integrated Circuit Symposium (CSICS), IEEE, 2015, pp. 1-4. doi:10.1109/CSICS.2015.7314528. 
[158] H. Madan, H.-T. Zhang, M. Jerry, D. Mukherjee, N. Alem, R. Engel-Herbert, S. Datta, 26.5 Terahertz electrically triggered RF switch on epitaxial VO2-on-Sapphire (VOS) wafer, in: 2015 Ieee International Electron Devices Meeting (Iedm), IEEE, 2015, pp. 9.3.1-9.3.4. doi:10.1109/IEDM.2015.7409661.

[159] J. Frougier, N. Shukla, D. Deng, M. Jerry, A. Aziz, L. Liu, G. Lavallee, T. S. Mayer, S. Gupta, S. Datta, Phase-Transition-FET exhibiting steep switching slope of $8 \mathrm{mV} /$ decade and $36 \%$ enhanced ON current, in: 2016 IEEE Symposium on VLSI Technology, IEEE, 2016, pp. 1-2. doi:10.1109/VLSIT.2016.7573445.

[160] S. Datta, N. Shukla, M. Cotter, A. Parihar, A. Raychowdhury, Neuro Inspired Computing with Coupled Relaxation Oscillators, in: the The 51st Annual Design Automation Conference, ACM Press, 2014, pp. 1-6. doi: $10.1145 / 2593069.2596685$.

[161] N. Shukla, A. Parihar, E. Freeman, H. Paik, G. Stone, V. Narayanan, H. Wen, Z. Cai, V. Gopalan, R. Engel-Herbert, D. G. Schlom, A. Raychowdhury, S. Datta, Synchronized charge oscillations in correlated electron systems, Scientific Reports 4 (1). doi:10.1038/srep04964.

[162] J. D. Ryckman, K. A. Hallman, R. E. Marvel, R. F. Haglund, S. M. Weiss, Ultra-compact silicon photonic devices reconfigured by an optically induced semiconductor-to-metal transition, Optics Express 21 (9) (2013) 10753. doi:10.1364/OE.21.010753.

[163] J. D. Ryckman, V. Diez-Blanco, J. Nag, R. E. Marvel, B. K. Choi, R. F. Haglund, S. M. Weiss, Photothermal optical modulation of ultra-compact hybrid Si-VO_2 ring resonators, Optics Express 20 (12) (2012) 13215. doi:10.1364/OE.20.013215.

[164] P. Markov, K. Appavoo, R. F. Haglund, S. M. Weiss, Hybrid Si-VO_2-Au optical modulator based on near-field plasmonic coupling, Optics Express 23 (5) (2015) 6878. doi:10.1364/OE.23.006878.

[165] A. B. Pevtsov, D. A. Kurdyukov, V. G. Golubev, A. V. Akimov, A. A. Meluchev, A. V. Sel'kin, A. A. Kaplyanskii, D. R. Yakovlev, M. Bayer, Ultrafast stop band kinetics in a three-dimensional opal- V O 2 photonic crystal controlled by a photoinduced semiconductor-metal phase transition, Physical Review B 75 (15). doi:10.1103/PhysRevB.75.153101.

[166] R. M. Briggs, I. M. Pryce, H. A. Atwater, Compact silicon photonic waveguide modulator based on the vanadium dioxide metal-insulator phase transition, Optics Express 18 (11) (2010) 11192. doi:10.1364/OE.18.011192.

[167] M. Maaza, O. Nemraoui, C. Sella, A. C. Beye, B. Baruch-Barak, Thermal induced tunability of surface plasmon resonance in Au-VO2 nano-photonics, Optics Communications 254 (1-3) (2005) 188-195. doi:10.1016/j.optcom.2004.08.056.

[168] L. A. Sweatlock, K. Diest, Vanadium dioxide based plasmonic modulators, Optics Express 20 (8) (2012) 8700. doi:10.1364/OE.20.008700.

[169] Y.-G. Jeong, H. Bernien, J.-S. Kyoung, H.-R. Park, H. Kim, J.-W. Choi, B.-J. Kim, H.-T. Kim, K. J. Ahn, D.-S. Kim, Electrical control of terahertz nano antennas on VO_2 thin film, Optics Express 19 (22) (2011) 21211. doi:10.1364/OE.19.021211.

[170] M. Seo, J. Kyoung, H. Park, S. Koo, H.-s. Kim, H. Bernien, B. J. Kim, J. H. Choe, Y. H. Ahn, H.-T. Kim, N. Park, Q.-H. Park, K. Ahn, D.-s. Kim, Active Terahertz Nanoantennas Based on VO 2 Phase Transition, Nano Letters 10 (6) (2010) 2064-2068. doi:10.1021/nl1002153.

[171] Y. Zhao, J. Hwan Lee, Y. Zhu, M. Nazari, C. Chen, H. Wang, A. Bernussi, M. Holtz, Z. Fan, Structural, electrical, and terahertz transmission properties of VO 2 thin films grown on c-, r-, and m-plane sapphire substrates, Journal of Applied Physics 111 (5) (2012) 53533. doi:10.1063/1.3692391.

[172] M. Liu, H. Y. Hwang, H. Tao, A. C. Strikwerda, K. Fan, G. R. Keiser, A. J. Sternbach, K. G. West, S. Kittiwatanakul, J. Lu, S. A. Wolf, F. G. Omenetto, X. Zhang, K. A. Nelson, R. D. Averitt, Terahertz-field-induced insulator-to-metal transition in vanadium dioxide metamaterial, Nature 487 (7407) (2012) 345-348. doi:10.1038/nature11231.

[173] M. J. Dicken, K. Aydin, I. M. Pryce, L. A. Sweatlock, E. M. Boyd, S. Walavalkar, J. Ma, H. A. Atwater, Frequency tunable near-infrared metamaterials based on VO_2 phase transition, Optics Express 17 (20) (2009) 18330. doi:10.1364/OE.17.018330.

[174] M. D. Goldflam, T. Driscoll, B. Chapler, O. Khatib, N. Marie Jokerst, S. Palit, D. R. Smith, B.-J. Kim, G. Seo, H.-T. Kim, M. D. Ventra, D. N. Basov, Reconfigurable gradient index using VO 2 
memory metamaterials, Applied Physics Letters 99 (4) (2011) 44103. doi:10.1063/1.3615804.

[176] J. H. Park, J. M. Coy, T. S. Kasirga, C. Huang, Z. Fei, S. Hunter, D. H. Cobden, Measurement of a solid-state triple point at the metal-insulator transition in VO2, Nature 500 (7463) (2013) 431-434. doi:10.1038/nature12425.

[177] B. G. Chae, H. T. Kim, S. J. Yun, Characteristics of W- and Ti-Doped VO[sub 2] Thin Films Prepared by Sol-Gel Method, Electrochemical and Solid-State Letters 11 (6) (2008) D53. doi:10.1149/1.2903208.

[178] F. Beteille, J. Livage, Optical switching in VO2 thin films, Journal of Sol-Gel Science and Technology 13 (1-3) (1998) 915-921.

[179] I. P. Radu, K. Martens, S. Mertens, C. Adelmann, X. Shi, H. Tielens, M. Schaekers, G. Pourtois, S. Van Elshocht, S. De Gendt, M. Heyns, J. A. Kittl, (Invited) Vanadium Oxide as a Memory Material, in: 219th ECS Meeting, 2011, pp. 233-243. doi:10.1149/1.3568865.

[180] AM1.5 spectra, According to the AM1.5 standard available online from NREL the relative division of energy between the different spectral bands of the solar radiation is; UV $(<400 \mathrm{~nm})=0.7 \%$, Vis $(400 \mathrm{~nm}-700 \mathrm{~nm})=48.3 \%$, NIR $(>700 \mathrm{~nm})=51 \%$. .

URL https://www.nrel.gov/grid/solar-resource/spectra-am1.5.html

[181] M. Saeli, C. Piccirillo, I. P. Parkin, R. Binions, I. Ridley, Energy modelling studies of thermochromic glazing,, Energy Build 42 (10) (2010) 1666-1673.

[182] S.-Y. L. . G. A. Niklasson, C. G. Granqvist, Thermochromic vanadium oxide thin films: Electronic and optical properties,, J. Phys. Conf. Ser 559 (2014) 012001.

[183] S. Li, G. A. Niklasson, C. G. Granqvist, Nanothermochromics with VO2-based core-shell structures : Calculated luminous and Nanothermochromics with VO 2 -based core-shell structures : Calculated luminous and solar optical properties 113515 (2011) (2014) 1-6. doi:10.1063/1.3592350.

[184] H. W. Verleur, A. S. Barker, C. N. Berglund, Optical Properties of VO2 between 0.25 and $5 \mathrm{eV}$, Physical Review 172 (1968) 788-798.

[185] H. Kakiuchida, P. Jin, S. Nakao, M. Tazawa, Optical properties of vanadium dioxide film during semiconductive-metallic phase transition, Japanese Journal of Applied Physics, Part 2: Letters 46 (47) (2007) 113-116. doi:10.1143/JJAP.46.L113.

[186] Thermochromic VO2-SiO2 Nanocomposite Smart Window Coatings with Narrow Phase Transition Hysteresis and Transition Gradient Widthsubmitted Sol. Energy Mater. Sol. Cells .

[187] C. Sol, J. Schläfer, I. P. Parkin, I. Papakonstantinou, Mitigation of hysteresis due to a pseudophotochromic effect in thermochromic smart window coatings, Scientific Reports 8 (1) (2018) 13249. doi:10.1038/s41598-018-31519-x.

URL http://www.nature.com/articles/s41598-018-31519-x

[188] Xiao, C. Yunzhen, Y. Chao, Y. Lu, L. Y. Wang, Vanadium dioxide film protected with an atomiclayer-deposited $\mathrm{Al}<$ sub $>2</$ sub $>\mathrm{O}<$ sub $>3</$ sub $>$ thin film, Journal of Vacuum Science \& Technology A: Vacuum, Surfaces, and Films 34 (2016) 01A106.

URL 10.1116/1.4931723

[189] G. T. Pan, Y. L. Yang, S. Chong, N. Arjun, T. C. Yang, Y. C. Lai, The durability study of thermochromic vanadium dioxide films with the addition of barrier coatings, Vacuum 145 (2017) 158-168. doi:10.1016/j.vacuum.2017.08.028.

URL https://doi.org/10.1016/j.vacuum.2017.08.028

[190] Y. Cui, Y. Ke, C. Liu, Z. Chen, N. Wang, L. Zhang, Y. Zhou, S. Wang, Y. Gao, Y. Long, Thermochromic VO 2 for Energy-Efficient Smart Windows, Joule (2018) 140doi:10.1016/j.joule.2018.06.018.

URL https://linkinghub.elsevier.com/retrieve/pii/S2542435118302836

[191] R. Binions, G. Hyett, C. Piccirillo, I. P. Parkin, Doped and un-doped vanadium dioxide thin films prepared by atmospheric pressure chemical vapour deposition from vanadyl acetylacetonate and tungsten hexachloride: The effects of thickness and crystallographic orientation on thermochromic properties, Journal of Materials Chemistry 17 (44) (2007) 4652-4660. doi:10.1039/b708856f.

[192] S.-y. Li, G. A. Niklasson, C. G. Granqvist, Thermochromic undoped and Mg-doped VO2 thin films and 
nanoparticles : Optical properties and performance limits for energy efficient windows Thermochromic undoped and Mg-doped VO 2 thin films and nanoparticles : Optical properties and performance limits f 053513. doi:10.1063/1.4862930.

[193] Y. Geng, L. Guo, S.-S. Xu, Q.-Q. Sun, S.-J. Ding, H.-L. Lu, D. W. Zhang, Influence of Al Doping on the Properties of ZnO Thin Films Grown by Atomic Layer Deposition, The Journal of Physical Chemistry C 115 (25) (2011) 12317-12321. doi:10.1021/jp2023567. URL https://doi.org/10.1021/jp2023567

[194] X. Lv, Y. Cao, L. Yan, Y. Li, Y. Zhang, L. Song, Atomic Layer Deposition of V <sub $>1-$ $<\mathrm{i}>\mathrm{x}</ \mathrm{i}></$ sub $>$ Mo $<$ sub $><\mathrm{i}>\mathrm{x}</ \mathrm{i}></$ sub $>\mathrm{O}<$ sub $>2</$ sub $>$ Thin Films, Largely Enhanced Luminous Transmittance, Solar Modulation, ACS Applied Materials \& Interfaces (2018) acsami.7b16479doi:10.1021/acsami.7b16479.

[195] A. Taylor, I. Parkin, N. Noor, C. Tummeltshammer, M. S. Brown, I. Papakonstantinou, A bioinspired solution for spectrally selective thermochromic VO2 coated intelligent glazing., Optics express 21 Suppl 5 (May) (2013) A750-64. doi:10.1364/OE.21.00A750.

URL http://www.ncbi.nlm.nih.gov/pubmed/24104571

[196] X. Qian, N. Wang, Y. Li, J. Zhang, Z. Xu, Y. Long, Bioinspired multifunctional vanadium dioxide: Improved thermochromism and hydrophobicity, Langmuir 30 (35) (2014) 10766-10771. doi:10.1021/la502787q.

[197] N. R. Mlyuka, G. a. Niklasson, C. G. Granqvist, Thermochromic multilayer films of VO2 and TiO2 with enhanced transmittance, Solar Energy Materials and Solar Cells 93 (9) (2009) 1685-1687. doi:10.1016/j.solmat.2009.03.021.

URL http://dx.doi.org/10.1016/j.solmat.2009.03.021

[198] C. Liu, S. Wang, Y. Zhou, H. Yang, Q. Lu, D. Mandler, S. Magdassi, C. Y. Tay, Y. Long, Index-tunable anti-reflection coatings: Maximizing solar modulation ability for vanadium dioxidebased smart thermochromic glazing, Journal of Alloys and Compounds 731 (2018) 1197-1207. doi:10.1016/j.jallcom.2017.10.045.

[199] M. J. Powell, R. Quesada-Cabrera, A. Taylor, D. Teixeira, I. Papakonstantinou, R. G. Palgrave, G. Sankar, I. P. Parkin, Intelligent Multifunctional VO2/SiO2/TiO2 Coatings for SelfCleaning, Energy-Saving Window Panels, Chemistry of Materials 28 (5) (2016) 1369-1376. doi:10.1021/acs.chemmater.5b04419.

URL http://dx.doi.org/10.1021/acs.chemmater.5b04419

[200] Y. Fink, J. Winn, S. Fan, C. Chen, A dielectric omnidirectional reflector, Science 1679 (1998). doi:10.1126/science.282.5394.1679.

URL http://www.sciencemag.org/content/282/5394/1679.short

[201] A. Szeghalmi, M. Helgert, R. Brunner, F. Heyroth, U. Gösele, M. Knez, Atomic layer deposition of $\mathrm{Al} \_2 \mathrm{O} \_3$ and $\mathrm{TiO} \_2$ multilayers for applications as bandpass filters and antireflection coatings, Applièd Optics 48 (9) (2009) 1727. doi:10.1364/AO.48.001727.

URL https://www.osapublishing.org/abstract.cfm?URI=ao-48-9-1727

[202] C. Liu, I. Balin, S. Magdassi, I. Abdulhalim, Y. Long, Vanadium dioxide nanogrid films for high transparency smart architectural window applications, Optics Express 23 (3) (2015) A124. doi:10.1364/OE.23.00A124.

URL https://www.osapublishing.org/abstract.cfm?URI=oe-23-3-A124

[203] Q. Lu, C. Liu, N. Wang, S. Magdassi, D. Mandler, Y. Long, Periodic micro-patterned VO2thermochromic films by mesh printing, Journal of Materials Chemistry C 4 (36) (2016) 83858391. doi:10.1039/c6tc02694j.

[204] A. Checco, A. Rahman, C. Black, Robust Superhydrophobicity in Large-Area Nanostructured Surfaces Defined by Block-Copolymer Self Assembly, Advanced Materials (2013) 16doi:10.1002/adma.201304006.

URL http://onlinelibrary.wiley.com/doi/10.1002/adma.201304006/full

[205] T. Maitra, M. K. Tiwari, C. Antonini, P. Schoch, S. Jung, P. Eberle, D. Poulikakos, On the Nanoengineering of Superhydrophobic and Impalement Resistant Surface Textures below the Freezing 
Temperature., Nano letters 14 (1) (2014) 172-82. doi:10.1021/nl4037092.

URL http://www.ncbi.nlm.nih.gov/pubmed/24320719

[206] Y. Ke, I. Balin, N. Wang, Q. Lu, A. I. Y. Tok, T. J. White, S. Magdassi, I. Abdulhalim, Y. Long, TwoDimensional SiO2/VO2 Photonic Crystals with Statically Visible and Dynamically Infrared Modulated for Smart Window Deployment, ACS Applied Materials \& Interfaces 8 (48) (2016) 33112-33120. doi:10.1021/acsami.6b12175. 